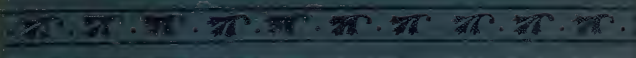

ROOT GRowing \& 

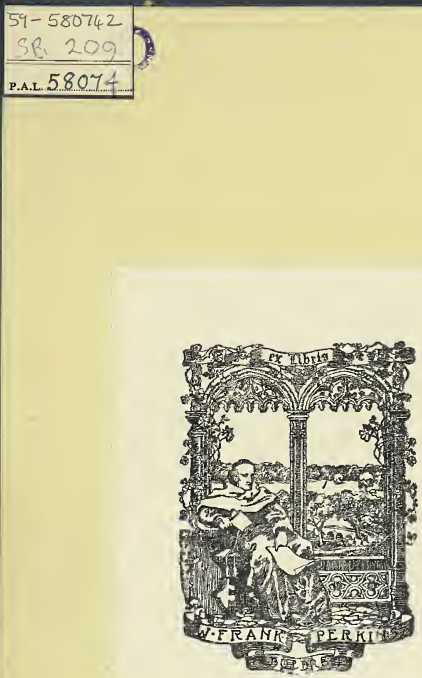

PERKINS

AGRICULTURAL LIBRARY

UNIVERSITY COLLEGE SOUTHAMPTON

59590742

||||||||||||||| || || |||||||||||||||||||| 


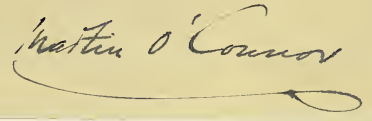

SOUTHAMPTON UNIVERSITY LIBRARY

Date due for Return

(Unless recalled for another reader)

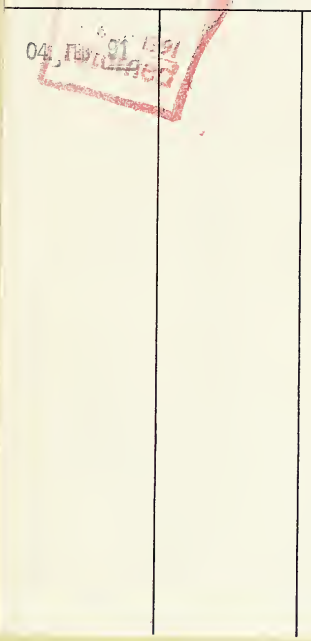


Punt at 57. 
ROOT GROWING AND THE CULTIVATION OF HOPS. 


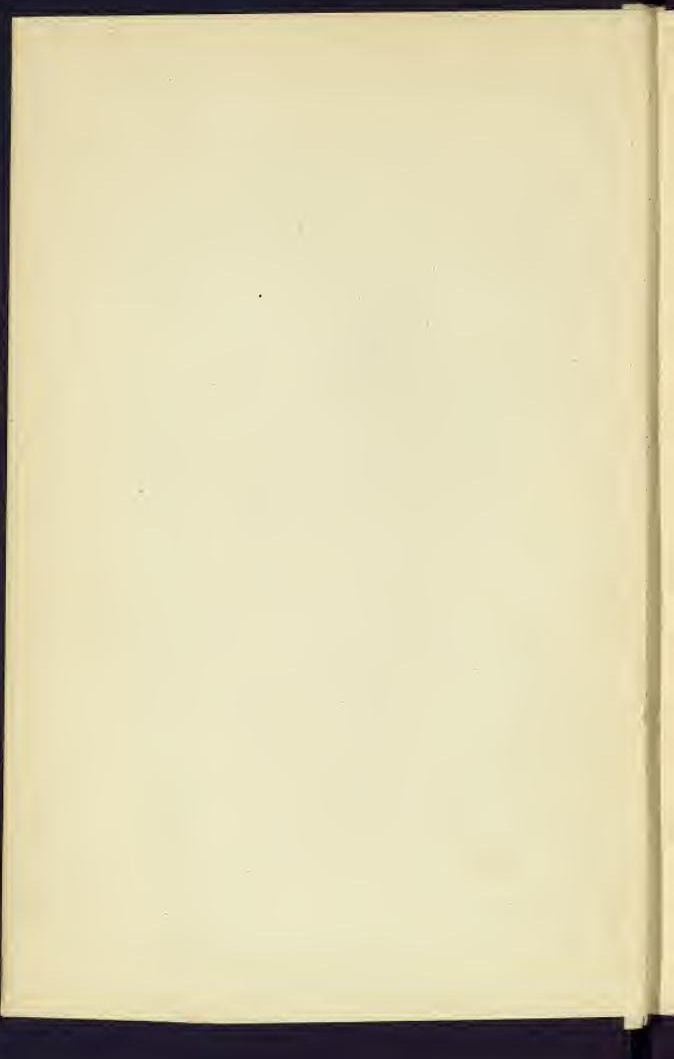




\section{ROOT GROWING}

IND THF:

\section{CULTIVATION OF HOPS.}

BY

ARTHUR ROLAND.

EDITED BY WILLIAM H. ABLETT.

Z3London:

CHAPMAN AND HALL, LIMITED.

I887. 



\title{
CONTENTS.
}

\author{
CHAPTER I.
}

AGRICULTURAL LABUUR.

Necessity for effective Labour-Condition of the AgriculPAGE tural Labourer-Labourers keeping Pigs and CowsReport on the Employment of Women and Children in Agriculture-Advantage of refraining from giving Beer to Agricultural Labourers--Beer AdvocacySteam Tillage-Dexterity of Farm Servants-Plans for improving the Condition of the Labourer-Piecework-Scale of Wages for Piece-work...

\section{CHAPTER II.}

ROOT-GROWING-TURNIPS.

Varieties of Soil-Climate of England more favourable to Mangold than Scotland-Relative Yields of Mangold and Turnips - 'Turnip Cultivation Concentrated Manures-Rotation of Crops- "Fingers and Toes" and Aubury-Cleaning property of a Turnip Crop-The Grubber an useful Implement to Clean Land-Couch Grass-Light Chalky Soils- 
Liquid-manure Drill-Turnip Manures - Varying Soils - Time of Turnip Sowing - Horse-hoeingVarieties of Turnips-Weight of Turnips at Stirling Agricultural Museum-Method of Testing the Standard of Solidity and Density-Growing one's own Turnip Seed-Ridging - Ploughing-in the TopsStoring Turnips-Snow-sledge-Diseases of Turnips

\section{CHAPTER III.}

ROOT-GROWING-MANGOLD WURZEL-CARROTS.

Mangold Wurzel-Beet Sugar-Cultivation of MangoldThinning-out Mangold Plants-Hoeing-Mangold Leaves as Food for Cattle-Ripening of the Crop - Harvesting and Storing - Using Mangolds. CARROTS: Soils - Sowing the Seed - Varietics Singling and Hoeing-Haulm of the Carrot-Ripening of the Crop-Storing, \&c.-Carrots as Food for

$\begin{array}{lllllll}\text { Stock-Growing Carrot Seed } & \ldots & \ldots & \ldots & \ldots & 6_{3} \text {. }\end{array}$

\section{CHAPTER IV.}

ROOT-GROWING-PARSNIPS-ARTICHOKES.

Soil-Cultivation-Storing-Parsnips as Food for Stock

-Artichokes-Composition of the Artichoke ..

\section{CHAPTER V.}

ROOT-GROWING-THE POTATO.

General Remarks - Soil - Cultivation - Ploughing-in Potatoes-The Lazy-bed System-Planting Potatoes 
and Draining at the same time-Varieties-Raising New Varieties-Planting and Selection of Seed-Mr. Cuthill's Method of Growing Early Potatoes- "Greening" upon a large scale-Leaving Seed-Potatoes in the Ground

CHAPTER VI.

ROOT-GROWING-DISEASES OF THE POTATO-MANURES.

Potato Disease-Dr. Wallace's Theory-Rev, Mr. Moule's Theory - Dr. Carpenter's Theory - Manures for Potatoes-Lifting and Storing Potatoes-Use of Diseased Potatoes-Baking Diseased Potatoes

... 120

\section{CHAPTER VII.}

HOP GROWING.

Preliminary-Soil and Situation-Varieties-Cultivation -Poling-Hop-picking-Drying the Hops-Bagging -Raising Hops from Seed-Male Plants-Clearing up the Hop Gardens-The Hop's Enemies, \&c. $\quad \ldots \quad$ I43 


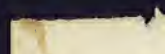




\section{ROOT GROWING}

AND

\section{THE CULTIVATION OF HOPS.}

\section{CHAPTER I.}

\section{AGRICULTURAL LABOUR.}

Necessity for effective Labour-Condition of the Agricultural Labourer -Labourers keeping Pigs and Cows-Report on the Employment of Women and Children in Agriculture-Advantage of refraining from giving Beer to Agricultural Labourers-Beer Advocacy-Steam Tillage-Dexterity of Farm Servants - Plans for Improving the Condition of the Labourer-Piece-work-Scale of Wages for
Piece-work.

Necessity for Effective Labour.-One of the principal items in connection with the successful management of agricultural business of any sort, is that of labour.

Either on a large, or small scale, the matter is one of equal importance, and whether a great number of men are employed on a farm, or only one is kept by a private person, who has a horse, a cow, and a pig, to look after, not only will it be found that, the question of profit hinges, to a great extent, upon the intelligent management, and division of labour, but as well, a good deal of the comfort, and discomfort that lies 
across one's daily path, will be found to be concerned in it.

Where only one or two men are kept, and these are not sharply looked after, through the occasional absence of their employer, the general complaint is, that most of them are found to be lazy, fond of gossiping, and idling about, instead of sedulously occupying themselves in their business; and it will be found far better to give one good, conscientious man high wages, or let him have a boy to assist him, rather than have a couple of idle fellows about the place, who appear to consider that their main business consists in seeing how much provender can be ordered of the corn merchant for the consumption of the horse and pig, where these are not raised on the spot, instead of using every economical contrivance that can be resorted to for sparing useless expense.

This is mainly the secret why it is that private people, who do things upon a small scale, find it much cheaper to buy, than grow for household consumption; though the first element of success, that of being one's own customer, and taking the profit-is there.

If properly done, the business-man, away from his home all day, who finds the expenses of his private house a heavy drag upon him, can have them very much curtailed by good management. A plot of lucerne will come in useful for the horse, which would also eat carrots from the garden, and prove an useful change of food into the bargain; and instead of keeping one pig, at a high cost for barley-meal, several pigs could be kept upon the wash from the house, and refuse garden-stuff, supplemented by 

judicious purchases, small in amount, of necessary

It is, therefore, incumbent on every one who expects to make a profit out of what he is doing in this way, that he should first secure the services of a good man, or men, on whom he can rely, to have the work about the place done properly.

Condition of the Agricultural Labourer.-Within the past century, the condition of the English agricultural labourer has altered very materially. Farms are much larger than they used to be, and men of opulence, and higher worldly position are now engaged in agricultural pursuits, who stand apart at a wider social distance from the men, than formerly was the case, when most of them used to board in the house with the farmer and his family, occupying the lowest place at his table. However the country may have benefited in wealth, and material prosperity, the peasantry have certainly suffered from this change of manners, as they have been deprived of one of the most obvious means of improvement, in the interruption of that daily intercourse with those a stage above them in worldly position; and while the farmer loses the performance of many little offices about the farm in the hours of cessation from regular toil, which used to be cheerfully rendered, the labourer is often driven to the beer-shop, and for amusement, commits acts which are often very questionable, and contracts habits of idleness.

However, as we have to deal with circumstances as we find them, and weekly wages are now paid to outdoor labourers, both on the score of good-feeling to our fellow-men, and that of self-interest, it will be found 
desirable to take a closer interest in their welfare thail is generally shown by the majority of employers, who, in paying their men the stipulated amount for their services, consider that all obligations end there-and so they do, in a strictly commercial point of view, but not when ethically considered.

To secure the services of valuable steady men, they must be made to feel comfortable and at home ; satisfied with their position, and anxious to keep it; and their condition may be materially improved through their own exertions, if the opportunities are given to them by which they may profit, which can be done without any appreciable outlay, or cost to their employers, if done in a wise, and considerate manner.

It is easy for theorists to expatiate upon a subject with which they are practically unacquainted, and suggest this thing or that, which on the face of it appears feasible, but often is not so in its working; and the subject, it must be confessed, abounds with many difficulties, which are, however, not insuperable.

Labourers keeping Pigs and Cons.-Many farmers have been blamed for not allowing their men to keep pigs. On the face of it, here is an apparent hardship, that the labourer should be compelled to forego such a very palpable advantage to himself and family. But it has been known to act as an inducement for them to steal the corn. The advantage of labourers' allotments is very obvious also, where an industrious man may profitably employ his surplus time, for-

" In the poor man's garden grow, Far more than herbs and flowers,

Kind thoughts, contentment, peace of mind, And joy for weary hours," 
But again, the men have at times been found to steal the guano, which is very portable, and goes in a small compass, and their plots have flourished with a surprising luxuriance, at their employers' expenzse.

It is a pity that the many have to suffer for the faults of the few, but such unfortunately is often the case. When a cottager manages to get a cow, instead of being a source of comfort and profit, it is often the occasion of ill-will. Not having sufficient ground for their entire support in the way of pasture, they are placed in the bye-lanes and on the roadside, to pick up a scanty subsistence, and under cover of night are sometimes turned into other people's meadows, and even into standing crops, and often commit depredations which are the fruitful source of quarrels and heart-burnings.

In order to obviate these difficulties, it would be found better to give, by fixed, and definite arrangement, the keep of certain animals, or partial keep, when necessary, when the labourer has not sufficient, and to have one or two permanent prizes, in the shape of a cottage, or two, with a bit of land attached, for the best men employed on the farm-the shepherd, the head ploughman, the carter, or, as the case may be, according to their degrees of value.

The calves should be purchased of those who have a cow, and everything made a matter of arrangement and bargain, in the shape of these extra privileges; for, of course, it would not be fair to the farmer to have a stock of animals brought up at his expense from off the farm.

Instead of allowing the men to keep the pigs themselves, let the smallest out of a litter be given to 


\section{6 \\ ROOT GROWING \& CULTIVATION OF HOPS.}

each man as they come round-not the smallest pig that is born, for this particular pig would be found to thrive in a mysterious manner, so that he overtook and beat the others, but the smallest when they are all killed, or sold. By this means all the pigs will make equal progress, and an arrangement of this kind will cause an extraordinary amount of interest in the various kinds of stock. In the same way a premium to the shepherd, as well, on the number of lambs reared, will transform dissatisfied labourers very often into intelligent partners, and sharers in the success of the farm.

A niggardly spirit in dealing with labourers invariably defeats the ends of those who practise the "pinching" system, for the men know well enough with whom they have to deal, and they will not exert themselves for those who take no interest in them. Men should be treated kindly, and even liberally, in a consistent manner, and the encouragement thus given, will be found a good investment, that will bear capital interest; and the full performance of their regular duties should always be firmly insisted on.

Some farmers will not sell the skimmed milk to their labourers, either from a dislike to the trouble, or because they want it for the pigs, and many little children, whose constitutions would be vastly benefited by the use of milk, are brought up stunted on the farm, at an ultimate loss of so much labour-power. Surely if a loss were even made, no Christian man should refuse such a privilege to his fellow! The milk should be sold at a cheap rate, not given, so that the independence, and self-respect of the labourer is preserved. 
The old labourers of a district are often better acquainted with the peculiarities of the soil and other matters, the result of long observation, than the farmer himself; and, although it is by no means necessary to act upon their advice, which would often mislead, and cause ignorance, or prejudice to reign instead of sound principles; yet there is often much that may be learned from them and turned to profitable account, when their friendly interest is thoroughly awakened, and they feel that they are sharers in their employer's prosperity, though even to a very limited extent.

A great responsibility rests upon those who ignore the natural claims which their men have upon their consideration; for, although the wages may be low which the agricultural labourer receives, yet his lot can be rendered comfortable from the little privileges that it is customary to allow him. Indeed, the position of the agricultural labourer is far better than many would suppose, who are unacquainted with the matter, and who form their opinion from the small money-payment that he receives (though agricultural wages are higher than they have been), which yet often compares favourably with that of the town artisan, who has to pay much more for rent and many other items of living; - and I am anxious not to make the case out worse than it is.

But their condition varies considerably in different parts of the kingdom. In the north of England they are much better off than in the south, and southwestern counties, in many of which their condition is sad enough, the disclosure of which, through means of the Report furnished by the Commission on the 


\section{ROOT GROWING \& CULTIVATION OF HOPS.}

Employment of Women and Children in Agriculture, a few years back, startled the optimists of society, and people seemed hardly able to credit the existence of such a state of things in this Christian country as is therein described.

Report on the Employment of Women and Children in Agriculture.-The Rev, Eldon S. Bankes, of Corfe Castle, at page 30 , says: "I have one family of eight living in an outhouse, built for a calf; and one cottage on this heath (divided into three) contained thirtythree souls at the last census."

Charles Whitehead, Esq., landowner and magistrate, of East Farleigh, Maidstone, page 43, says: "Cottages in this part are bad, and generally insufficient in number. Their accommodation is generally miserable, especially as to bedrooms, it frequently happening that boys and girls sleep in the same room; lads and lasses also; fathers and mothers and big children also, in very many cases occupying the same rooms. No decency can be observed in this kind of bedroom arrangement; and it is also difficult to see how chastity and virtue can be inculcated under such circumstances. The sanitary arrangements are horrible; and, in short, the cottages of the working-man are so curiously contrived as to sap the foundations of morality, religion, and health."

The Rev. Lord Sidney Godolphin Osborne, rector of Durweston, at page $8:-$ "I am quite satisfied of one thing, that, be the wages what they may, it is generally admitted, and acted on, that good labourers - the best of them-are ever on the verge of pauperism; a week's interruption of work generally throws them upon the poor rate; a sick child, the 
confinement of the wife-any, the least, excuse for union aid is made, and rarely refused. The relieving

- officer's books will prove the truth of this. It is clear to me that this class are as much pauperised as ever they were in my recollection; indeed, I cannot see how they could be more so."

On the subject of food, page 10, Dr. Aldridge remarks: "I have not the slightest doubt but that a great deal might be done to improve the diet of the labouring man by the ladies of the district teaching the labourer's wife how to make use of the food which a kind Providence has bestowed upon them, as well as pointing out to them that which is most nutritious and within their limited means. A clergyman (eight miles off) assured me that he had seen a piece of uncooked mutton supplied to a labourer's wife thrown under the table for the cat to eat. She did not know how to cook it !"

The Rev. Francis Warre, vicar of Bere Regis, page 22, says: "Unhappily, the labourer lives in circumstances in which social comfort is in most instances impossible. He looks to the public-house for society -his club is held there; there is no other place, except in the corner of the street, in which he can meet his friends, or hear the news. And so it is not surprising that he catches the custom, and drinks more from love of company and excitement, than love of beer. The system of giving credit to the poor is a cause of much distress to them, and often loss to the tradesman. It has been practised to an extent by the shopkeepers in this place, recourse being had to the County Court in the event of non-payment within a stated time," 
Rev. W. Barnes, B.D., rector of Carne: "I can see in a great gathering of labourers and farmers at a fair that the young farmers are, in the main, finer and more shapely men, and men of better bodily carriage than are the often very ungainly, if not stunted, young labourers. It may be said, and allowed, that the young farmers are of a finer size from better food; but this is an evil worthy of all thought, that our labourer's children are so far underfed that they are stunted, and live on to take the heavy work of the land with less than full man's might. One of the most awful evils is the want of room, so that there is the most unbecoming, and pernicious nearness, not to say openness, of sex to sex in their bed rest; an evil to which we could hardly look in thought, without seeing its taint on the mind. It is a hardship to the labourer that all the cottages should be let with the farms. It opens room for cases of great tyranny on the part of the employers, and as often keeps the houses in a bad state of repair."

The Rev. N. Roberts, of Milton Abbas (page 19): "Fuel is so scarce here that the families, as a rule, never have a fire, except at meal-times, even in the depth of winter. One of the evils arising from this is, that the poor people have a difficulty in drying their clothes when they come in wet. I have known instances in which they have had to put them on next day just as wet as when they took them off. Shepherds, and carters, suffer much in this respect, the former especially, as it is a rule with them, the worse the weather, the harder the work."

Mr. J. G. Horner (page II) thought: "One of the 
most important points was the proper supply of food to the labourer. The allotment system he believed to be of great consequence, and almost a necessity to the rural population. He did not mean that a man should have a large extent of land, but merely enough to cultivate during his spare time on summer evenings, whereby he could produce a large quantity of nutritious food, and keep a pig at very little cost ; he considered a man with a family should not have less than half an acre, which himself and his boys could keep in excellent order. The farm labourers were under a great disadvantage in purchasing their food, as they were obliged to buy at the dearest rate; his men had often mentioned the high price they paid for provisions, and he had told them he could buy the same articles for two-thirds the price, but the fact was they were obliged to go to the small shops, and under the circumstances a man with 245 . a week was not better off than another with $\mathbf{r} 8 s$., if he could lay out the money to better advantage."

There are many evils pointed out besides in this Report; as, the mismanagement of the funds of friendly societies, beer-house clubs, \&c.; but the reader of this Report will find, as well as cases of wretchedness, instances of brave self-denial, where men exposed to cold and want, go through the privations of distress and sickness, and yet deny themselves, to pay a heavy doctor's bill; and although he may read of squalor, disease, and drunkenness, he may also read of trials and sufferings borne with fortitude and heroism, that can make us feel proud of our countrymen, though they be but an English ploughman and his wife ; and stir us up to do what is pos- 
sible to better their condition, so that they may be enabled to preserve their honest independence.

The Rev. Dr. Begg, speaking of the Scottish peasantry, who, as a rule, are better off than many of the English, recommends that philanthropists should endeavour to diffuse sound information, and, in assisting to clear away obstacles, to help this class to help themselves. Good houses for the people, and especially their own, properly form the true and most effectual antagonists to the public-houses. Christians ought to consider how impossible it is that either decency or devotion can exist under present circumstances. How can men "enter into their closets, and shut their door," when no such thing as a closet exists? Whilst the masses of the people are living in discomfort and neglect, and sinking into deeper social degradation, all classes should be made to feel the necessity of spreading universally a spirit of temperance, frugality, and forethought, founded on Christian principle. This will underprop the tottering social fabric, and may justly be called the chief defence of nations. All history proves that nations are not generally overthrown from without. Corruption begins, and spreads from within, and it is only when the moral strength of the nation has been destroyed, that some hungry horde, or other form of external aggression, completes the ruin. That man must be blind indeed, who sees not, in the accumulating moral desolation of Britain, suggestive symptoms of approaching and imminent danger, and a loud call "to set our house in order."

With the great majority of individuals who have interested themselves in this subject, the opinion 
exists that the evils which abound in many places are too deeply seated to be touched by acts of legislation alone, and that they can only be effectually relieved by a general, serious, kind, and thoroughly practical drawing of the upper, and middle classes of society towards the lower.

There can be no doubt but the habit of giving men beer and cider in part payment of wages, which is practised to a great extent in the southern, and western counties of England, has had a very injurious effect upon the morale of the labourer.

That men who, from the small pittance they are in the habit of earning, should be encouraged to squander a great portion of it in animal indulgence, or miscalled enjoyment, which in many instances leads them to permanent degradation, and a continuance in a state of extreme poverty, in which their family shares, and yet for people not to see the evil effects arising from the system, shows how custom can blunt the perception, and the bad effects of labit -habit, which makes everything easy, whether it be good or bad-for the practice is necessarily fatal to all resolves of thrift or self-denial.

Advantage of refraining from giving Beer to Agricultural Labourers.-The advantage of refraining from giving agricultural labourers beer during harvest time, was forcibly illustrated in a letter addressed to the editor of the Agricultural Gasette, a few years back, when teetotal ideas were not so prevalent as they are now.

If ever the giving of beer to labourers is to be justified, it certainly is during the period of either hay, or corn harvest, when the profuse perspiration 
caused by pitching, reaping, or other hard work, exhausts the salts of the blood, and thus causes intense thirst. The letter referred to, is to the following effect :-

"On the eve of another harvest, may I once more express my earnest belief that, of all swindles, the harvest-beer swindle is one of the greatest? In most swindles two parties are concerned-the swindled and the swindler; but in this case several parties are concerned, and the whole of them are swindled. I have been farming for thirteen years, at Newlands, near Mansfield, and cut, on an average, about 400 acres of corn annually, and never gave a pint of ale or beer the whole time ; never used any myself; discouraged its use, as far as persuasion could go, at all times, and prohibited it entirely in the fields and stack-yard. Moreover, I have made some inquiry after those like-minded with myself on this matter, and find that there are dozens and scores of menpractical men, too-in all parts of the country, who concur with me in the conviction, that the work can be done not only as well, but decidedly better, without these drinks than with them; while the health and wealth, as well as habits and conduct of the labourers are promoted by their disuse. Then what are they to drink? 'Cold water,' says the theorist; 'it's Nature's beverage.' Perhaps it may be, but as we don't happen to be in a state of nature, I find no practical man to recommend it. Tea, or coffee, not too strong, is about the best thing to use, and of this we used to get through 30,40 , 50, and even sometimes 60 or 70 gallons a day. Day-workers were supplied with three to four quarts a day, and piece- 
workers had as much as they liked at $5 d$. per gallon for coffee, and $4 d$. for tea ; and I venture to say not one of my neighbours got more work done at the busy time, or enjoyed the same freedom from accidents, disputes, and foul language among the men. Besides this, the men's heads were clear, and their pockets heavy, for their drink only cost a third of the price of their beer or ale, and they had the benefit of the difference. Like everything else, it takes a little trouble at first to manage the supply of hot tea on a large scale three times a day, as we did. 'Where there's a will, there's a way.' Practice makes perfect, and as the advertisers say, 'No one who will give it a trial, will ever use any other.' I had no difficulty in getting plenty of labour, even when it was scarce; the best men knew their own interests well enough to prefer money to beer. Forty, fifty, or sixty men, women, and boys, found they could work hard on tea and coffee; and we finished off with a jolly harvest festival, to which the wives and little ones were always welcome.

"Now, on the other plan, these are the parties swindled: Ist. The men who mistake stimulation for strength, who forget that only nutritious food can keep up the power of the system for continued exertion, and who deprive themselves of the best chance of laying by for the future, by consuming a large proportion of each day's earnings in drink, which positively diminishes their power of working; 2nd. The wives and children who lose their fair share of new clothes, good food, and house comfort, because the head of the house has consented to receive, perhaps, ten to fifteen per cent. of his wages in a 
useless and costly beverage for his own personal, and selfish consumption; and 3 rd. The employer, who does not realise that, the constant, and copious consumption of 'strong drink,' even when it stops short of intoxication, has always and everywhere a degrading, and deteriorating influence on the drinker; and who has not perceived that a larger amount of firstclass work will be done by steady application than by the alternative of 'spurts' and relapses, so often seen where beer is depended on as the mainspring of the system.

"I must stop, for the time would fail me to enter into all the details of this subject, and the many aspects in which it bears favourable comparison with the beer system. The moral and religious side of the matter, too, though very important, cannot be meddled with now.

"Hoping that some of your readers may be disposed to try the better plan, I heartily promise them any further particulars they may wish, on application, either privately or through your columns.

(Signed)

"H. T. Wilson.

"Moorgate,

"Rotherham."

This sensible letter disposes of the question as to the real necessity of resorting to beer during harvesttime. At the same time, the men must drink something. How often may be seen, where enormous quantities of beer are consumed, that the men having done a certain amount of work, throw themselves down near a hedge to sleep off the effects of what they have drunk, when, perhaps, threatening skies 
give a warning that rain may be expected and the crops injured? In hay harvests this is specially the case very often.

Beer Advocacy.-It will only be fair, however, to give an opposite view to this, expressed by one who has faith in beer-a faith which is, unfortunately, held by a great many. But it should always be remembered, that if a man's beer is taken from him, he naturally requires to be recompensed with food of a better quality than that he only could procure whilst a beer drinker; and if he does not spend his money in liquor, he will have the wherewithal to purchase meat.

There cannot be two opinions which is the better plan to pursue when the system can be carried outwhether one has steady respectable labourers, who are abstainers, or whether there is occasion to deal with a batch of half, or wholly drunken people, during harvest-time; who, however they may succeed in filling the farmer's barns, or piling up his stacks, do so very often at the expense of their own moral welfare.

The following letter appeared in the Times of October 26, I877 :-

\section{A FARMER'S VIEW OF THE PERMISSIVE BILL.}

TO THE EDITOR OF THE "TIMES."

"SIR,-As a large farmer, I will just write you my experience as to beer being essential to give to my men in haying and harvesting. In the first place, I must state, my bailiff is a teetotaller, and he wished me to try the experiment of giving my men money 
instead of beer; and we tried it, and the result was, the men would neither buy beer nor work, and what little labour I got them to do cost me double, and my teetotal bailiff and myself had to go back to the old plan. We ordered beer in tubs from a neighbouring brewer as usual, and gave the men their usual allowance, and we got twice the amount of work out of them, and the men were more satisfied. The fact is, beer acts on a labouring man just as oil does on a machine, and anyone can prove this fact by trying. No other drink will do this-viz., water, tea, coffee, cocoa, or ginger-beer. These drinks only quench men's thirsts for the time, but give them no energy for their work.

" Now, I will suppose the Permissive Bill is passed, and my parish has adopted it, and all the publichouses are shut up. This would make no difference to me, for I get my beer straight from the brewer, and this most certainly would be the case with the labourer when he wanted beer. The brewer would come through our village loaded with small tubs of beer, holding only four and a-half gallons, and would leave a tub at every cottage in the parish, and would trust the labourer to pay for it every week, one under the other, so that the beer he was drinking would not be paid for till he had drunk it along with his wife and children; whereas, if this Permissive Bill had not been adopted in our parish, he would have gone to the public-house, as before, and got his beer, and his wife and children would have gone without.

"So I contend, by shutting up the public-houses, you will increase the consumption of beer double or treble. Now the labourer goes alone to the public- 
house and drinks what beer he wants. But if there is no public-house to go to, then he will order his tub of beer to be left regularly at his house every week, and the brewer's man will provide him with a brass tap, and will regularly tap it for him when he brings it, and take the empty tub away; and you may be quite sure the tub will be empty when the brewer comes with the full one.

"And now for the consequences: It will be this, that instead of the husband alone drinking his beer at the public-house, and his wife and children having none-never even a taste of beer-the whole family, the husband, wife, and children will drink beer at every meal, and even between their meals, and will. all become drunkards as they grow up. Pray, who is to stop this? You cannot shut up the breweries; you cannot stop the brewer from supplying every cottage within ten miles of his brewery with tubs of beer (you would find the four and a-half gallon tub would give place to a nine gallon tub very soon). You cannot stop the labourer from buying his beer, nor his wife and family helping to drink it. What then would be the result? Why, that the Permissive Bill would have to be given up, after it had made drunkards of all the labourers, artizans, \&c., and it would take years to bring them back to their present state. Thus it would be the greatest curse this country ever had during its existence, which must be very short.

"Your obedient servant,

(Signed) "ADDIS JACKSON,

"Mayfield Place,

"Orpington, Kent." 
It is easy to put the finger upon the weak place in the foregoing. If men are to be deprived of their beer, they must certainly have better food than they are usually in the habit of getting, and, unquestionably, to the poor, beer is a great assistance; but a very small piece of beefsteak would contain as much real support to the system as two quarts of beer, and if the money of the labourer was not spent in the latter, he would have more with which to purchase food for himself and family, and unthrifty comfortless homes as often drive men to the beer-shop, as love for the vile rubbish they often drink. But the comfortable fire, and well-lighted tap-room, and the companionship with others, that is often to be enjoyed, constitute a very great share of the attractions of a beer-house, and like the "navvy" mentioned by the authoress of "English Hearts and English Hands," who could scarcely imagine Heaven to be more delightful than sitting in a public-house with a good jug of ale before one, and a capital fiddle going, the ideas of happiness and comfort entertained by the labourer, as a relief from his daily toil, centre so much in the beer-shop, because his own home is too often dull and cheerless.

In Mr. Jackson's case, I am afraid there was not an adequate provision made in the form of substitutes for beer, and the encouragement of others who had benefited by their abstinence, and who had the stamina to set about their work cheerfully, and do it, too, effectually, was not present. There is, however, without doubt, one very forcible moral conveyed in the above, and that is, the difficulty in eradicating bad habits. 
Men cannot be converted from free livers into abstemious ones all at once, for the bodily system is subject to a re-action: so that a man, missing his habitual stimulant, at first misses it very much indeed. But "a patient continuance in well-doing" would most certainly overcome this difficulty in time, and there are also other causes at work which render it imperative to improve, whenever practicable, the social condition, and intelligence of the labourer.

With the increased necessity there now is for getting more out of the soil than has hitherto been got, a higher order of intelligence and skill will be required to be brought to bear upon all agricultural operations, and steam is ultimately destined to do most of the work of men's hands, which will need to be guided by more skilful labourers in the future.

Stean Tillage. - The advantages resulting from steam tillage, which, perhaps, I may with advantage cursorily allude to here, was explained at the meeting of the British Association at Dundee, by Mr. David Greig, who remarked that, it was asserted by all who have tried spade-husbandry, that the crops obtained under that system, are much better than those which can be got from horse-cultivated land; indeed, this is so far the case that, although to cultivate land by the spade, a foot deep, costs about $£ 4$ an acre, it would pay the farmer better to employ the spade than the horse, providing the necessary amount of manual labour could be procured at the proper time.

The state of the labour market in England, however, renders such a system of cultivation impracticable; but the superiority of the spade to the plough 
nevertheless remains an indisputable fact. The chief feature of advantage in spade husbandry is, the thorough loosening, and mixing of the soil, and as this is much better accomplished by steam, it logically follows that crops upon steam-tilled land will be far superior to those grown under horse culture; and this is borne out by actual experience, the exchange of horse for steam-power being generally followed by a marked improvement in the crops, and much greater yield per acre; varying, of course, with the nature of the soil, but amounting, in some cases, to two quarters more corn per acre. Ample proof of the accuracy of this statement may be found in the published "Reports of the Royal Agricultural Society's Commission on Steam Cultivation."

The reason for this increased productiveness can be easily understood. A team of four horses ploughing a twelve-inch furrow, will leave more than 300,000 foot-prints per acre, and as these nearly cover the ground, it becomes worse with every successive ploughing at the same depth. The machine power that horses are able to exercise upon a plough, or other implement, is very limited; and it is further decreased in consequence of having to convey their own weight over the broken and uneven soil; and also to partly undo the compression caused by the treading of their feet. If a horse be taken when the land is in a rather plastic state, and walked across the track of the steam-plough, and made to travel to and fro transversely on every ten inches width until a breadth of six yards is trodden over, it is then found that if the steam cultivation has just sufficient steam to perform its work properly, before it arrives at the 
ground so trodden down, it will be completely stopped before it gets through the six yards; and considering the momentum of the fly-wheel, this experiment shows plainly that the power required is something very material; and experience shows one-third additional draught to be required on land that has been trodden down to the same extent as in cultivation by horsepower.

With steam the case is different. The engine stands on a headland, and hauls the implement to and fro by means of a wire rope ; all treading and compression of the soil, and subsoil, is thereby entirely avoided, and the implement is driven at a much more rapid pace, throwing up the soil to a greater depth and in a loose state, enabling it to derive full benefit from the influences of the atmosphere.

It is found in practice that, the rapid motion of the steam-driven implement tends to loosen, and aërate the soil much below the actual depth at which the tire, or share is running. In horse or ox-ploughing the case is just the reverse, as the sole of the plough and the treading of the animals so consolidate the bottom, that the necessary chemical action between the soil and sub-soil is prevented, and, consequently, all escape of gas and water. The result of the deep tearing-up and loosening of the soil at the proper time by steam is, that its temperature is raised and a much greater quantity of ground is permeated by air. The air is replaced in the same proportion by water when rain comes, and this moisture is retained in the cultivated ground as though in a sponge, any superfluous quantity sinking away to the drains beneath, instead of the whole lying for some time 
in a hard-trampled sub-soil, as though held in a dish, making the land cold and ungenial. I am now more particularly referring to heavy land; but a similar result is observable in light land.

Light lands are never much damaged by wet; the principal danger is from "burning" in dry weather; but the deep cultivation and loosening of the soil (instead of having it lying on what might be termed a "board") causes even light land to retain its moisture in a dry season for a considerable time. The more question of aërating the soil deserves much more attention than is generally given to it.

This principle, so effectively described, was the main theory of Jethro Tull's system, the author of the horse-hoe, and originator of the horse-hoeing system of husbandry, the foundation of which has for its base the necessity of a thorough pulverisation of the soil, which is, indeed, too often lost sight of; and it would be to the advantage of the nation if the men engaged in agricultural work (if not the lowest grade of labourers, at least the foremen and working bailiffs) became better acquainted with the nature and object of the work that has to be performed which can only be attained by an increased intelligence.

Dexterity of Farm Servants.-This has long been insisted upon by the best writers on agricultural subjects, one of whom, many years ago, in the Introduction to Vol. VIII. of the "Papers on the Bath and West of England Society," said : "It has been well observed, that, in proportion to the general decency of servants and dependants, is their general usefulness in their several stations; and in order to have them the most actually useful, to acquit them- 
selves with judgment and dexterity, and, indeed, with that degree of taste which every field employment requires, or admits, they must have acquired strong habits of order. This gives men of every station a bias to exactness, and propriety, in every part of their labour, and the more they have been so practically accustomed at home, the more habitually will they aspire to excellence abroad. Whether the business to be done be the cleansing of a stable, a pen, or a fold for cattle, of a farm-yard, a pond in the field, the making or mending of a ditch or drain, the planting or plashing of a hedge, the mending of a road, or whatever else in the common offices of the labourers; any, or all of them, will be done the better by how much the labourer has been accustomed to value conveniences and the appearance of neatness in and about his own dwelling. If he be accompanied in his labour by one or more of his own children, they will naturally emulate the taste of their father, and they will, in general, not fail to carry those ideas of useful exactness alternately from the cottage to the field, and from the field to the cottage." *

* Plan for Improving the Condition of the Agricultural Labourt:A short account of the editor's experience some years back in connection with an endeavour made to devise some definite plan to improve the condition of the labourer, without interfering with either the farmer's pocket or his relation to his servants, in the management and duties of their labour, will doubtless prove of interest to the readers of this work, though all the definite results of the plan, beyond being the means of causing the subject to be earnestly considered by certain noblemen and landowners throughout the lsingdom, resulted in some heavy expenses, and two years' rent of offices in Westminster Chambers, London, which the writer had to pay, who would not have begrudged the money, could he have seen some general plan adopted, from which definite results were sure to arise.

The rough outline of the plan was (and the idea will be as good at 
In Morton's Cyclopadia of Agriculture, the following passage occurs- "Mr. Bravender, of Cirencester, tells us, in a paper he lately published in the foumal of the English Agricultural Society that according to his cal-

any future time as ever, in some particulars) to establish an Association with the following objects in view. (It must be borne in mind tbat School Boards have been established by Act of Parliament since the date of wbich we are speaking.)

1st. 'To secure suitable systematic education, and the acquisition of useful knowledge in connection with agricultural matter's likely to benefit their condition, and cause them to become more valuable to their employers.

2nd. To procure better cottage accommodation where required, and for some houses to be let irrespective of furms, so that a labourer may have the option of working for more masters than one.

3rd. To obtain large gardens or allotments.

4 tb. To secure adequate weekly wages where they are notoriously insufficient, and to eucourage payment by piece-work as much as
possible.

5 th. To eudeavour to facilitate the easier acquisition of laud in small portions.

6th. To encourage petty trades, such as the manufacture of rustic garden seats, fences, and omaments, bircb-brooms, straiv bottle-covers for packing wine, burdles, \&c. ; aud establish a system for their disposal to aid those who may be industriously inclined in their leisure on winter evenings, or when out of work.

[In the United States, the farm labourers spend their loug, chilly nights performing the crafts of the blacksmith, carpenter, and harnessmalker. In England we have a large number of people in easy circumstances who live in the suburbs of large towns who would gladly buy various kinds of rustic ornamental work-garden seats and bencbes, swinging receptacles for flower-pots, and many both usefil and ornamental objects were made, to serve as illustrations of what could be done in this way, in the hope that rustic museums of iudnstrial objects might be established in various country districts, to show the labourers what to aim at producing.]

7 th. To secure by co-operation some of the many advantages that are enjoyed by every other industrious class in the community, which, from their isolated and dependent condition, agricultural labouters have hitherto been unable to obtain.

A co-operative food store would be of the greatest possible assistance 
culation-and he is a good authority-every acre of down land broken up would increase the labour now spent upon it six-fold, and would pay the tenant Is. over and above his ordinary profit on the increased

to labourers in agricultural districts, who have to pay so dearly at the village shop for most of their necessaries.

At the time referred to, being engaged in writing upon agricultural topics for one of the London dnily newspapers, the first agricultural topics for one of the London daily ne enough to attract public atten-
strike upon anything like a scale large enoughire. Being desirous of
tion, took place at Garcott, in Buckinghamshire put himseif into comlearning the actual views of the men, the writer put himself into communication with them, and subsequellar-maker of Grent Missed in person by Mr. Michael Harding, " Great Misscuden Agricultural Ion; bourers' Society." died shortly afterwards, and, like many other The poor fellow died shortly and deal in his business through the part he took in endeavouring to help thc labourers; and as before an evil can be redressed it is necessary to know exactly what its nature is, in order that proper means may be employed to effect its cure, the subject as it presents itself from the labourer's point of view will be exhibited in the following letters.

Allowance, of course, must be made for prejudice and mistaken ideas, and the imputing of motives to others, which are so characteristic of persons in a certain condition of life.

\section{LETTER I.}

\section{"GRtist Missenden, "Fune $19 t h, 1867$.}

"DeAR Str, - I was much plensed to see in your note of yesterday that you were willing to take an active part in elevating the condition of the agricultural labourer.

"I am sorry to say I meet with abuse and opposition from the farmers, who are much opposed to the men uniting together, and to any improvement in their condition, as the poorer and more ignorant they can keep them, the more they can oppress them.

"If our land was properly cultivated, there would be employment for all, and the land let in smailer quantities.

"The landowners should be appealed to on this subject, and good cottages provided, with large gardens adjoining. 
capital he must spend. Every acre of light sandy pasture would, in like manner, pay him $8 s .6 d$. a year, while its labour was increased four-fold. Every acre of stiff clay pasture would pay $4 s$, a year, and increase

“'Labourers' children receive little or no education, being compelled. to work very early in life, on accotint of the low wages of the parents.

"I believe public opinion must be enlightened on the subject.

"I have enclosed a copy of the rules of the society, and an appeal, which, if you could give publicity to, would be a great service.

"I have forwarded a newspaper with an account of our last meeting, and wishing to have an interview with yout to explain matters,

"I remain,

$$
\begin{aligned}
& \text { "Yours faithfully, } \\
& \text { (Signed) "M. HARDing. }
\end{aligned}
$$

" P.S.-I should like to see you when it would be convenient, if you would be so kind as to let me know."

LETTER II.

"Gritat"Missenden, "Yune $24 k$, 1867.

"DEAR SIR,-I intended being in Town to-day, but have been prevented, having received a note yesterday requesting me to be in Bedfordshire to-morrow.

"The suggestions in your last letter, with many others, if carried out, would greatly benefit the Iabourer, particularly if they could obtain small patches of land; and education would greatly benefit them.

"Several in this parish that have the means, or friends to help them to the means, could cultivate from one to ten acres, and would get a living off it. That would talse them of the large farms, and make
room for others.

"Some do not employ more than two men and one boy to a hundred acres, consequently the land is foul, and yields weeds instead of ccrn. If the landowner would make it his business to ride over his farms after harvest and examine the stubbles, he would see for himself, and not trust the matter to his agent.

"Land averages here about $£ \mathrm{r}$ per acre; if let in small patches would readily let at $£ 2$ or more. If rents were higher it must be better cultivated, and more labourers employed.

"Farmers would be greatly opposed to let any quantity of land. This must be done by the landowner. We have one farmer who holds 
labour eight-fold; and of good grass land, $4 s$. or $5 s$. a year, while its labour would be doubled. If $4,000,000$ acres of land, now in second-rate grass, were broken up, the employment they would give to 43,000 men would be increased, so as to maintain a body of 170,000 men. The country would benefit at the same time by more food, and the landlords by more rent. Then again as to "high" farming in place of "low" farming-were the capital invested in arable land to be $f_{12}$ an acre instead of $£ 6$ or $£ 7$, as it now generally is, we believe that the farmer would

apwards oî a thousand acres. Many little farms have been added to his where men have brought up families and saved money. One recently held 32 acres, and saved $f_{4} 0$ per annum.

"It's very injurious both to trade and labour, one man holding so much land.

"If you will send me word, when you return from Yorkshire, when it will be convenient for me to see you, I will come up and more fully explain the matter.

$$
\begin{aligned}
& \text { "I remain, } \\
& \text { "Dear Sir, } \\
& \text { "Yours truly, } \\
& \text { (Signed) "M. HARDING." }
\end{aligned}
$$

Dispassionately considered, this poor man's views were very reasonable, whose idca, instead of the one most freely indulged in by labour ing men, that landlords must reduce their rents (rather a difficult matte for them to do, in the face of increased expenditure of living) suggested that by a better course of cultivation it should be made more valuable and pay even a higher rent.

We have given the viervs herein expressed by a working man at an epoch when the labourers engaged in agriculture were beginning to be more dissatisfied with their lot, and the efforts then referred to as being made by benevolent persons were swamped by the angry feelings caused by the more pronounced action of the men in different parts of the country ; but poor Harding's views tallied in a remarkable manner with some of those who occupy a position which enables them to form a correct judgment upon such matters. 
profit more, and we are sure the labourer would do so too. If we had $\delta I, 000$ to start farming with, we would spread it thickly over a small farm rather than thinly over a large one. If we had but ten hands, we would not freight a ship which required twenty. No doubt she would much more rapidly carry the goods we wished to export, but then storms might come, and we could not manage her. It is our interest to take a smaller vessel and man her thoroughly, that so we may take advantage rapidly of any change of weather, and that so we may be able to work her safely when she is in danger. Besides, we can have the smaller vessel for less money. Just so with the farmer; it is his interest to take the smaller farm with the smaller rent, and man it well; he will find himself better able to carry on a thorough cultivation, and he will be able to work it with more safety and profit in difficult times. There is an immediate and close connection between the style of farming in a country, and the condition of the labourers. Go where there is nothing but dairy farms held from year to year, and you will be sure to find wages low. Go where arable cultivation prevails, where the land being let on lease has secured an occupation by men of capital and intelligence, and you will find its labourers better off. Compare Somersetshire, on the one hand, with Northumberland on the other-grass lands and poor wages, with good arable farming, and a well-conditioned peasantry. By seeking for profitable modes of employing labour, then, much good can be done to labourers by those who are also doing good to themselves, and it is in this way that, in the long run, machinery benefits the labourer; it increases the 
profits of farming, and so enables farmers to cultivate their land more energetically, and more laboriously.

"And landlords will benefit labourers, not only indirectly by adopting such a mode of managing their estate as shall induce an intelligent, and energetic tenantry to settle on their property, but also directly in a variety of ways. We may refer, for instance, to their adopting the allotment system as unquestionably of great benefit to labouring people. This is quite a different thing from the small farm system. We do not believe that labourers would benefit by the land being all divided out into small farms. We would indeed have farms of every size, a series of ten acres up to that of largest size; nowhere should there be an interval so great as that a man, determined to rise, might not succeed. We would have the ladder up which a man should climb, as he improved his condition, with plenty of "rounds" in it, and those near enough together to allow of an ascent as easy as possible ; the platform of the middle classes should be accessible from that of the lower classes by ladders enough; but that is a very different thing from lowering the platforms themselves. The majority of farms should be from two to five hundred acres, not from twenty to fifty. But there should be some of twenty, and fifty, and seventy, and one hundred, and so on, up which a man with improving means might rise."

Piece-work.-It will be found the best plan, where many men are employed, to occupy each man in the same kind of work as much as possible. One will always perform a certain class of work in a superior manner to another, and the constant succession of 
routine labour begets excellence, and the work will be better done, and more of it got through by this means, than if each indifferently set about what there was to do with an equal hand. No occupation on the farm shows the truth of this more clearly than the operation of singling turnips, which is one of considerable nicety, and requires a good deal of practice, and a fine eye, to be done well. In this many men have acquired a considerable amount of dexterity, and one thoroughly experienced man will get through double the amount of work an inexperienced one is able to perform, let him work his hardest, and to the best of his ability.

Notwithstanding anything which may be said to the contrary, it will always be found better, both for the master and the labourer, to set out the work of the farm, where it can be done, by piece-work. Not that there is any occasion to have the system definitely laid down as the only one to be pursued in the case of every trifling job that has to be executed, but it will be found better to have nominally weekly wages, and put the labourers upon piece-work, whenever there is a large amount of work to be got through. They will be found to set about their tasks with all their might, in the case of industrious men, working at it early and late, and the business of the farm will be found to go on much more briskly.

Care must be taken by the farmer, or, in the case of the gentleman, by his working bailiff, that the work is not "scamped ;" as, for example, in the case of trenching, he must see that the labourer does his work effectually, and goes down to the proper depth with his spade.

If the labour is let carelessly, and not properly 
looked after, it will be done in a slovenly manner, as unfortunately men will cheat if they can at times; and the work done should be carefully measured, and an accurate account kept of it, and if the rate greatly exceeds the amount a good man is supposed to be able to earn, the price should be adjusted accordingly, making due allowance, and paying the full rate for the extra time that has been given to it. For example, if a man begins work at three or four o'clock on a summer's morning, and sticks to it late at night, if he makes up a day and a half, according to the usual hours of labour, he is clearly entitled to a day and a half's pay for his extra diligence. It will be the master's fault if he does not see that the work is properly executed.

Scale of Wages for Piece-work. - The proper superintendence of labour, indeed, ought to be one of the chief concerns of the farmer, and although the amount of work which can be performed per acre will differ very much according to the nature of the soil, and at times be influenced by the weather, a rough calculation can always be made as to what certain work ought to cost. Potato harvesting is supposed to cost from $£ \mathrm{I}$ to $24 s$. per acre; mowing clover, about $3 s$. to $3 s .6 d$. per acre ; and natural grass, $3 s .6 d$. to $4 s$. ; the whole operation of haymaking, about I2s. or I3s. per acre. Private gentlemen are sometimes charged $£ \mathrm{I}$ an acre for the entire job, including stacking, who may let their harvesting out to some one who may undertake it; but in the case of haymaking, and potato harvesting, the labour of women and children is supposed to bring down the rate that would otherwise have to be paid. But crops will vary in the rate of cost, 
for, sometimes, when beaten down by storms, the expense of getting in will necessarily be much greater.

Beans cut by men with hooks, and tied with straw brought to them for the purpose, will cost from 9 s. to IOs. per acre. Hacking between rows of potatoes, $7 s$. to $9 s . ;$ and moulding up the rows, $4 s$. $6 d$. to $5 s$. per acre.

Potato planting, if done by the spade, and the rows thirty inches apart, I $3 s$. to $14 s$, per acre, but less than this, if done by women and children, who place the sets in the drills.

Hoeing-in wheat, $8 s$. to $9 s$. per acre. Broad-cast sowing, about $4 d$. per acre for the sower, and the assistant conjointly, who supplies the seed.

Harrowing, from $5 d$. to $9 d$. per acre, according to whether the soil is light or heavy, and the weight of the harrow used.

Rolling, from Is. to Is. $2 d$. per acre, and scarifying, or grubbing by a pair of horses, $2 s .9 d$. to $3 s .9 d$. per acre.

Grubbing up old fence, about $3 s$. per perch; hoeing grain crops, about $3 s .6 d$., second hoeing, $2 s .6 d$.; hand hoeing turnips (three times), I2s.; reaping and tying barley, $8 s$. to IOs. ; pitching from field to rick, Is. to Is. 3 d. ; harvesting carrots, which have to be dug with a fork, $22 s$. to $26 s$.; dibbling beans, 5 s. to $9 . s$. per acre; and so on. The prices, however, must necessarily vary a great deal, but in every district there is a kind of approximate scale of payment, which varies very much in accordance with the geographical conformation of the soil.

In some parts of the country the labour of women and children can be utilized in a far greater degree 
than in others. In the neighbourhood of large towns, this description of help is often not procurable, and even that of men much scarcer, and consequently labour has to be paid for at a higher rate.

Many years ago, before the potato famine in Ireland, the ordinary amount of labour engaged on farms used to be supplemented by the exodus of a great number of men with their wives and children, who came across to England regularly as the harvest time approached, and even in the most distant counties, as Suffolk and Norfolk, the same men were regularly employed year after year, in getting in the harvest.

Emigration, and a different condition of matters, has now altered all this very considerably, and were it not the case that labour-saving contrivances have been invented, by which much of the work of the farm can be done by machinery, which cuts down the crops, and even ties the sheaves at the same time, great inconvenience would often be experienced from a short supply of labour for the ingathering of crops; and the proper management of the men, and the due classification, and setting out of their daily tasks, in order that they should be performed in the most thorough, and efficient manner, constituting one of the most important departments of modern husbandry. 


\section{CHAPTER II.}

\section{ROOT GROWING. TURNIPS.}

Varieties of Soil-Climate of England more favourable to Mangold than Scotland-Relative Yields of Mangold and Turnips-Turnip Cultivation-Concentrated Manures-Rotation of Crops- "Fingers and Toes," and Aubury-Cleaning Property of a Turnip Crop -The Grubber an useful Implement to Clean Land-Couch-grass -Light, Chalky Soils-Liquid Manure Drill-Turnip ManuresVarying Soils-Tine of Turnip-sowing-Horse-hoeing-Varieties of Turnips-Weight of Turnips at Stirling Agricultural MusenmMethod of Testing the Standard of Solidity and Density-Growing one's own Turnip Seed-Ridging-Ploughing in the TopsStoring Turnips-Snow Sledge-Diseases of Turnips.

THE successful growing of root-crops depends very much upon the nature of the soil, and comparisons cannot well be made as to the desirability of growing this or that crop in preference to another, unless this very important consideration is taken fully into account.

Mangold-wurzel likes a soil which is moderately moist and of a rich quality, for it to do well upon. On sandy soils the roots never attain any considerable size, unless it happens to be an extremely wet season. Therefore, on a sandy soil, carrots will be found a far better crop. Those who have land of a deep loamy nature, or of an open clayey texture, will be able to grow good mangold, fifty tons to the acre not being an uncommon crop where the upper soil is deep 
Where the upper soil is not deep, mangold seed should be sown on raised ridges.

Turnips succeed upon much more diversified soils, so that it is tolerably light, dry, and pliable, but do not answer on heavy clay. The relative merits of turnips and mangold have often been discussed amongst agriculturists; some preferring one, and some the other root; each spealking according to the measure of success which has attended the cultivation in the separate experience of each grower:

But the fact is, the plant thrives best in a cool, temperate, and moist climate, and, therefore, turniphusbandry is successfully followed, more especially in those districts upon the borders of England and Scotland, where valuable crops of swedes are grown.

At the same time, following out the principle to which I have referred, of its adaptation in some form or other to a great variety of soils, the white globe, or Norfolk turnip, has been largely cultivated on light land devoted to the feeding of sheep, the system of "turnip-husbandry," as it is called, having quite revolutionised farm practice in some districts, and raised the value of land considerably. In fact, the common kinds have been grown on the poorest sands, and gravels.

On the other hand, the general climate of the southern counties of England is more favourable to the growth of mangold, than that of Scotland.

Upon intermediate soils in the Midland counties of England, which may be considered moderately favourable to the growth of either mangold or turnips irrespectively, the relative yield might be put down, perhaps, as about three to two. That is, the land 
which produced thirty tons of mangold, would yield twenty of swedes. The fattening quality of a ton of swedes would be greater for stock-feeding purposes than a ton of mangold, but twenty tons of swedes would not be of so much value for feeding purposes, as thirty tons of mangold, therefore the latter would be the best paying crop.

The difference in weight between swedes and white turnips is also very great; a bushel of the former weighing sometimes eighty-eight pounds, while the latter, perhaps, will only reach sixty.

Then, again, with mangold, its kecping properties rencer it a most valuable crop; for although very susceptible to frost, and needing to be lifted from the ground immediately there are signs of its approach, it can be kept all through the winter far on into the early portion of the succeeding year, when, from the nature of the season, it is difficult otherwise to find moist food for cattle. In fact, mangold, in the present day, plays a most important part in stock-feeding.

\section{TURNIP CULTIVATION.}

Taken by themselves, turnips are not generally considered a paying crop; but they must not be strictly looked upon in the debit and credit form of what they cost to grow, and their actual value when grown; but they must be considered in reference to other crops, for, without them, in many districts it would not be possible to have a proper rotation; for' their growth enriches the soil, drawing a large amount of nitrogen and carbon from the air, the absorbing properties of the leaves collecting ammonia, and 
carbonic acid from the atmosphere. A wet summer, and a moist, warm autumn is the most favourable "season" for turnip-growing, and the principle that is now most generally recognised to ensure a good crop, is to stimulate the early development of the plant by the application of concentrated manures. Guano, superphosphate of lime, and bones, are the favourite applications; and a few hundred-weights of these per acre, will be found most efficacious with this end in view.

The introduction of turnips into this country as a field crop, is supposed to have commenced in Norfolk about two centuries ago, and gradually to have spread all over the kingdom, the cultivation, after a period, reaching great development in Scotland, where the climate is particularly well adapted for the growth of turnips. Before the system of turnip husbandry came into general practice, it was a matter of great difficulty to manage light soils to advantage, as they were soon exhausted by the drain of repeated crops of corn; and as, in old times, no regular rotation of green crops was practised, the land was continually thrown for a series of years into pasture to recruit itself, and bare fallows were common.

Another great advantage, also, has been gained by the introduction of turnips as a field-crop, in the supply of food they furnish to stock throughout the winter, upon which they can be fattened, and made ready for market; where, otherwise, there would have been only hay to depend upon; and, consequently only a few head kept throughout the winter, by which in turn, again, a smaller amount of manure would be made upon the farm; and thus land, which was once 
considered too poor for the production of corn, the growth of which had been never attempted, has been rendered fertile, and productive, by the system of rotation.

The common plan in Scotland is to grow turnips after a corn crop, the methods of rotation being as follows :-

Four Course:-First, clover: Second, wheat: Third, turnips: Fourth, barley.

FIve Course:-First and Second, grass: Third, oats: Fourth, turnips : Fifth, barley.

Six COURSE: First, grass: Second, oats: Third, potatoes: Fourth, wheat: Fifth, turnips: Sixth, barley.

SEVEN Course:-The same as the sixth, with the exception of there being two years' grass instead of one.

EIGHT COURSE:-Same as that generally practised in England, i.e, First, clover: Second, wheat: Third, turnips: Fourth, oats: Fifth, beans, vetches, or pease: Sixth, wheat: Seventh, mangold-wurzel: Eighth, barley with seeds, which admits of a great many variations.

In the four-course rotation, the turnip crop is extremely liable to the destructive diseases known as "fingers and toes " and "aubury;" and, in Norfolk, the remedy for this is a liberal application of clay-marl, which has for its object the bestowal of an amount of freshness to the land; and the general practice where these diseases are prevalent is to substitute a leguminous, crop, such as pease, for one course, which Liebig shows exercises such a beneficial influence upon the land, in fixing and retaining constituent 
principles derived from the atmosphere. Although turnips are grown successfully upon clay lands at times, the business is often pursued under somewhat difficult auspices, the main advantage to the clay-land farmer being to lengthen out his rotation; and the chief value of a turnip-crop consists, in addition to what I have remarked respecting its value as an item of food, in its cleaning properties, extirpating the weeds which the other green crops have been unable to perform.

On most friable soils, save in exceptional cases, the practice is to plough a good deep furrow early in winter, regulating its depth in accordance with its quality. If there is a good deep surface soil, the furrow cannot well be too deep, but if the top soil is shallow, deep ploughing would bring too much of the inferior stratum to the top. The earlier the ploughing is done, the better, so as to secure the utmost amount of atmospheric influence to the land. In dry weather in spring, the land is cross-ploughed with a furrow of the same depth, which, under the most favourable circumstances, can seldom be nade to exceed nine inches. The cross-ploughing mixes the soil well up together, and if left untouched for a fortnight, and the weather remains dry, the land will then be in prime condition for the harrows, which are set to work in contrary directions, one across the furrows, and one in a line with them, by which means it will be well cleaned of couch-grass and weeds. Dry weather is of such importance in thus emptying the land of weeds, that it is better to wait for a favourable "season" for this operation, rather than hurry on matters; and when the weeds have been 
taken away, the grubber should be used to bring any that may have been left by the harrows to the surface, and lime applied, if the land requires it, which is best done by ploughing lightly in, and afterwards harrowing. The sooner in the spring the lime is applied, the better, so as not to interfere with the germination of the seed.

The above applies to friable land in fair condition. But where the soil is heavy, autumn cleaning is resorted to, either by scarifying or grubbing, on soft easy soils; and by the plough on stiff clay, especially when root-weeds exist.

The grubber is a more manageable instrument in hilly districts in preparing the land in autumn, as it can be made to go in the easiest direction for the horses, whereas the plough is not so accommodating an agent, and good farmers make a point of taking time by the forelock, during the fine, dry, autumn weather, which is suited to these occupations.

If the land is very foul, the grubber is used three times, and by spring there will not be many weeds to be seen, but what there are, are easily freed from the earth, and collected together by a hand-rake, when another good ploughing is given, and the land harrowed and rolled, and the grubber used once more to make a complete job of it, and this is considered a better practice than winter ploughing, which often fixes the weeds deep in the soil, and are consequently afterwards difficult to extract; while by the use of the' grubber the weeds are drawn to the surface in autumn, and killed by the frosts of winter.

By well using the grubber, and harrow, before the seed is put into the land, it is made much cleaner and 
in better order than subsequent drill harrowing, and scarifying between the rows where the crop is growing, and will often make the difference between a good crop, and a bad one.

Although from the limited amount of land I have under cultivation, there is no space for the employment of a large staff of men, following one another promptly in their operations with the different agricultural implements in use, yet there is sufficient opportunity for me to test the different processes which are most advantageous for the object in view ; and I can generally take advantage of a favourable "season," as the little I require doing can be promptly performed, and turned out of hand. Thus, I have one patch of four acres, which I set aside out of my small quantity of arable land, upon which I grow in turn clover, wheat, turnips, beans, oats, potatoes, \&c., and vary the crops according to circumstances. One busy season, which turned out a wet autumn, we missed our winter sowing of wheat, and substituted spring corn (Talavera), and on this small scale there has been just sufficient opportunity to test the various results which ensue from a certain method of procedure; the four acres being just the half of a field as nearly square as can be, with a wide grass path running across it, just sufficient to form a pleasant promenade; the remaining two acres of arable I have forming a small enclosure, or field of itself.

As I was saying before, a good deal of my labour is performed with the fork, which I often resort to, although more costly; yet it answers my purpose well enough, as can be easily imagined, when I do not want to trouble my neighbours, who may perhaps 
be busy themselves at a moment when I might want something done.

In this way, if the land gets infested by knot-grass in patches, we fork it up before ploughing the stubble; but if this exists in land on too great a scale for the fork to be used, the best plan is to plough a shallow furrow, so as to lift the bean-like roots in a line with it, and in the first dry weather in spring to drag the harrow across the furrows, which will bring them to the surface in unbroken clusters, from whence they can be easily removed. In land infested with knot-grass, rolling should not be per- formed, as in breaking the root-clusters, the particles cannot be gathered up cleanly. When the knot-grass is collected together, it should be burnt.

A method pursued by some in cleaning a soft soil of couch-grass, is to rib or half-plough the land in winter, and plough again in spring, in the same direction, not across, so as to turn the whole furrow heels over. The couch-grass will thus be contained in an entire and unbroken state in each furrow, if the ploughing has been sufficiently deep, which the harrows will bring to the surface without the roots being broken. The harrows should be first drawn in the same direction as the furrows, to avoid depositing the couch-grass in the hollows, where it would get covered up with soil. It is strictly essential that this operation be performed in dry weather.

In dealing with old pasture land, even when it has been previously broken up, and a crop of corn has been taken off it, there are often found large quantities of undecomposed sods mixed with couchgrass. When this is anticipated, it is best to plough 
as early as possible in autumn after harvest, with a good deep furrow. In spring, cross-plough, harrow, and roll repeatedly, until the sods are all brought up to the surface of the land. When the time comes to open the drills for manure, these sods should be lifted up before the plough, and placed evenly in the bottom of the drill as it is formed. The manure is then placed above the sods, and all covered in. The seed is then sown by a wheel-coulter machine, and if small wheels are substituted for coulters to make the seed ruts, the sods and manure will remain in the land undisturbed, and a better crop of turnips than ordinary obtained by this method.

In light chalky soils, which are often met with in the south of England, the general practice is in autumn to scarify, grub, harrow, and pick off the weeds. Well-decomposed farm-yard manure is laid on and ploughed in early in winter. 'If weeds make their appearance, the land is kept clean by grubbing and harrowing, till the season comes round for sowing; two and a half hundredweight per acre of guano, or eight to ten bushels of bone-dust are sown with the drill, or an equivalent mixture of other concentrated manures, care being taken to keep the land as moist as possible, by performing the operations connected therewith quickly.

A liquid-manure drill is, on this account, often advantageously employed, dissolved bones, or guano being mixed with the liquid, calculated according to its strength. In light soils the quicker the sowing of the seed is done after the ploughing and harrowing, clearing and rolling, have been performed, the better. 
In dry seasons, those who have used a liquidmanure machine have had crops of turnips, when their neighbours who have not resorted to its use have been without. The water-drill contains a small tank in which the manure is mixed with water, which is delivered into ruts made by the coulters, the seed being deposited above the moist manure, and when light manures are used, they are drilled under the seed by a machine which performs both operations at once, on the flat surface, in narrow drills, from fifteen to twenty-two inches broad, in opposition to the Scotch system, which would admit the drought at too great a depth, drilling turnips on the flat not being practised in Scotland.

Turnip growing upon stiff tenacious clay, has generally been looked upon much in the light of experiment; but a plan has been tried with success by ploughing, harrowing, and clearing the stubble in autumn, after which the drills are drawn and filled with manure, and redrilled to cover it in, remaining in this condition all the winter. The outside of the drill or ridge gets in a fine pulverised condition from the exposure it has been subjected to during the winter. In spring the drills are lightly harrowed, and the spaces between are scarified, to kill surface weeds, but not so deeply as to raise clods, which would obliterate the drills. A few hundredweight of concentrated manures, as guano, or dissolved bones, are sown broadcast, and the drills lightly made up again, by which a good bed is formed for the reception of the seed, the pulverised soil, and light manure being thrown to the top.

The principle invariably laid down in the prepa- 
ration of clayey land for a turnip crop, is the complete pulverisation of the surface soil before sowing, without permitting the moisture wholly to escape; and to attain this end, the land must never be worked in a wet state.

There has been frequently a good deal of disagreement as to the best description of manures to be applied to turnips, especially in the case of farm-yard manure; whether it should be old and well rotted; or, if fresh and rank, whether it can advantageously be used ; but the fact is, the quality of the manure itself makes all the difference; and in the case of a farmer who has tried unsuccessfully rank fresh manure in his turnip drills, all laid there, perhaps, without rotting during the summer, and has been like so much dry straw lying at the bottom of the driil, and the result has been very unsatisfactory in a dry season, the rate of decomposition being so slow and protracted as not to advantage the crop; but this manure was probably of a very poor quality, made by stock fed on turnips, chaff, \&c. On the other hand, rank, fresh manure, which has been taken from out a covered cattle enclosure from animals which were fattening upon corn and cake; this, richer in the gaseous elements, retains its moisture long enough to supply liquid nourishment to the plant, during the most important period of its growth. So that farm-yard manure, if it is rich in itself, will answer when applied in a fresh condition, but if poor, in all probability it will not. In a dry season, the crop is sure to turn out a poor one, for what moisture is in will be absorbed by the surrounding earth, which will impede its powers of decomposition until rain fall; while the richer will 
retain its moisture long enough to start the young plants well.

On clay soils the best manures for turnips are farm-yard manure and Peruvian guano. On light and medium turnip soils the cheapest method of manuring and growing turnips, is to sow eight to ten bushels of bone-dust per acre with the drop-drill, which deposits little clumps of the manure at intervals of nine inches. The earth which falls from the sides of the rut made by the coulter lightly covers this over, and the seed is dropped on top of it from a box attached. For gravels, light loams, and kindred soils, two bushels of drill-bones, and three to five hundredweight of guano (according to quality), spread along the bottom of the drills, and covered by the double-mould plough, is generally considered a certain application to produce a crop. Where the land is manured in the winter, however, fresh farm-yard manure may be used at its time of application; it will be decomposed enough in the spring, and the land be in good growing condition. But even then the application of artificial manures is profitably resorted to, as it promotes a quick growth of the young plant at a critical period of its existence, which will well repay its cost, and secure a good braird.

With this view, on what are termed light turnip soils, artificial manures are resorted to, which promote a steady growth in September and October; such as guano, dissolved bones, or bone powder, particularly if the farm-yard manure is fresh. If, on the contrary, well-rotted dung has been used, too rapid stimulants will cause a premature ripening, and expose the crop to mildew. 
The time of sowing the seed must depend upon the variety of the turnip, and a good deal upon the state of the land, and the weather. As there are several varieties of turnips, of which I shall shortly speak, it may be as well to observe, that, the most nutritive species take the longest time in coming to perfection, and need to be sown as early as possible. Swedes should be sown from the beginning of April up to the close of May, and not after; for unless a wet season follows, the crop will be deficient in weight. The yellow sorts follow next, and afterwards, white turnips, which may be sown any time from the middle of May till the end of June, though the operation is frequently not completed until July; the common Norfolk species, indeed, having been frequently put into the ground upon one ploughing after corn crops have been taken off the ground, being termed "brush-turnips," which are considered useful for early dropped lambs, as they are a delicate root; but the yield is very scanty.

An experiment has been chronicled by a turnipgrower who began his operations on the 14th of May, and sowed seed every other day for two months. The result of his trials showed that, the yield of the crop planted in May was, acre for acre, worth two acres of those sown in July.

As no crop, however, is so much influenced by the weather as turnips, supposing the land to be ready, and there is a choice in the matter, experience shows that, while there is an advantage by sowing early, in the soil being moister, and the heat less intense, which promotes the rapid growth of the young plant; if sown too early, in warm seasons the 
plants run up their flowering stems before winter; which has caused the end of May to be looked upon generally as early enough for the lighter species, it being good practice to make sowings of white turnips. successively.

Of course, this practice would be always followed in garden management, so that the crops came into rotation for consumption; while even very late sowings will bring "turnip-tops" for use, often as a welcome green vegetable; but I am now speaking only of field crops.

The state of the weather, too, in turnip husbandry influences the depth at which the seed should be deposited. In dry weather the practice is to sow deep, in order to shelter the seed from the scorching influence of the sun; but in damp weather, when the soil is moist, quite shallow sowing is to be recommended.

Both the time of sowing, and quantity of seed used, is very varied in different parts of the country. In some of the home counties of England, as little as a pound of seed per acre is used when drilled, and two pounds sown broadcast. The Scotch plan in drilling is usually to sow from three to four pounds of swedes, and two to three pounds of the common sorts; the time selected being from the Ist of May till the 2oth of June, those planted from the $\mathbf{r}_{5}$ th of May till the end of the month generally answering best, the night frosts injuring the earlier sown crops; but when delayed later, there is a chance of their being caught by the autumn frosts; while in the southern portions of the kingdom, and in Ireland, their growth extends further into the winter. Roughly speaking, 
the average time of turnip-sowing in the southern portion of England and Ireland may be set down from the $25^{\text {th }}$ of May, till the Ist of July. Rain generally falls in England about St. Swithin's, which often starts the turnip crop very favourably.

In a soil of a cold nature, slow in communicating its vegetating powers, early sowing is therefore advisable; but in a rich, well-manured soil, later sowing can be necessarily resorted to. Those bulbs which make the best autumn growth are always the heaviest, soundest, and of the best quality.

After the seed has been sown, the young plants generally make their appearance in about ten days or a fortnight, according to the soil and the weather, which, if showery, will put the plants in rough leaf, when they are about two inches high.

The horse-hoe should then be run up and down between the rows as near as possible without doing injury to the crop-about three inches from the plants-so as to destroy the weeds which may have sprung up, and turn off a shallow portion of earth from the turnips. Two or three days afterwards, singling, or hand-hoeing, is performed. Some men are very expert at this, and have a true eye, performing their task very evenly and regularly. The man who singles, walks along the sides of a drill with a hoe about eight inches in breadth, and at one stroke across the ridge, he cuts out the plants at regular intervals, leaving a vacant space of nine, or ten inches between each. If needed for consumption earlier in the season, the distance which each plant stands from its next neighbour is increased to a foot, as their bulk will increase according to the amount 
of space left for each to grow in ; but when intended for spring use, the object in leaving them standing on the ground thicker, is to check their growth and cause their bulbs to become more solid, when they are less likely to be injured by the frosts of winter; and the roots also possess greater nutritive qualities.

In Scotland, a great portion of the turnip-hoeing is performed by women, four of whom will single an imperial acre in a day; but in the case of swedes, they are struck out, leaving tufts standing a foot apart, and after a few days, when these tufts have grown, and they will make rapid progress, the superfluous plants are removed, the strongest being left standing; this process requiring six women to the acre.

\section{VARIETIES OF TURNIPS.}

The varieties of turnips differ greatly as to hardiness. The ruta baga, or Swedish Turnip (Brassica campestris ruta baga), is comparatively of recent date, when compared with the introduction of other kinds into this country, being by far the hardiest species known, severe weather having but little effect upon it, when others are destroyed by the alternate changes of frost and thaw. The flesh of the true kind is yellow, and without a stem, and it retains its nutritive powers much later on in the spring, which renders it so valuable for stock-breeding purposes, the root having a higher specific gravity than the common sorts. The leaves are of a darker green, and though not yielding so many tons per acre of bulbs as the others, in the case of the ordinary yellow 
turnips would be as twenty to twenty-five, and as twenty equal to thirty of the white turnips as regards comparative nutritive qualities.

There are about a dozen standard varieties, including Common Purple-top, Common Green-top, Green White-top, Skirving's, and many new-named varieties which are recommended by different seedsmen, various kinds being appreciated for some quality or other.

Then follow an equal number of Green-topped Yellow Turnips (Brassica rapa), the common field turnip, as Cambridgeshire, Yellow Aberdeen Bullock, Old Scotch Yellow, Pollexfen's Green-topped Yellow Bullock, which are old-established favourites, with many newer kinds.

Then come Purple-top Yellow Turnips, Green-top White Turnips, and Red-top White Turnips, which are all leading field sorts, with upwards of a score of garden turnips, better adapted for quick raising, and succession of crops.

Each kind possesses some peculiarity or other of its own. Thus, Skirving's 'Improved Purple-top Swede stands out of the ground more than many other sorts, having a longer neck, which, in consequence, does not keep so well when intended to stand all through the winter; but it suits those who intend to lift the crop and store it, as it comes early to maturity, and keeps well. Laing's Improved Purple-top Swede has larger leaves than ordinary, which, by their thick covering of the soil, is said to check the growth of autumn weeds, while it has not a tendency to run to seed in autumn.

The Green-top Swede has the upper part of the bulb a dull green colour, the under portion being 
yellow. It is rather a coarse-looking turnip, but yields a good crop.

Of the common turnips, the Yellow Aberdeen Bullock Turnip is considered one of the best for land in good condition, being a later, or winter turnip, which admits of late sowing, and it stands all kinds of unfavourable weather without injury, either in the form of rain, snow, frost, or thaw.

The Old Scotch Yellow stands the winter well, and retains its juices late on in the spring, which causes it to be held in estimation for feeding purposes; but this description also needs a good soil.

The dislike which exists to the taste of "turnip butter," is against their use as an article of food for milch cows, though the unpleasant flavour can be remedied by a certain method of dairy management; but for feeding milch cows Gibbs' Improved Green-top Yellow is considered a useful variety, though I never gave my cows turnips at all. Still, where cows are used to bring up calves, such food may, with advantage, be given, one cow bringing up five calves; two pairs and an odd one, to finish off with; though this again is not my system, but one which has been extensively followed by others. For the same purpose the Green Globe, or Green-top White Tumip, is also considered a useful variety, attaining a large size, and standing well till the advent of the new year, when it should be taken up.

The Common White Globe Turnip gives a heavy crop, and is much liked for early autumn use, where there is a quantity of stock to feed. As the roots attain a very large size when standing far apart in the rows, it is customary, when singling, not to allow 
more than ten inches, or at most a foot, between each plant-forty tons per acre being a common weight for this kind, though the weight of turnips vary considerably: thus, in an old report of the Ardrossan Society, it is stated that the respective weights grown on one occasion upon an imperial acre, without any peculiar mode of cultivation, were :-

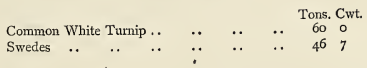

The Common White Turnip comes in capitally when the grass is failing at the end of September or beginning of October.

The White Stone Globe is considered one of the best turnips for feeding sheep upon. The bulbs are not so large as those of the Common White Globe, but are much more hardy and capable of resisting frost, growing deeper in the ground.

The Red Globe Tumip and the Red Tankard Turnip are sometimes considered useful sorts for growing on inferior soils, and, like the White Tankard Tumip, is of poorer quality than the other sorts, coming early into maturity being its chief recommendation; but it cannot stand the least frost, in consequence of the bulb being entirely above ground.

The Green Tankard Turnip is of a better quality than the White Tankard, but inferior to the common green-top whites. Samples of single turnips were shown at an agricultural museum at Stirling, grown upon various soils, the weights of which were as under :- 


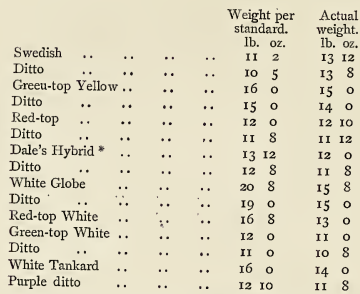

With regard to the above table of the comparative weights of standard of solidity, or density, with actual weight, it may be necessary to explain to the uninitiated, that if sound Green-top Yellow Turnips, of seven or eight pounds weight, give, as their highest average, 32 cubic inches per pound, which is assumed to be a medium standard of solidity, by dividing the number of cubic inches contained in any bulb by 32 (the remainder being halved for 16 ths or ounces), the quotient gives the number of pounds and ounces

* Dale's Hybrid Green-top Yellow Turnip has now been grown for upwards of half a century, and is a cross between the Green-top Swede and White Globe. It is a capital turnip for folding sheep upon, as it grows mostly above ground, so that nerrly the whole bulb can be consumed before the picker is put into requisition, and is well suited for clay land, being easily pulled and carted off if needed before winter for storing, as it is a capital keeper, and will remain sound for several months. Like all the other varieties which grow mostly above ground, it is hurt by frosts, and is therefore not fit for standing in the ground during winter. It springs quickly, the young plants being very vigorous, and comes in after the White Globe as early winter food for stock. 
that should be of the standard solidity : the actual weight of the bulb will indicate the solidity, which will be either at, above, or below the standard, as the numbers of the weight are equal, less, or greater than the numbers of the size, the above test showing the superiority of the Swedish turnip over all others.

Good seed can be purchased of the first-class seedsmen, who are known not to lend themselves to adulteration; but a sure method of obtaining pure seed is to grow one's own, by selecting the finest roots when they have attained perfection, and planting them separately in good soil, which has previously been dug deep, in rows, two feet and a half asunder, with a space of fourteen, to eighteen inches between each bulb. In the following July or August the seed will be ripe, but it should not be left until too ripe, or the birds will get the greatest portion of it. The haulm is then cut down, and stacked and thrashed out in the usual way. If more than one kind is grown, the various sorts should be planted at a considerable distance from one another, or in the flowering season the farina of one may be carried by bees to another, and a bastard stock be the result.

By planting a few specimens close together, some hybrids may be produced, which will be found very interesting by those who take an interest in such experiments, and are possessed of enough patience to make them.

The horse-hoe is a most valuable implement in turnip cultivation, and it is generally customary, after the last hand-hoeing has been performed, and when the turnips begin to assume their rotund shape, or "bottle," as it is termed, to pass a double mould- 
board plough between the rows, for the purpose of ridging them, and earthing up the plants, with the intention of laying them dry during the wet months of winter. There are, however, two objections to this if heavily earthed: first, the bulbs do not swell so much, and this has to be considered in relation to the description which has been planted, and when the crop is intended to be used; and secondly, if the land is dry enough to be fed off by sheep; the ridging it up is likely to expose them to accidents, by causing them to fall on their backs into the furrows, when they are unable to extricate themselves, by which many animals have been lost. On the other hand, if the turnips are intended to stand on the land, this method shields them from the spring frosts, and supplies the place of their riatural covering-the leaves.

The common early sorts are sometimes fed off in the autumn, and the land sown with winter wheat, and where they have not been got off in time, spring wheat has been substituted, in contra-distinction to the prevalent system of allowing barley and clover to follow turnips.

In Scotland and the north of England, the shaws or tops are often ploughed in for manure when the crop has been carted off for storing, in order to make room for sowing wheat. Where this is done, the leaves should be cut off a short distance above the bulb, so that they fall separately on the ground, and are thus more evenly distributed. The roots, however, should not be cut off when it is intended to store them, as the turnips keep better with them on. 


\section{STORING TURNIPS.}

When it is theintention to feed sheepon the land with stored turnips, the best plan is to put them into conical heaps of two or three cart-loads, at regular distances, and cover them with straw lightly, and a little earth. The tops will answer for a covering for those which are intended to be used first.

The plan of storing chiefly followed in the north, is to set up two rows of hurdles nine feet apart, and fill the space between with turnips, with a thin sprinkling of straw between the hurdles and the roots, so that ventilation is not impeded, with a hurdle at each end. They are piled up in a roof-like form, and thatched roughly with about twelve inches of straw, which will efficiently protect them against rain and frost.

Another plan is to place them against the northern side of a wall, or building, piling them up as high as they will stand, and then cover over with straw, laying hurdles, or branches, against the straw, to keep it in its place.

In storing in October, or the early part of November, before severe frosts set in, it is better to leave them uncovered for a few days, which will cause them to be less liable to heat, or sprout. When the season is more advanced, this precaution is not needed, as the juices are set, and they are not so liable to ferment.

Turnips will keep a long time (that is, the best keeping sorts), but they lose a portion of their nutritive juices, and it is best to use them first, and depend upon mangold for the later feeding of stock.

In the southern counties of England, the use of 
hurdles for storing is not so much resorted to, but the turnips are carted to a dry spot near the feeding sheds, and placed upon the ground in narrow ridges about five feet wide at the base, and then thatched with straw, fern, or rushes, and when severe frost sets in, they are covered in addition with long stable dung. Some again store them in pits, or under sheds, according to the amount of accommodation they possess.

When a heavy fall of snow has taken place, covering up the turnips which are in the ground, and they may be wanted for use, a contrivance called a "snow sledge" is resorted to, which merely consists of two or three boards, seven or eight feet long, and ten or twelve deep, set upon their edges in the form of an equilateral triangle, screwed strongly together at the angles, at one end of which is a hook to attach the horses to. When this is drawn along the ground, it forces the snow up into a ridge, and a row of turnips is laid bare without receiving any injury of consequence.

\section{DISEASES OF TURNIPS.}

In addition to "Fingers and Toes," and Aubury, of which I have spoken before, and which are sometimes confounded together as being one and the same thing, and are often considered to arise from the too frequent growing of turnips upon thesamesoil, though the malady has been found to exist in ground that has been recently broken up; there is also a disease called "Black Canker," which arises from a species of slug or caterpillar, when the plants are in rough leaf, and have partly formed their tops. The common remedy prescribed is rolling heavily during the night when they 
come out to feed, but this is not effectual in rough and stony soils, and a number of ducks turned on to the land have been found to do good service in extirpating these vermin.

But the most persistent enemy is the "turnip fly," as it is commonly called (Altica nemonum), which makes its appearance as soon as the tender seed-leaves burst forth, but which disappear as soon as the plant acquires its rough leaf. Slight sprinklings of quicklime by the hand early in the morning is the best remedy for this; a mixture of soot and quicklime being resorted to by some, six or eight bushels per acre being used at times, which is also regarded as a top dressing to the land.

A receipt mentioned by Sir Humphrey Davy, is a composition of three parts of soot and one of quicklime slaked with urine, four bushels of which per acre, are to be made to fall with the drills along with the turnip-seed, and it has been observed in reference to this treatment, that although the volatile alkali of this mixture may be offensive to the insect, the stimulus it gives to the plant, most likely hurries on its growth and puts it out of danger, the weak and sickly plants being always the first to be attacked.

A legion of enemies prey upon the crop at different stages, the caterpillars of the white butterflies, Pontice brassica, napi, and rapa. The larve of flies mine the green leaves, Phytomyza nigrocarnis, and Drosophila flava, and a number of others, whilst wire-worms from the click-beetles, centipedes, the winter gnat, and rovebeetles, which are generated by decomposing bulbs, are accompanied by others to prey on them in turn, and are also kept down by birds, which, at certain 
62 ROOT GROWING \& CULTIVATION OF HOPS.

seasons of the year, live almost entirely upon them, rooks and winged game, such as partridges and pheasants, destroying great numbers.

Botrytis parasitica, which somewhat resembles potato mould, is apt to attack turnips where too much manure has been used, which causes the leaves to assume a rank green colour, and to become large and watery, the roots becoming liable to decay. 


\section{CHAPTER III.}

ROOT GROWING. MANGOLD-WURZEL AND CARROTS. Mangold-Wurzel-Beet-Sugar-Cultivation of Mangold-Thinning-out Mangold Plants-Hoeing-Mangold-Leaves as Food for CattleRipening of the Crop-Harvesting and Storing-Using Mangolds. CArrots: Soils-Sowing the Seed-Varieties-Singling and Hoeing-Haulm of the Carrot-Ripening of the Crop-Storing, \&c.Carrots as Food for Stock-Growing Carrot-Seed.

Although the common garden beet had been cultivated for a long time previously in England, mangold-wurzel was introduced into this country about ninety years ago by Dr. Lettsom, as a field crop, being brought to us from Germany.

There are five leading sorts : the Orange Globewhich is the best keeper-the Long Orange, the Long Red-which grows enormous crops at times-the Red Globe, and the Sugar-Beet.

Beet-Sugar.-The manufacture of beet-sugar,though so largely followed on the Continent, especially in Germany and France, has not turned out successfully in England, though from what causes I am not in a position to say; but various attempts have been made in different parts of the country, and at different times, with comparatively poor results to those obtained abroad, where preference is mostly given to the White Silesian beet for this purpose.

Perhaps the unreadiness with which English 
farmers take to any manufacturing processes in connection with their ordinary avocations, may perhaps explain, to some extent, the want of success in sugar-making from beet, together with the high price of machinery used in the process; but the latter is now considerably cheaper than it used to be.

As pigs could be economically fed with the refuse pulp, manufacturing industries of this sort, one would think, could be most suitably adopted by farmers, so as to chime in with their ordinary business; but very little is ever done by them in any way out of the common rotation, though they might well take a hint from the country millers, many of whom of late years have supplemented their profits by largely feeding pigs with the refuse that accrues to them from their grinding.

The beet-root sugar trade has attained such large dimensions abroad as seriously to interfere with the English sugar refiners, though the article is much inferior in sweetening properties, and owes its establishment there chiefly to the arbitrary decree of Napoleon, which virtually prohibited the importation of cane-sugar into France and other countries embraced in the continental system of his dominions while emperor.

In manufacturing sugar, the roots are first thoroughly cleansed, and then grated, or sliced until they are reduced to pulp, from which the juice is next separated. In this condition it is turbid, more or less yellow, or dark coloured, which has to be clarified before it can be evaporated to the point of crystallization, which is done by heating it by steam in a large pan, and evaporated down to a certain 
specific gravity, when hydrate of lime is added, and the boiling continued for an hour. The lime separates the nitrogenized particles in the juice, and removes the fatty and colouring matters, as well as several salts. The clarified juice is poured from the dregs, and filtered hot through animal charcoal, and afterwards passed through filtering vessels till it loses all colour; the impurities being allowed to drain through the ends of the conical moulds, which forms the loaf sugar into the shapes called "titlers" in the subsequent stage of manufacture.

The future will doubtless see many manufacturing processes connected with farming which our countrymen are very slow to avail themselves of, but is not the case on the Continent. Where there is timber grown, or even coppice to a large extent, a species of turnery business might well be added, without any very great trouble beyond the employment of an extra man or two, in the making of such things as spools, bobbins, and other articles largely used in manufactures, as well as the handles of agricultural tools, \&c.

Cultivation of Mangold.-The ordinary methods followed are very much the same as those with turnips, the land requiring to be equally well worker, but ploughed deeper in autumn; and when clean, heavily manured with farmyard dung spread equally, being generally preferred in this form, instead of depositing it in the drills, which is the practice with many.

It should follow some corn crop or other in rotation; and if there is any choice, the stiffer part of the land destined for root crops should be chosen.

After the land has been ploughed in autumn, in 
April, it should be harrowed down, and the weeds gathered off, and if necessary, cross-ploughed in wide lands, and afterwards harrowed, and cleaned again.

Long dung has been employed with good effect in the first autumnal manuring, as it tends to keep the ground open; and also green crops that have been ploughed in.

After the harrowing has been thoroughly performed, artificial manure may be sown broadcast; three hundredweight of guano, or the same of superphosphate of lime, being sufficient when the land has had a good dressing of farmyard manure.

In inland situations, from two to four hundredweight per acre has been advantageously applied to mangold, the larger proportion according to the relative dryness of soil. The land is then ribbed, or drilled, at intervals of about twenty-six inches, and is ready for the seed.

When the land has not been manured in the autumn, it can be applied broadcast, or in these drills. The artificial can then follow, sown broadcast over drills, manure, and all ; and the drills, being then split, the manure gets covered, and the guano is mixed with the soil over it, just in the situation where it will be of most service to the young plant.

The seed is best dibbled, or dropped in by hand, in the end of April, or beginning of May, six pounds, or seven pounds being needed per acre, and if soaked beforehand in diluted tank-water for twenty-four, or thirty-six hours, it will be advantageous; the water swelling the seed, and making it ready to sprout at once; and it is a good plan to set the turnip drillmachine empty over the rows before sowing the seed, 
so as to form a slight furrow on the top of each drill; and for the sower to make a shallow place with a light hand-hoe, with a short handle, fifteen or sixteen inches long, to measure the space between each with, and drop in two or three seeds and cover them up.

Thinning out Mangold plants.-In thinning out the plants, greater care is necessary than with turnips, for two or three of them generally spring from each grain of the mangold, and adhere so closely together that it is extremely difficult to separate them with the hoe without injury to the root, which it is the object to preserve; and the operation of thinning is best done by children by hand, when the little bunches of plants have attained three or four inches in height.

All the blanks in the field should then be filled up with transplanted plants. Large spaces may often be seen vacant in some fields, which in the case of large ones, would grow many hundreds of good roots, which, without this measure of attention, would be entirely lost to the farmer. When the plants are the size of a crow-quill, they can be easily drawn before they have entwined their roots together; for if two are growing in one place, neither will develop into perfection. I consider it so necessary a precaution to have a supply of mangold plants to fill up vacant places, that I always make a point of growing some on warm beds, so as to be ready for transplantation when about the size of a goose's quill. I stick these in upon any vacant place which I can find about, amongst other crops even, and we get a great many roots from following up this method perseveringly.

Hoeing.-As soon as the young plants have re- 
covered their uprightness, the horse-hoe should besent down between the rows, and the manual operations will consist of one hoeing between the plants, and perhaps in addition, the pulling out the iall weeds and plants running to seed just before harvest; two or three horse-hoeings at fortnightly intervals, until the leaves cover the spaces in the rows, being sufficient.

Mangold succeeds better in the southern counties of England, as a rule, than in the northern ones, liking a somewhat dry, and warm climate, and is very susceptible to injury through frost. The end of April is thus thought quite early enough to sow the seeds, up to the middle of May; on cold soils earlier than those which are warm, and in accordance with the state of the land, and the appearance of the weather.

Mangold leaves as food for Cattle. - The leaves of the plants become broad and succulent in the month of August, and they are relished very much by cattle. The side leaves only should be taken away, leaving those upon the crown standing. If stripped too early, the stripping will have an injurious effect upon the root, and it is better to leave them on somewhat later, when they are wanted for cows. They may be as well taken towards the close of the season, as the first touch of frost will cut them up, and they produce an abundant flow of milk with cows which are fed on them, and it forms so much extra food gained; for cows, for a short time, can be mainly supported upon them.

Ripening of the Crop.-Mangold-wurzel arrives at maturity some time from the latter end of September till the middle of October; and the crop should be 
lifted before the commencement of frost. Before this period, however, it should be carefully looked over, as some of the plants will be found running to seed. These should be drawn at once and given to the stock.

Sometimes, in stiff land, the soil has to be loosened round their roots before they can be taken up; in general, however, they can be pulled up with tolerable ease, or turned up with the plough.

Harvesting and Storing:-When the roots have been pulled up they are lopped and tailed like turnips, and they need to be placed under cover before the frost can touch them, when they will keep sound all the winter, and come in for use in the beginning of the following year, at a most welcome time, when other food is getting short.

They are sometimes stored in long narrow heaps, piled up to a conical form, when a little straw is placed over them, and then covered with earth, flattened down with a spade; draught-holes for ventilation being made at intervals, by twisting up a handful of straw to serve as a chimney, and allow the accumulating gases to pass off.

Another plan is to set up a line of hurdles nine feet asunder, and fill in with mangolds, putting a little straw between the hurdles and the roots, piling them up at top to form a roof. Another row may be made within a yard of the other, and the tops roughly thatched over with straw about a foot thick. The bushy eaves of the straw interlocking each other is a sufficient protection against frost, and the three great requisites of safety to the crop are thus secured - good ventilation, and protection against frost and rain. The job is quickly managed in this way: as 
the loaded carts can be backed to the hurdles, and their contents tilted out, while the old straw comes in for litter after the mangold has been used.

Using Mangolds.-The mangold-wurzel should not be used as food till February, the cattle being supplied with swedes and turnips up to that period, though a little may be used in January, mixed with swedes, in the daily allowance of green food. Mangolds, when taken from the ground, contain certain acrid properties which have the effect of scouring animals when given in any considerable quantity; and the stock both relish them more, and thrive better upon them, when they have been kept stored up for a few months.

With regard to the chemical results in connection with mangold-wurzel upon the soil - weight for weight - the leaves are said to remove a larger amount of mineral matters from it than the bulbs and are richer in phosphoric acid and in magnesia, than the roots, but do not contain so much alkaline carbonates. As the crop requires potash in large quantities, for the perfection of both leaves and bulbs, the application of wood-ashes, liquid manure, green manures, and other fertilisers rich in soluble potash, will raise the quality of the mangolds grown. For flesh-forming constituents, mangolds are said to rank higher than carrots or turnips, the crop being considered more exhausting to the land than turnips, which, from its greater volume and bulk, would only seem. to be feasible; so that succeeding corn crops should have a slight dressing-of course, in relative proportion to that given to the mangold. 


\section{CARROTS.}

The Carrot (Daucus carota).-We are said to be indebted to some Flemings, who settled in the neighbourhood of Sandwich, in Kent, in the reign of Queen Elizabeth, for the introduction of the carrot as a garden plant, though its cultivation appears to have been so little developed that we find it was imported from Holland in the latter end of the sixteenth century. This is seen to have been the case from an entry in the household book of the Cliffords, kept at Skipton Castle, in Yorkshire, where I Is. were paid for a few cabbages and carrot-roots bought at Hull.

It is a very valuable root for growing on sandy and inferior soils, too poor for the successful growth of turnips, mangold, and other crops.

Soil.-A loose, sandy, friable loam, of good depth, is the best adapted for carrots, free from stones or any other obstruction to the free striking of the root downwards, which is otherwise apt to become forked, mis-shapen, and crooked; the extremities of the root extending to a depth of from three, to five feet, finding a good deal of its nourishment from the subsoil, which causes it to be looked upon as a crop not at all exhausting to the surface soil; so that succeeding crops of barley have fared as well as when following turnips, one-third of which have been fed upon the land.

On this account long manure, when it is applied, is considered objectionable; not only giving a bad flavour to them, but dividing the roots, and causing them to form prongs, and on this account it is preferred to allow the crop to follow another, where the 
land has been richly manured previously; and in the case of very poor soil, when it is absolutely necessary to use farmyard manure, it should be thoroughly well decomposed.

The long fusiform root of the carrot, penetrating so deeply as it does, loosens the earth, and the effects of the growth of a crop of carrots in this respect is equal to that produced by the use of the subsoil plough, and it has been often observed that better wheat has been produced after carrots than turnips.

Although deep sandy loams are the best for carrots, yet fair crops are at times to be got off light sands and gravels. The ground, in all cases, must be thoroughly well pulverised, free from stagnant water, and clean.

It is said by some that carrots will do very well without any manure at all, provided the ground is thoroughly well trenched and pulverised; but from experiments that have been made with carrots grown on manured and undressed land, the produce per acre has been twenty-five per cent. greater in the former than in the latter case. On very light sandy soils good crops are secured by allowing them to follow a clean crop of turnips that has been fed off the land in January or February, ploughed once or twice, and subsoil ploughed to a depth of fourteen or sixteen inches. Folding the sheep on the land does away with the necessity of applying any other manure, and the soil is clean, and free from weeds, and in a capital condition for receiving a carrot crop. Two root-crops are not generally sown in succession; but on poor soils, especially, this method will be found a good one. 
On the best light soils of Norfolk the practice mostly is to select a clean wheat or barley stubble for the carrot crop; and in November or December to apply a dressing of from twelve, to fifteen tons per acre ?of well-decomposed farmyard manure, ploughed in with a shallow furrow. In February, or March, a deep ploughing, and subsoiling is given, so as to loosen the soil to the depth of fourteen inches and upwards, and is then allowed to lie undisturbed in this condition until the middle of April. Two or three heavy harrowings are then given to destroy the weeds that have sprung up, followed by a two-horse roll to keep in the moisture, which hastens the vegetation of any weeds that may be left in the soil, to be satisfactorily dealt with hereafter.

When the land is stiff, and not naturally favourable to the growth of carrots, they have been sown in ridges, the seed being either drilled or dibbled. On such soils ridge cultivation admits of a more perfect pulverisation between the rows by horse-hoeing, and the rows of carrots are more plainly apparent, and thus there is less trouble and expense in the first hoeing. The ridges are usually from two, to three feet in width.

Sowing the Seed.-The time of sowing must depend upon the state of the weather and the situation. In some of the northern counties, sowing is deferred till the end of April and beginning of May, but in the southern ones, from the middle of February till the end of March is considered the best season; as where they can be sown early, the crop is both more productive, and of a better quality, and I have always 
found my carrots answer best when the seed has been sown about the middle of March.

The quantity of seed to be used depends very much upon the quality, which varies a good deal, a marked difference resulting on, the same land when seed that has come from different dealers has been used; so that it is better to grow one's own, which can be done by the exercise of a little extra pains. and trouble. When the seed can be depended upon, about four pounds per acre are thought sufficient, but if there is any doubt upon the point, it is better to make sure by using six pounds.

The seeds are very slow to germinate, so that in many cases the weeds make their appearance first, and the foliage being slender, it is sometimes difficult to hoe out the weeds without injuring them. In order to obviate this difficulty, some persons drill a small quantity of oats, barley, mustard, or turnip seed; these springing before the carrots, mark the lines of drills, so that horse-hoeing and hand-hoeing can be proceeded with, but recourse need only be had to this precaution where weeds are very abundant. I never have had occasion to practise this method myself, my ground always being clean, and the rows showing themselves plainly.

The sprouting of the seed is hastened many days by mixing it with damp sand, or sawdust, and placing it in a warm corner, or, at all events, a covered corner, taking care that it is not too warm. The seed of the carrot being extremely light, the forked hairs which accompany it causing it to cling so closely together that it cannot be separated without considerable difficulty, it is invariably mixed before being sown with 
dry sand or ashes, and the seed rubbed, to remove the hairs with which it is clothed, and being allowed to stand in a heap to "chip" for eight, or nine days in. damp sand, hastens on its progress.

Another method is to place the seed in a bag about nine days before drilling, and steep it in water for forty-eight hours. It is then taken out and spread on the floor at a depth of nine inches, according to the temperature of the weather. In about a week, or a little less, it will begin to sprout, when it should be drilled in.

The common corn drill is the best for the purpose, from two, to three bushels of sand, or ashes, being mixed with the seed. The land should be well pulverised by rolling, and harrowing, before the drills are drawn, and the seed sown as shallow as possible; harrowing after drilling removing the coulter marks, is an objectionable practice; but when the seed is sown broadcast upon a well-pulverised soil, it is then covered in by a light harrowing.

Varieties.-The Early Horn is only suitable for garden culture, to be used at table, the Long Orange and the Altringham being the most suitable for field culture, the White Belgian producing the heaviest crops, when the object is to feed cattle with them. There are, however, many varieties differing from each other in rapidity of growth, colour, and length, and also in the height which some species grow out of the ground; the latter, in game districts, being considered somewhat a disadvantage, as it exposes them to injury, though it causes them to be suitable for thin, or adhesive soils. The Large White and Yellow Belgian carrots are best suited for loamy soils, or 
where weeds abound, as the rapid growth of their leaves gives them a better chance of outgrowing their bad neighbours; the common red carrot bringing good crops on light, sandy, or gravelly soil. The species are all of the same original nature, which have been made to differ by cultivation. Some botanists consider the cultivated carrot to owe its origin to the common wild carrot, native to our hedgerows, though the large root is wanting in the wild variety, there being little else to distinguish it from the cultivated sorts.

Singling and Hoeing.- In about three weeks' time, in ordinary seasons, the carrots will make their appearance above ground, when the hoeing between the rows may be commenced. When the drills are from twelve to fifteen inches apart, this is best done with the Dutch hoe, which can be performed very quickly by an experienced man on light soils. A few days having elapsed, they may be singled out at the distances they are intended to stand, varying, according to the nature of the soil, from eight to twelve inches, the strongest plants being of course left. Other hoeings will be wanted to follow whenever the weeds make their appearance.

The horse-hoe may be used with advantage when the drills exceed eighteen inches, particularly on stiff loamy soils.

Haulm of the Carrot.-The haulm of the carrot is sometimes used as food for cows, the tops being mown off with a light scythe, and the animals relish them very much. They have also, in rare cases, been made into hay, as much as three tons per acre having been obtained. They are often folded with sheep, or 
carted off the land to be thrown out on a pasture ; but, where there are animals to feed, a much more profitable use can be made of them than by the latter disposition of the tops. When given to sheep, turnips, hay, or chaff should be given in addition.

Ripening of the Crop, Storing, \&c.-Carrots usually ripen at the beginning, or some time in November, at which period they generally have attained their full growth, when they should be lifted from the ground during dry weather. Considerable care is necessary to raise the crop properly in some soils; but in sandy ones, the task is easily performed with a light fork used by one hand, while the other is employed to draw the carrots up by their tops.

In some works on husbandry it is stated that, carrots may be allowed to remain in the ground during a great part of the winter without injury. It is possible they may escape through good luck, in some seasons, but the practice is a very bad, and unsafe one, as a hard frost will often do them considerable injury, and cause them to suffer much more than parsnips, which stand the cold better, and at best it is but a slovenly method of treatment. It causes a delay in cropping the soil ; and while in frosty weather it is impossible to fork them out of the ground, in wet weather the roots are raised in bad condition, with a large quantity of earth adhering to them, besides the land being deteriorated by the trampling which takes place upon it. If, too, the crop has been raised, and remains unstored during the prevalence of frost, it is easily injured; and it is the safer, and better plan to secure it in good time, immediately it has ripened. 
Carrots are often made up in heaps, piled in narrow ridges, covered first with some straw, and then with earth over them, in the same way as other root-crops; but I have never followed this system myself-my plan always having been that of stacking them up inside a shed, barn, or in the lower part of the hopkiln, where the furnaces are, head and tops alternately piled against the wall, with a thin sprinkling of sand between each layer. They keep in sound, good condition in this way; but perhaps there may be a little drawback in their throwing out later on in the season a great number of very minute fibres, which, however, attests their vitality.

A small part of the crown of the carrot should be cut off with the top to prevent its vegetation, though some are opposed to the system (which is generally followed in France), and consider it better to remove the leaves only, close to the crown. Of course only a small portion must be cut off the crown, for if the root itself is deeply cut into, it will rot at the top perhaps, or at all events bleed, and get covered with a kind of mould.

When I first began to store carrots, I adopted a plan recommended in one work that $I$ had read, which prescribed making a pit with a trench round it, and lining it with pea-straw; but I found the pea-straw heated, and did a good deal of injury to the carrots, and I have never used pea-straw since for such a purpose ; which, indeed, can be much more profitably applied as an item of food for stock.

The greater part of my small quantity of arable land being of a sandy nature, carrots are by far the best, and most valuable roots I grow, excepting the 
mangold wurzel we "steal" between the hop rows-a practice I occasionally indulge in, notwithstanding the protests of my neighbours-when I think there are signs of a failure in the hop crop, by which I make sure of getting a crop of something.

The hop land being richly manured, produces very heavy crops of mangold, which are planted in every alternate row with plants I have in readiness, raised in separate beds, some of the roots of the Long-red description frequently weighing thirty-five pounds and upwards, though I may here remark I prefer the Yellow Globe Mangold, on account of its better keeping qualities.

But carrots are alike useful to horses, cows, and pigs ; and a cow can be kept in good condition during winter, when green food is short, upon a bushel of carrots per day, with a little barley-straw and haychaff in addition; while a horse can be kept upon the same quantity, and do his work well upon the farm, with the addition of a bushel of oats per week, and a little chaff.

Carrots as food for Stock.-The cost of growing the carrots will not average more than threepence or fourpence a bushel at the most, and putting the oats at the outside value of three shillings, it will be seen that half-a-dozen shillings or so will keep a working horse in condition per week. Some farmers have tried the experiment of keeping farm horses on carrots alone, but they are too loosening by themselves, and not sufficiently warming in their nature during the inclemency of winter; half a bushel of ground beans per week being a good alterative, with half a bushel of oats instead of a whole one. 
For fattening oxen or sheep, they are very excellent food, as well as for feeding young cattle, hogs, sows and store pigs-all thrive well upon them. In accommodating each other with carrots amongst neighbours in our part of the country, we estimate the market value to be sixpence for a bushel of carrots, and as I grow seven or eight hundred bushels per acre, it will be seen that the crop is a paying one.

Putting, however, the crop down at a yield of only four hundred bushels per acre, for land not so well adapted for their growth as mine is, and the cultivation at $£^{8}$ per acre, they will be found a capital crop to grow for the purpose of feeding stock, as the money value of the food is considerably more than that nominally assigned to it in the above calculation, and the stock of provender is at hand, ready of access when wanted.

We also sell a good many carrots that are used as vegetables, besides consuming a considerable quantity ourselves in the house; and altogether we find the crop a very desirable one, as we make our stock a leading consideration. In feeding, we cut the carrots small with a machine, and $\mathrm{mix}$ in the troughs with the chaff. Straw-chaff alone we often use for economy's sake, which the cattle eat readily with the carrots, especially when steamed, a description of our method of doing which, I give in another place.

Grocuing Carrot-seed.-To grow carrot-seed in perfection, two kinds of soil are needed : rich sand in the first place, to raise the root in; and strong loam in which to plant it the succeeding year for the production of secd.

The roots from which it is intended to grow seed 
should be carefully chosen, as being straight and clean when the crop is lifted, and those with a double top covering the crown should be rejected, as they are likely to produce "runaways," those with single tops only being taken. The tops are cut off about an inch from the crown, and the roots then packed away under cover somewhere where there is plenty of air, as in a barn, where all frost is excluded, and kept there between straw till the end of February or March, when they should be planted in a dry season on a piece of deep soil that has been well manured and trenched deeply.

Before planting, the top end of the roots is cut off, and they are inserted in rows two feet and a half apart, the carrots standing about twenty inches asunder. If too great space is allowed, the stems are apt to be broken down by the wind and rain; and with this result in view, another plan is to plant four or five roots together within the space of a square foot or so, the clumps being at the distance of a yard from each other. The roots require to be inserted in holes of sufficient size and depth, made by a wooden dibble cased with iron at the top.

They should be well hoed five or six times in the course of the summer, beginning as soon as the plants are above ground; and in the case of the clusters planted together, the practice is, to mould and round them up into hills after the third hoeing, the hill being enlarged each time by the fourth and fifth hoeing. The very largest roots are not always considered the best, but those are chosen of moderate size, in preference, which give indications of being solid, vigorous roots. 
The ripening of the seed is very irregular in point of time, and the gathering is usually performed by women who go between each row, and with a knife, or scissors, cut off every head that appears ripe, and drop it into a bag or basket at once, this operation sometimes requiring to be repeated four or five times, till the whole crop is secured. They are then carried to a barn and stowed away in bags until they are thrashed. The thrashing needs to be repeated threeor four times before the seed can be completely separated from the husk, and between each interval of thrashing it is sifted through sieves, each one finer than the preceding, in succession, till the last and final thrashing.

After this has been done, there will still be seed amongst the offal, which though not of a saleable character may yet be used for sowing on the farm. 


\section{CHAPTER IV.}

ROOT GROWING : PARSNIPS, ARTICHOKES.

Soil-Cultivation-Storing-Parsnips as Food for Stock-Articholes - Composition of the Artichoke.

The Parsnip (Pastinaca sativa).-Although the produce of carrots is very large upon congenial soils to their growth, that of parsnips is still greater, a crop of thirty tons being sometimes secured from rich and well-manured land, the average produce being generally estimated at twenty-four tons per acre.

Like carrots, they are peculiarly exempt from accidents arising either from the weather or attacks of insects, and the crop can generally be relied upon with tolerable certainty, being in a great measure independent of the seasons, as frost does not affect the seeds, nor do the young plants ever materially suffer through the severity of the weather.

Soil.-A stiffer soil than that most appropriate to carrots suits the parsnip, the best adapted being a good clean, hazel loam; or a strong, deep, mellow loam upon a dry, gravelly, or sandy bottom; or they will succeed in even a sandy soil, if it is not too sharp and hungry; but strong clay, unless well opened by liming and ashes, as well as by deep ploughing and thorough drainage; strong shallow loams, with a chalky bottom, or abounding with flint, or sharp gravel stones, are not of a suitable description. 
The preparation of the soil should be much the same as for carrots, the more tenacious the bottom the deeper the ploughing, all that can be done to effect perfect pulverisation being resorted to. Three ploughings are usually given, the first in September or October, the second in November or the beginning of February, and the third at seed-time if deferred later; the ploughing being effected to the depth of twenty inches, or two feet.

Occasionally, however, the land has been prepared earlier than this, and indeed in a few cases the seed has been sown in the autumn, immediately after it has become ripe in the middle of October, by which means the plants have appeared early in the following spring, and have got strong before the weeds could injure them.

Cultivation.-The time of sowing is usually from the first week in February to the first week in March, though operations have sometimes been delayed until the beginning of April before the seeds have been put in the ground, by reason of a wet season, or other cause. As a general rule, in cold or exposed situations the seed should be put in the ground as early as possible; while in the warmer ones, where the progress of vegetation is more rapid, the sowing may be left until later.

A potato fallow is a good preparation for a crop of parsnips, because the manure will have become thoroughly incorporated by the digging of the potato crop and the subsequent ploughing, fresh manure being as objectionable as to carrots, where it can be done without. As soon as the rough leaves get high enough to be distinguished from weeds, the ground 
should be harrowed, and the hoeings performed in the same way as that described for carrots.

The seed is very light, but not so tenacious and adhesive as the carrot; six or seven pounds per acre being the quantity required, though sometimes a smaller quantity is used; at times, as little as four pounds, according as the season is wet or dry, or the soil strong or light.

Much depends upon the quality of the seed, and the kind sown; there being a very great difference in the amount of the produce, some farmers not getting more than a dozen tons per acre; and there is a great difference in the yield between the common kind and the hollow-crowned variety, imported from Guernsey and Jersey, where parsnip cultivation is most successfully carried on, where their cultivation forms a regular part of the field system. The hollowcrowned is superior to the common in the sweetness of its flavour, tenderness of pulp, and hardiness of constitution. The seed, however, must be quite new, and much that is sold is mixed with seed that is two years old.

It is a good plan to steep the seed in water a couple of days before it is sown, and afterwards spread it pretty thickly upon a floor; or it can be mixed with damp sand, the same as recommended for carrots, and allowed to "chip" or germinate.

Storing.-Parsnips are best stored in the same way as that recommended for carrots, but they can be allowed to remain longer in the ground without injury than carrots, not being at their best, perhaps, before December or January, when they have become thoroughly well ripened. Some, indeed, consider 
that a little exposure to frost mellows and improves their flavour, though it is needless to say that no root can be positively frost-bitten without injury, at all events to its keeping qualities.

Parsnips as food for Stock.-Parsnips contain a far larger portion of saccharine matter than carrotsabout 6 per cent. more mucilage-and are very grateful to the palate of animals. They render the flesh of pigs white, and of a juicy flavour, which at first eat them very greedily, but they soon become cloyed with parsnips alone; but animals fatten sooner, and do better upon them than on any other vegetable. Neat cattle, as well as poultry, relish them, but they are not good food for horses-causing them to be dull; and it is said in some cases they have been injurious to their eye-sight, but there are no definite instances of the latter known to have been recorded. Carrots, on the contrary, when given in moderate quantities, are known to improve horses' coats, and are said by some to have a good effect upon their wind, but this I cannot myself vouch for.

They are capital food when given with hay to cows, and the butter produced is thought to possess a superior flavour from the animals that have been fed on them, and are highly beneficial to weanling calves and all young beasts, and store cattle. They are better steamed than raw, the steaming process imparting an agreeable flavour to the chaff with which they are mixed, highly relished by all cattle.

It should be noted that, when parsnips are left too long in the ground, the roots become rusty, owing to the attacks of the maggots of small flies (Psila Rosa and $P$. nigricortis), as well as the caterpillars of two or three 
small moths, and the maggots of the fly Tephritis onopordinis live between the skins of the leaves, giving them a blotchy appearance. On the whole, however, the crop is remarkably free from the attacks of insects, like the carrot; and both, in my opinion, deserve to be more largely cultivated than they are as food for stock.

The Pastinaca sativa, or common wild parsnip, is a native of waste places, in the chalky districts of England especially, growing about three feet high, and flowering and dying off the second year. In the course of cultivation, it entirely loses the pungent acridity which distinguishes it, and it is supposed the common parsnip as is now found in its cultivated state, originally proceeded from the wild description.

\section{ARTICHOKES.}

Helianthus tuberosus.-The Jerusalem Artichole is but very little cultivated in England as an useful root for stock, save by gentlemen who preserve largely as winter food for their pheasants ; but it is well deserving of more notice than it receives, as its nutritive qualities are unquestionably great, and they form capital food, either boiled or raw, for pigs.

The root will grow almost anywhere, and there are many odd corners often, which might be advantageously planted with artichokes. The richer and better the soil, the more productive will be the crop. It adheres so pertinaciously to the place where it has once been cultivated that, there is some difficulty in extirpating it when required; resembling horseradish somewhat in this respect, in clinging to the site it has once occupied, so that a few tubers left in the ground 
will often prove sufficient to form a good crop for the next year.

They should be put whole into the ground in February or March, and any of the small misshapen ones will answer the purpose equally well as the best, and there are many of this kind, consisting of protuberances forming an ill-shaped tuber.

As they send up stems in summer from six to eight feet high, they make capital screens, reaching even to ten feet in congenial soils for their growth, and their roots can be eaten in lieu of potatoes by those who like them, being cooked and boiled in the same way as potatoes, either mashed or whole, or served up at table with a white sauce, many people preferring them to potatoes.

They require no storing, but can be left in the ground and dug up when wanted for use, being much more hardy than the potato-although both of them are natives of the same hot climate, Brazil-and sharp frosts do not kill it.

The tubers should be planted in rows two and a half to three feet apart, the roots standing a foot and a half from each other in the row, manure seldom being used, a good clearing of the ground and trenching being thought quite sufficient for them.

The name is a corruption of the Italian Gircasole, having been introduced into Europe first at the Farnese garden at Rome, laid out for the celebrated Roman banker, Chigi, from whence it was originally distributed. It produces a small yellow blossom, but they are very seldom seen in this country. The tubers are said not to contain focula, but a vegetable principle termed Fuline or Dahline. 
If prepared for the table, it is best to throw them into water as they are peeled, so as to keep the cut surface from contact with the air, which prevents them from getting discoloured, and keeps them of better appearance.

Many animals eat them with avidity, and they are especially good for sheep. The use, however, I have appropriated them to, is to give them chiefly to my pigs. Any odd rough bit of ground in an out-ofthe-way corner that would have been overlooked and made no use of otherwise, I plant with artichokes. By the side of the hedges where there are vacant places, and any strip of spare ground that can be found, they come in very useful to plant, as they form a hedge of themselves. As they are seldom grown in any large quantities, it is somewhat difficult to estimate the exact yield, but they may be safely set down at 400 bushels per acre.

The chief advantage in growing Jerusalem artichokes where they are not consumed in the house as a vegetable is, that they form a useful auxiliary in the shape of food for stock, got off odd corners and out-ofthe-way places, which otherwise would not have been utilised; and about November, when we dig them up generally, I have been quite surprised to see the large quantity of roots collected together from one place or another, that otherwise would have been unproductive, and entirely waste.

In books upon agriculture, the artichoke is seldom mentioned as a root worthy of cultivation, being mostly regarded at best as a kind of eccentric garden plant, only occasionally entertained even in gardens; but from an economical point of view, under the 
90 ROOT GROWING \& CULTIVATION OF HOPS.

circumstances I have described, the artichoke is by no means to be despised.

Composition of the Artichoke--Boussingault estimates the organic matter contained in the artichoke free from nitrogen, in the fresh state, to be about twenty per cent., the precise summary being as follows :-

$\begin{array}{lllllll}\text { Nitrogenous matter .. } & \ldots & \ldots & \ldots & \ldots & 2 * 38\end{array}$

$\begin{array}{llllllll}\text { Organic matter } & \text {.. } & \text {.. } & \text {.. } & \text {.. } & \text {.. } & 1999\end{array}$

$\begin{array}{llllllll}\text { Ashes.. } & \text {.. } & \text {.. } & \text {.. } & \text {.. } & \text {.. } & \text {.. } & \mathbf{I} * 43\end{array}$

$\begin{array}{llllllll}\text { Water } & . & . & . & . & & & \end{array}$

$100 \% 0$ 


\section{CHAPTER V.}

\section{ROOT-GROWING,-THE POTATO.}

General Remarks-Soil-Cultivation - Ploughing-in Potatoes-The Lazy-bed System-Planting Potatoes and Draining at the Same Time-Varieties-Raising New Varieties-Planting and Selection of Seed-Mr. Cuthill's Method of Growing Early Potatoes"Greening" upon a Large Scale-Leaving Seed-Potatoes in the Ground.

The Potato (Solanum tuberosum).-The potato, which is a native of South America, was brought to this country from Virginia by Sir Walter Raleigh on his return from America in I 586, some writers stating that the first ever grown in this country were upon Sir Walter's estate in the neighbourhood of Youghal, in Ireland, early in the seventeenth century; but there is evidently a mistake in the date, as Gerard, in his "Herbal," mentions that some specimens were sent from Virginia which he planted in his garden near London, in I597. They were for a long time only cultivated to a small extent in gardens and small patches of land, and were very slow in making progress as a field crop. After the lapse of about a century, they became more universal in Ireland, from whence the potato was introduced into Lancashire, about the year 1694 . In that county its cultivation soon became general, and gradually spread over all the other English counties, its progress being still 
slower in Scotland, where it has never attained the amount of favour it has enjoyed in Ireland, and England, until quite lately, when heavy crops have been grown for the English, and especially the London, market.

In the Merry Wives of Windsor, act v., scene 5, Shakspeare alludes to the tuber, "Let the sky rain potatoes, and hail kissing-comfits," being, at the period at which he wrote, more an object of curiosity than of profit and economy.

The potato has had many bitter enemies-none more decided than the late William Cobbett, who made severe remarks upon the pauperising effect which the great extension of its growth and its habitual use occasioned among the peasantry of Ireland, and although there may be a degree of truth in some of the strictures which have been lavished upon it, there cannot be the slightest doubt but that the material comforts of the working-classes have been considerably increased by the introduction of the potato as an article of food; though, perhaps, taken as a whole, the class just above the artizan or labourer are the largest consumers.

But whether considered as the food of man or beast, it may certainly be regarded, next to corn, as being the most valuable of our vegetable productions, and is invariably a capital paying crop when not attacked by disease.

The people of England, and Scotland, have never depended upon the potato to the same extent as the Irish have done, where, to a slight degree, perhaps, Cobbett's strictures were justified, and never wholly employed it as a substitute for corn. The dreadful 
Irish famine of 1845 , which destroyed the entire food of a people, as it were, showed the extent to which it had been depended upon in the sister kingdom, and the folly of relying upon one description of food for entire subsistence.

Scotland experienced a year of famine-r742-43which was called the "dear year." Many destitute persons then wandered about the fields in search of food, eating sorrel and other wild herbs, the leaves of peas and beans, or anything they could find ; and this condition of national distress not only called special attention to the potato, but to the whole agricultural system of the country; and to this cause must doubtless be attributed the rapid strides made in husbandry in Scotland during the latter half of the eighteenth century. After this time the farmers of Lothian began to cultivate the potato upon an extensive scale.

The potato had, however, been cultivated widely in gardens and small patches amongst the peasantry before this, very much owing to the exertions of a day-labourer named Thomas Prentice, living near Kilsyth, in Stirlingshire, who drew part of his subsistence from his little plot of ground. This man cultivated the potato very carefully about the year 1728 , and supplied his neighbours with the produce of his crop, gaining enough by their cultivation as to enable him to buy himself an annuity with two hundred pounds which he had saved-a much larger sum in those days than the same amount at the present time.

There is no doubt, however, that, upon the whole, the climate of Ireland is more favourable to the growth of the potato than England; its humidity and more genial character, and freedom from chilling 
east winds, which nearly always prevail in England during the early part of the year, and which inflict great damage upon the tender spring crops, giving it a natural advantage over England.

It has been pointed out by writers that, no plant of any description has exercised so great an influence on the moral, physical, and political condition of a nation as that of the potato upon the Irish people, which, causing them to place dependence for their food upon a crop not demanding continued exertion, gave birth to indolent and lazy habits, exceedingly prejudicial to the development of their intellectual and moral powers of mind, so that by entire dependence upon it the natural stimulant to varied exertion was overcome.

Soil.-The potato will grow upon almost any kind of soil, provided it be not too wet, or clayey; light, dry, and friable loams, or sands of tolerable consistence, being thought the most appropriate. There is no question, however, but that potatoes raised upon the last-named soils are deficient in quality and flavour to those grown upon heavier land that has been well drained and pulverised.

Reclaimed bogs and peat-land produce large crops when they have been well drained; and good potatoes have even been raised upon wet land by means of the lazy-bed system, which I shall describe hereafter. Some of the best quality have been grown in Lincolnshire upon the warped land in the neighbourhood of the Humber.

Grubbed wood-land is also extremely well adapted for the growth of potatoes, and the heaviest crop I ever grew was upon the site of a broad old straggling hedge that I grubbed up, to which we applied no 
manure. Potatoes, indeed, like fresh ground of any kind, and two crops in succession are often grown upon the same land. When a sward has been first broken up, the crops grown upon it are both heavy in yield and good in quality, but when planted a second time, as the yield is sensibly diminished, it proves the crop to be undoubtedly exhausting.

An experiment is recorded in the Report of the Board. of Agriculture to have been made upon"four different kinds of soil, the produce of four eyes cut from the cluster species, which resulted as follows:-

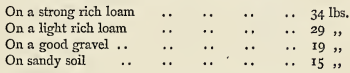

which gives a result in favour of strong land.

Such trials are not, however, always conclusive, as a species might have been selected, perhaps, better adapted to some of the soils; but sandy soils would naturally require a larger quantity of manure.

Yet, although the potato must be looked upon as a somewhat exhausting crop, the labour which is bestowed upon it in the course of digging it up, and in its general cultivation, causes the land to be put into a friable condition, so that when it precedes wheat, one ploughing is often thought sufficient. Most farmers, however, consider the land is never in so clean a state as after turnips, though the wheat is of a better quality when it follows potatoes, being cleaner and stiffer in the straw, brighter in the grain, and, when growing, much less subject to mildew.

In a five-course shift, where wheat does not take part in the rotation, and the crops follow in order, 
two years pastured, oats, turnips, and barley, with seeds, the land is apt to get turnip-sick, and "fingers and toes" make its appearance, when potatoes may well be substituted; and the same end is gained by the following arrangement:-

I, Grass; 2, potatoes ; 3, oats or wheat ; 4 , turnips ; 5 , barley.

Cultivation.-I have been in the habit of planting potatoes myself for the most part with the spade, after the ground has been thoroughly well dug, opening a trench against a line of sufficient depth in which to place the seed, that is afterwards covered over in the process of forming the succeeding row. By this means the seed-potatoes can be rapidly placed in position by the hand, the ground is not trampled over, and the job can be much more quickly and better performed than by dibbling them in. Any irregularity of the soil can be avoided, or made straight, and the seed-crop put into the ground in a uniform manner, the potatoes in due time springing up without a break, in even rows at correct distances from one another.

As land, however, varies in quality, and handlabour is not always to be procured in sufficient quantity where there is a large extent of ground to plant with potatoes, it will be necessary to indicate the methods that are usually resorted to when planted upon a large scale.

Upon well drained, deep alluvial, or clayey soils, the best method is usually considered to be that of planting them in raised drills, made by the single or double-mould plough.

By this method the land is ploughed with as deep 
a furrow as possible in the early part of winter; and as early in.spring as the weather will admit, it is cross-ploughed to the full depth of the corn-stubble, which the crop often follows, if it does not precede it. The land is then harrowed down, after a few days' exposure to drought, and dragged afterwards thoroughly by a grubber, if it wants it; but if it is clean, this will not require to be done when the formation of the drills commences. The ploughman makes the first drills, and carters follow with manure, which is laid on every three $\mathrm{cr}$ four drills, and spread equally along the bottom of the drills; women or boys then deposit the seed about a foot, or rather less apart; another plough then proceeds to split the drills, which covers over both seed and manure.

As there is an objection to the weight of the carts and horses trampling down the drills whilst the manure is being haled out of the carts, some farmers obviate this by laying off the land in five or six-yard ridges, or stretches, by slightly marking it with a plough, the dung being laid in heaps along the line of these furrow markings. The double-mould plough then begins its work on the further side of the field, and as soon as one drill is formed the seed is placed in it, and the manure spread above the seed. When the six drills are thus planted and manured, another plough commences to cover them up by splitting the drills.

If the field should happen to be steẹp, the two ploughs can be worked round and round after one another, opening new drills when going one way, and closing those that have been planted and manured in returning. Those who prefer to have the seed above 
the manure instead of under it, must, of course, spread the manure first ; and so that the horse does not displace the sets with his feet, he must be made to walk on the top of the drill.

When the seed has sprouted about half-way to the surface, the drills require to be well harrowed by the bent harrows, which are made so as to break the outside crust, and thoroughly scarify them. When the young plants begin to make their appearance above ground, which they will do in the course of a week or ten days, the intervals between the rows should be well stirred with drill grubbers, the plants themselves being hoed round with the hand-hoe. A week or ten days after this again the young plants need a slight earthing up, and they are left till they get pretty well forward, when they are again grubbed between the rows, but this time not so close to the plants, and afterwards lightly hand-hoed, and the weeds all removed, after which a final earthing-up is given, as deeply as the horses can go with the plough.

Some farmers delay the earthing-up later on, and satisfying themselves with one good earthing-up; but in deep soils, where it is not too hilly, the crop benefits by the two earthings-up, and the land is always found in much cleaner condition in the autumn.

Plonghing-in Potatoes.-Where the soil is light, thin, or upon upper chalk, or in a hilly situation, the ploughing-in system is generally followed, many sandy and gravelly soils suffering from drought during the summer, so that it is not advisable to plant potatoes in raised drills.

When potatoes are planted upon a large scale by light-land farmers, the course usually followed when 
the land is clean, and soft, is to rib, or half-plough it across in November, and allow it to remain until February, when it is well harrowed down, and the field laid off in six-yard stretches. This is done by first drawing a straight line six yards from the boundary on the farther side of the field, which is most convenient when a straight line, following with another furrow six yards from the first, and parallel to it, the depth of ordinary ploughing. A return journey is made along this furrow, and another thrown out, which forms a kind of open trench, resembling the hollow between two raised drills ; then eight more sixyard ridges are drawn off, and at the eighth, which forms the tenth from the edge of the field, another deeper trench is made by one bout of the plough, and throwing out the furrows on either side in the same way, and repeated over the whole field, leaving an open furrow at every eight ridges, the object of which will be seen when the ploughing is done.

As soon as two or three ridges are formed in this way, or the whole field completed at pleasure, the manure is laid on in heaps, six yards apart, the first row as close as possible to the edge of the field, and the second at the first marking; where the deep furrow has been formed is passed over in the second marking, the third, fourth, and fifth ridges being manured in the same way as the two first, while the sixth receives a double portion. The seventh, eighth, and ninth ridges, are manured in the ordinary way, while the tenth, where the open furrow has been made, is passed over.

By this method of laying on the manure, the second, tenth, eighteenth, and twenty-sixth markings 
are open furrows, which get no manure; while the sixth, fourteenth, and twenty-second markings get twice the quantity. Three ploughs are then set to work, one plough previously having filled in the first open furrow by going one round, and thus leaving an ordinary open furrow on each side of the crown. The manure-spreaders, and seed-planters, then begin their operations, and by the time the first plough has gone one round, the furrows so made are both manured, and planted, and the three ploughs following one another, the manuring and planting proceed on every third furrow without interruption.

When the first four ridges have been completed by turning to the right hand at the headland (by "hupping," as it is termed), the whole turn their attention to the next open furrow, where four other ridges are ploughed in the same manner. When these are done, there will remain four other ridges to plough between the two portions already done, and these are ploughed by turning the ploughs to the left-hand of the headlands, by "winding-out," as it is termed, and in the course of this process the double portion of manure in the centre of this "winding-out" supplies as much as will manure a ridge on each side of the row of heaps.

Care should be taken in spreading the manure that it should be done evenly in the furrows, so that each gets its due share up to the last, or closing furrow. The manure and seed being well covered up in the ground, the crop is better able to stand draught than when ridged up in drills, though when the crop is ripe, the depth at which they are planted causes extra labour in raising it. 
After the potatoes have been ploughed-in, and the tubers have started their shoots about half-way to the surface, the ground is well harrowed, and rolled if its surface is rough and lumpy, and harrowed again. When the plants make their appearance, the intervening spaces need stirring with a long-tined drillgrubber, and the plants hand-hoed carefully between the spaces in the rows. With a slight earthing-up, they may be left until they get strong, when they should be drill-harrowed, and finished by earthing-up.

Although the ploughing-in of potatoes every third furrow is a practice to be recommended upon soils of a friable nature, on clay soils the system does not answer, as they are apt to get consolidated, and if heavy rains succeed immediately after the crop is planted, it will most likely become a failure; so that either on lands liable to retain surface water, or clay soils of a retentive nature, the raised drill system is to be preferred.

When potatoes are required to be planted on one or two year old lea, every third furrow, it is best to rib the land across as early in the season as convenient, so as to give it as much time as possible for the sods to get well decomposed by the middle of February. As soon as the weather will permit, the harrows should be set to work, and-the sods torn to pieces, and afterwards laid off in six-yard ridges, and manured and planted every third furrow, in the way mentioned above. The decaying sods are found to give a steady supply of nourishment to the plants when growing, and less manure will be required; as a rule, also, the crop will be found less liable to disease from this mode of treatment. 
The plan, however, I have always adopted, and which will be found the best where the labour is to be obtained, is, in breaking up old rich leas for potatoes, to dig the ground two spits deep before winter, completely covering up the sod. After remaining all the winter exposed to the action of the elements, if need be, it can then be ploughed and harrowed in early spring, and the land worked down, and the potatoes planted in raised drills without any manure.

The breaking up of this kind of land is never so thoroughly well done by the plough as by digging; but where the latter is not practicable, the skim-plough should be used; one good deep furrow being opened, a plough with a sharp coulter and a broad-winged, sharp-edged share, skims off about four inches 'deep by eight broad of the sod, and turns it completely over into the bottom of the deeper furrow; a common plough follows in the same tract, and throws up a furrow from the subsoil of five to six inches deep, and so leaving a furrow of from nine to ten inches deep to receive the surface sod. The seed can be planted above the sod-furrow, and covered by the subsoil furrow without manure, or the land may be afterwards cross-ploughed lightly, harrowed, drilled, manured, and planted in the same way as that pursued under the raised-drill method. In skim-ploughing, and raising the subsoil, wheel-ploughs are the best to use, though the setting of the share demands nicety, and attention, otherwise the work is made severe for the horses.

The Lasy-bed System.-Waste, and rough land was formerly got into cultivation to a very great extent by the method of what is termed the "lazy-bed" 
system, particularly in Ireland, which obviated the necessity of paring and burning, and in many cases without draining, upon the old con-acre system which used at one time to prevail, before the potato-blight of 1845 ; though where land has been well drained, spade cultivation on the flat is quite sufficient, as the sods, turf, and rough grass can be buried by trenching.

On old rich grass-land and waste land, neither would be fit to carry a crop of corn without the improvement of such a cultivation as the growth of a crop of potatoes will afford. On rich grass-land, the corn would be too rank, especially in wet seasons; while from their avidity for vegetable food, it is the best there can be found for potatoes which like newly broken-up land in which rank herbage has been buried.

As well as in Ireland, in some parts of Lancashire, Cheshire, the Isle of Man, and many parts of the western islands of Scotland, the lazy-bed system of planting potatoes has been practised. The beds are formed of various widths-from three to five, or seven feet-with trenches between, from eighteen inches, to three fect wide. The tops of the beds are manured, and slightly dug over, burying the manure shallow. The sets are then placed in drills at nine or ten inches asunder, and at various distances between the rows, according to circumstances, and covered with soil from the trenches, which are excavated from the depth of one foot, to twenty inches. About three weeks afterwards, or as soon as the first shoots make their appearance, the beds are covered equally with two or three inches of earth, taken also from the trenches. This operation is not only of advantage in giving the growing crop a supply of fresh earth, but 
it checks the growth of, and tends to destroy, the couch-grass and weeds which make their appearance.

Very large crops have been grown in this manner upon undrained, and peaty soils, where neither the raised-drill, nor third-furrow mode of cultivation would have answered, owing to the roughness of the land, or its wetness, as the case might be. With the introduction of a thorough system of draining, which has now become universal, there is seldom occasion to resort to this system except on stiff, retentive clays, where drainage is difficult; but a hint may be taken from the plan in very wet seasons, when, by sacrificing a few rows of potatoes, the trenches will act as drains, and dry up the excessive moisture, which might possibly threaten to spoil the whole crop.

Planting Potatoes and Draining at the same time.Where wet land requires draining, as in the case of old marshy districts, where it is moderately flat, and of a loose texture underneath, the united operations of draining, trenching, and planting the seed, may be done at once, and at a much cheaper rate than when performed at various times.

The tiles or pipes are laid down on the field first in parallel rows, and, on that side of the field which is in a line with the first row of pipes, two spitfuls deep of the upper and lower soils are thrown back and spread over the adjoining ridge. The trenching is then begun by taking one spit deep from the surface of the land to the breadth of twenty-seven inches from the open trench, and throwing the whole of the soil, top downwards, to the bottom of the trench. The second' spitful is taken from the subsoil and deposited on top of the first, so that, when the first 
trench has been filled up, the soil, to the extent of twenty-seven inches, will have been turned topsyturvy to the depth of eighteen, twenty, or twentyfour inches, as may be deemed desirable. After the first spitful of the surface has been thrown into the second trench, the planting of the potatoes is begun by putting them in a row along the line formed by the edge of the mound of soil previously thrown into the first trench, and the lower, and outer edge of the first spitful thrown into the second trench. As this would place the seed too deeply, where a second spitful of nine inches or so of subsoil would be thrown above them, three or four inches of earth from the subsoil above the line should be put where the sets are to be placed, so as not to have them more than six inches from the surface.

The trenching and planting go on simultaneously, until the first row of drain-pipes is reached, when the drain is formed in the bottom of the last trench by digging out two or more feet of soil with a narrow spade made for the purpose. The pipes are laid down at the bottom, the earth returned, and the planting and draining continued as before, and so on till the whole is completed.

Where tiles are not procurable, or there is a long way to cart them, bush drains may be made by loppings and cuttings of the hedges, laid down and packed as lightly together as possible, and stamped down with the feet; or loose stones which may have been collected. This is, of course, only a slovenly proceeding, and the first named only lasts comparatively a short time; but I have resorted to it in those instances where there has been a wet corner or two 
upon a slope where the land was clayey, and retained water, where it was sour and cold, upon which nothing grew well. By adopting this plan, I have cured such unpromising patches, where regular draining operations were not thought of being resorted to, and have drained the water off into a neighbouring pond or ditch.

The landlord, however, for his own sake, ought to be always willing to supply drain-pipes to his tenant, if the latter is willing to undertake the job when planting potatoes, which would not cost him much to do, and by which he will be amply rewarded in the increased fertility of the field, the cost of the pipes not being more than about a quarter of that paid for trenching and digging the drain; the cost of the whole, including labour, seed, tiles or pipes, and the entire cultivation of the crop, not exceeding $£$ I 4 per acre, when the farmer, if he has a good crop, will be able to make a good profit upon his outlay in the very first year.

In making the drain, the lower end, or outfall, must be done first; and, in carrying out the operation, the workman at the lower end of the field must be twenty-seven inches its advance of the one above him, at least, and so on to the next in turn all through.

Each man, as he completes his part of the drain, has the pipes laid in before him by the foreman, who stuffs some straw in the end of the topmost pipe to keep out the earth, which is drawn out when the next man has his part ready, and the pipes laid as before, and thus the land is drained, trenched, and planted all at once. 
The necessity for having resort to the "lazy-bed" system has been now pretty well done away with; but had the old con-acre tenant in Ireland followed the simple method of shifting the position of the bed two feet aside every year, and made fresh alleys in that part not previously deepened, and have further deepened every third or fourth alley a foot and a half more still, and filled this extra depth in with small stones or tiles, the land would have become permanently drained bit by bit, instead of planting potatoes in lazy-beds three or four years in succession in the same place.

Varieties.-For general field culture, perhaps, there is no better potato grown than Yorkshire Regents, where the soil is deep, rich, and loamy; but some kinds are more suited than another to particular soils, and the list of varieties is almost endless, a great many new American varieties having lately come into favour.

Both Scotch and Lincolnshire Regents are also generally considered good in their way, as well as many of the Fluke varieties, which are great favourites with some people.

Of recent American varieties, the Early Rose has been largely planted, as well as the Late Rose, which is of the same colour as the Early Rose, comes later, is larger, and a better keeper. The flavour is, however, much inferior to the old Ash-leaf Kidney, which is only suitable for garden cultivation, and are a somew hat precarious crop.

The Extra Early Vermont resembles very much the Early Rose, and produces good crops. Brownell's Beauty, King of the Earlies, Compton's Surprise, 
Breeze's Peerless, Breeze's Prolific, Climax, Early Goodrich, and several kinds recommended by Messrs. Carter, the London seedsmen, as Carter's American Bread-fruit, Carter's American Snow-flake, \&c., are recommended. Standard round potatoes, consisting of the kinds known as Early Oxford, Early Shaw, Dalmahoy, Flour Ball, Forty-fold, Walker's Regent, Paterson's Victoria, Red Regent, and White Rock.

Of the Kidney varieties, named in the order of earliness, the same as the above-mentioned round potatoes, there are Early Racehorse, Veitch's Improved Ash-leaf, Rivers' Royal Ash-leaf, Early Ashleaf, Myatt's Prolific Ash-leaf, Gloucestershire Kidney, Lapstone, Yorkshire Hero, King of the Potatoes, and Webb's Imperial, the latter being a capital potato.

Messrs. Sutton and Co., of Reading, have also introduced some capital varieties lately, many of which, the same as some mentioned by other growers, are recommended by reason of their freedom from disease, of the nature of which I shall speak of presently; but for field planting, out of the old-fashioned sorts, Yorkshire Regents, American Earlies, Hen's Nest (which has the tubers arranged somewhat regularly around the stem of the root in the form of a hen's nest), and Orkney Red, have kept their ground, as well as a few others; but it is hopeless to attempt to mention them all.

Raising Nezu Varietics.-Anyone, however, who is curious in new sorts, should raise varieties themselves from the seed contained in the apples, which grow upon the stalk. In order to do this effectually, some of the largest ripe apples should be selected from a 
healthy plant, and be carefully preserved in dry sand during the winter.

The seed should be sown in rich garden ground in April, or, better still, on a hot-bed early in March, and expose the shoots gradually to the open air, and when duly hardened, plant them out in a bed of rich earth about the middle of May. By the following October these seedlings will produce tubers, the largest of which should be planted out in the following spring, a few inches from one another. When they have attained two, or three inches above ground, they should be covered with about three inches of mould, and managed in the same way as the ordinary crops of potatoes.

When these attain maturity, they should be carefully examined and sorted, in order to separate the earliest which come to perfection from the others, which will be indicated by the dying off of the haulm. These should be kept separate, as also those of a later growth, those displaying marked vigour being selected; and the produce being sown in the ensuing season, a correct estimate may be formed of the qualities of each. The process, though slow and troublesome, is yet a very interesting one, as it will take three years to develop a new variety properly.

Although the greater part of the crop will partake of the same nature and character as the original stock, yet new varieties are constantly produced, differing in size, colour, flavour, and the periods in which they ripen.

It is recorded of an experiment made of this nature by Mr. Knight, in the garden of the London Horticultural Society, upon twenty-five seedlings, that 
the estimated produce varied from one ton to upwards of eighteen tons per acre, all of different qualities; the best, produced from a single tuber, twenty-seven large and seven small roots, the aggregate weight of which upon an acre of ground it was supposed would equal seventeen tons, nine and a half hundredweight; and being large, solid, mealy, white, well-flavoured, and in substance and appearance much resembling the white yam, was named by the Society after Mr. Knight's country-seat, the "Downton Yam Potato."

Planting and Selection of Seed.-In putting aside potatoes for seed, the practice is too commonly the faulty one of employing only the smallest, and comparative refuse, which are considered too small for use at the table. Repeated experiments have shown that, large whole tubers, or large sets, produce the heaviest crops, whole tubers being preferable where the plants are large and of very strong growth, and are not likely to become broken. The distances also at which the seed is placed in the ground should be regulated by the species, a weak dwarfish kind requiring less space than the more productive sorts, and thus crops have been planted at two feet and a half apart, two feet, one and a half foot, and one foot. The height the haulm attains, of the kind planted, must be taken into consideration. Where the stems are too luxuriant, they are apt to be broken by the wind, and where this is the case, it has an injurious effect upon the root; and it has been supposed by some that good sets cut from a large potato are safer to plant than whole tubers, because the haulm is not so luxuriant, and the crop is more likely to be per- 
fected. Otherwise, if the haulms were not exposed to the chance of being broken, the crop grown from whole seed would, in all probability, always be larger.

Crops turn out the best where the distance between the rows is most in accordance with the average height of the stems, and two feet will generally be found the best distance, in the majority of cases, for field crops.

Seed potatoes need to have attained their full maturity, and should never be taken up until their haulms are entirely withered, it being commonly noticed, that the stray potatoes which have been overlooked in the ground, and are turned up, perhaps, at the beginning of the year, make the best seed.

In cutting potatoes for sets, it must be borne in mind that the upper, or nose end, although the most watery part of the potato, is stronger and of better quality than those grown from the bottom end of the tuber; for, upon looking at a patch of potatoes, some of the stems may be seen growing much more vigorously than others, and this is often to be attributed to the fact that, the stems proceeding from the lower sides of the tuber are weaker than the others, the roots becoming sooner ripe when the cuttings have been taken from the top end.

Some persons thinking to act impartially with potato sets, cut the tuber longitudinally from nose to tail, and set both halves indiscriminately; but this is bad practice, for the sap rising to the crown eyes first, so much is taken away from the lower ones, that they either shoot weakly, or in bad seasons not at all. The crown sets, therefore, ought to be kept together, and the bottom ones planted separately; or better 
still, if there is no waste to be feared, and there are animals to eat them, they may be given to the pigs. When sets are cut-which should always be from large potatoes-they should be exposed to the air for two or three days to allow the cut surface to dry, and harden, as they will sometimes rot in the ground. Occasional breaks will be thus avoided, and the crop be level, and even. A little care in such matters makes a great difference very often in the gross results of a crop.

I have stated before that, it is not desirable to use small potatoes for seed, for even where planted whole and uncut, which is thought to be the correct system by many growers, they are likely to bring forth a great many small, soft stems, which commonly produce smaller tubers than where there is only one, or two stout stems.

Experiments have been tried by planting these at smaller distances, and the result has shown the employment of these small-sized bulbs for seed to be an error in management; for, although it has been proved that, weight for weight, the crops yielded, whether from small or large potatoes, will be in proportion to the seed deposited in the ground; yet in the case of the smaller potatoes it is not possible to crowd them in thick enough without interfering with the adequate space necessary for them to grow in.

All these little points of consideration make a great difference in the successful growth of a crop. When sets are used, and the cuttings taken from the top end of the potato, the produce is not only better, but earlier; and it is by the proper observance of these facts, which should be made rules, that greater 
profits are to be obtained in the management of a farm.

Nothing pays better, perhaps, than a good crop of potatoes, as ten tons per acre are commonly got, sometimes as many as fifteen tons, and occasionally much more. In the Transactions of the Horticultural . Society it is stated that Mr. Knight once planted in his garden some tubers of a variety of potato of very early habit, but possessing more vigour of growth than is usually seen in such varieties (but the species is not mentioned). The soil in which they were planted was in good condition, but not richer than the soils of gardens usually are; and the manure it received consisted chiefly of decayed oak-leaves. The tubers were planted nine inches in the soil, and the mould was afterwards raised three inches higher in ridges, to guard the young plants from frost. The produce was at the rate of thirty-four tons nine hundredweight per acre, and $\mathrm{Mr}$. Knight was of opinion that still larger crops might be obtained.

Although there is no parallel between field culture and garden cultivation, yet, as a matter of course, valuable hints are to be obtained by instituting these comparisons, and although it would be difficult in many districts to get enough oak-leaves to manure a field, yet the hint ought to be taken, to carefully sweep up, and collect all leaves for this purpose, and add them to the manure-heap.

I have long made a practice of doing this, and the place is not only kept tidy, but vast quantities of leaves are got together which, with me, serve the purpose of litter; and the pigs find a good many acorns, beech-nuts, and other edibles amongst them, 
with which they are very much entertained. Instead, therefore, of allowing the leaves to blow about, making the place untidy, and lodging in all sorts of out-of-theway nooks and corners, they are swept up every day and carefully put away in such quantities as will not heat, and are properly dried for use hereafter. Not only is an expense, which would otherwise have to be incurred for straw, saved, but a valuable manure is secured in addition. But of this I shall have occasion to speak at greater length hereafter.

Mr. Cuthill, a very successful grower of potatoes, recommends the storing of those intended for seed in dry airy sheds or lofts, in order to prevent their heating, sweating, or premature growth, and also to mix charred peat with them, stored in out-door pits or clamps. Wherever this substance can be obtained it should be resorted to.

Mr. Cuthill's Method of Growing Early Potatoes.The method Mr. Cuthill pursued for growing early potatoes will be found instructive by those who have not read his published account of it.

"The sets, well greened, are laid out singly (with their heads all one way to preserve order at taking-up time when planted out) under a stage in a cold greenhouse. All persons will not have such a convenience, but market gardeners may fill their 'lights,' putting the glass on and covering up accordingly as the winter advances. If they cannot spare frames, trenches may be dug. One five feet broad, and a hundred feet long will hold enough potatoes to plant an acre of land. Farmers may find room in lofts, sheds, trenches, and other places. Care is taken that no water fall upon them, and nothing more is done until about the 
middle of January, by which time the shoots have grown about an inch. The shoot is very strong and green, the young fibres striking out from the base of the shoot, and very bold and strong. I now put on as much mould as will cover them, and one watering is given to mix the earth in between them. They are then left untouched till planting-out time. They are not even watered, because the less water given to them, the hardier, and more wiry they become, sending out an immense number of roots to collect food; in fact, when taken up in the middle, or end of February, they have produced a complete mass of strong fine roots with a powerful stem. The ground is prepared during the winter by trenching two spades deep and laying it in ridges. The ridges ought to run north and south, this being of the greatest consequence, in order to allow of an equal action of the sun and air on the sides. Early potatoes should be planted in ridges from eighteen inches to two feet apart, and the sets be placed at intervals of nine inches. Late potatoes ought never to be planted closer than two feet, to two feet six inches from row to row, and one foot from set to set.

"As soon as the ground is trenched I sow salt and soot, in the proportion of about two tons of salt and thirty bushels of soot to the acre. I have used no other manure than this for five years. The planting is commenced by taking up the sets carefully and placing them at the bottom of the first furrow, the shoots being placed parallel with the ridges. The mould of the first ridge is then laid over them carefully, as the shoots are by this time three, four, or even five inches long. The next ridge is proceeded 
with in the same way, and so on, the ground being left at last in ridges lying directly over the sets. If all the side shoots are removed, leaving only the main shoot, the crop will be ripe, or fit to dig nearly a week before the tubers with all the shoots attached, although the crop will not be near so heavy.

"When the plants come up they grow so fast that they smother the weeds if there be any. If May should be very dry, as in some seasons, I am obliged to water, and when I do, of course I continue it twice a week until rain comes; for, if watering be not continued, you only bring up the fibres to be killed by the heat of the sun. The main points in the above mode of management are, that the potato is not allowed to shoot and waste its substance in growth to be thrown away. The first shoot, or bud, is allowed to proceed onward to its perfect development, while in the common method of procecding, the tubers are allowed to sprout from all the eyes, to produce a quantity of weak shoots, which are broken off and wasted at planting time, leaving the impoverished tuber in a condition which necessarily retards, and weakens the future plants."

"Greening" upon a Large Scale.-Where potatoes are to be planted upon a large scale, and there is not room enough to follow out the plan recommended by Mr. Cuthill, they may be placed in readiness for planting in long heaps not more than thirty inches wide, on a dry surface, in an airy situation, and covered with bunches of straw, which should be removed in dry sunny weather in order to allow the potatoes to green, and every night the straw should be replaced to keep off rain or frost, when, in the course 
of ten days or more, and the weather has been favourable, they will have got sufficiently dry and green, and it will not be necessary to uncover them any more. At the beginning of November the straw should be taken away and fresh wheat-straw spread rather thickly over them. Some one-and-a-half-inch drain pipes should then be placed every two or three yards perpendicularly along the top, and some horizontally along the sides in a zig-zag manner, so as to be the means of diffusing the air equally throughout the potatoes. The straw is then covered over with earth, more on the north than the south side if the pit is from east to west. Care should be taken in making up the potatoes to form the bin so as to bring it up as sharp as possible at the sides and top, so that earth may press as lightly as possible upon them. The air will enter at each side of the lowest part and ascend through the heap and escape at the top; but when there is a hard frost, and the cold air might do damage, the pipes should be stopped with a little straw, which can be removed when it goes away again. In this way potatoes can be kept without sprouting or heating or sweating till the month of March.

As all these contrivances and arrangements take time, however, I find it answer the purpose best to leave those potatoes I am likely to want for seed in the earth, which I manage in the following way:-

Leaving Seed-Potatoes in the Ground.-Being upon occasion in Ireland I saw a field of potatoes ploughed up in the spring that had been so badly diseased in the autumn that the field was given up as not worth digging the crop. As the plough worked in the field it turned up a great many sound potatoes in first-rate 
condition, that were perfectly healthy, there not being the slightest trace of any disease, the infected ones having decayed in the ground.

I therefore took a hint from this, and left my seed potatoes in the ground, and I find that by this method the vitality of the tuber is so much increased that every eye produces a strong healthy stem. Potatoes that are stored tip often become heated, and the quality of the seed is thereby deteriorated. When potatoes are thus left in the ground for seed, although they can be allowed to remain without much fear of injury in either Ireland, or the southern counties of England, in those districts where keen frosts may be expected, the safer plan is to pull off the haulms and earth up the drills with a double-mould board plough, having the boards set narrow so as to allow the plough to enter the earth deeply without disturbing the potatoes.

They should be allowed to remain in the ground until they are wanted to be planted (not leaving them, of course, for too long), and they should be cut, or planted whole at once, as may be decided upon. Being full of sap, all risk of heating is avoided by this means. The ground which these seed potatoes have occupied will always come in advantageously for some crop or other afterwards.

There is no doubt in the world that taking these precautions to obtain healthy, and good seed by strengthening the vitality of the tubers, or rather by not allowing their vitality to deteriorate, tends mainly to diminish the chances of disease.

The close observation which has been made on this head has been the means of showing that the 
first stems of the potato, which produce a hard, woody stalk, those which first spring are not so liable to disease as the others, consequently the advantage may be seen in Mr. Cuthill's system, the soundness of the theory being beyond dispute, that, when the first shoots are broken off, those which come after are weaker, the haulm being softer and more delicate, and consequently falls an casier prey to disease, upon the principle of the doctrine of the strongest and fittest being the survivors and objects of selection. 


\section{CHAPTER VI.}

\section{DISEASES OF THE POTATO.-MANURES.}

Potato Disease-Dr. Wallace's Theory-Rev. Mr. Moule's TheoryDr. Carpenter's Theory-Manures for Potatoes-Lifting and Storing Potatoes-Use of Diseased Potatoes--Baking Diseased Potatoes.

WITH regard to the theory that the tuber has deteriorated in quality, and is therefore more likely to succumb to disease; it has been pointed out that, so far as the disease itself is concerned, there is no material difference in the composition of the ash of diseased, and sound potatoes; and this experiment of burning shows its presence (disease) cannot be attributed to an alteration in the relative proportions of inorganic matters which enter into the composition of the root.

The observation of most growers has confirmed the theory that, whatever may be the nature of the disease, it is invariably communicated to the tuber by the prevalence of heavy, rains. With this fact in view, it is urged that the disease is to be evaded by laying down the potato-stalks on each side of the drill, and covering the whole of them up with earth, except the ends or tips of the haulm, when from indications of atmospheric operations disease is to be expected.

The desirability of this practice would appear to be 
confirmed by the results of an accidental circumstance that has been recorded, where some planks of wood which had been thrown down on a portion of a field of potatoes, that ultimately turned out to be very much diseased all over it, except in those places whereon the planks had been thrown, where they entirely escaped its ravages.

Dr. Wallace's Theory.-Dr. Alexander Wallace has said in reference to the potato disease, having tried various remedies, and experimented in various ways to no purpose, that out of the numberless theories which have been propounded relative to it, three only are worthy of credence, and that remedy and cure have yet to be found; but as the first step towards cure is a proper understanding of the nature of the malady, he records his observations, which are in effect as follows :-

One person attributes the cause of the disease to an insect-Smee's Aphis vastator; another to a fungus; a third to atmospheric causes-a theory, owing to the suddenness with which whole districts are apparently sometimes invaded, obtains general belief. From these three causes, taken conjointly, he believes the disease to arise; the error of most observers consisting in finding but one link of the chain, on which alone hung their theory, but there being three links, any one of these being absent the disease will not appear.

Thus, towards the end of June, or in July, if anyone approach growing potatoes, and strike the haulm gently with a stick, he will see numerous small green flies or midges dart away. These are Eupteryx picta, E. viridis, and other varieties, and are common in our 
gardens. If the observer proceed to examine the haulm and leaves, he will find numerous white specks, and, looking closely, will find small green insects without wings - the larvæ of the eupteryx.

There are also two or three other species, one a bug, and other aphides, which prey similarly upon the potato. He will see that these white specks are made by these larva, which have consumed the chlorophyl on the under surface of the leaf; the haulm will also, to some extent, be similarly affected. If he continue his observations for some days, he will find these specks increase in size, and coalesce, and as the weather gets warm, they get discoloured (chiefly in July), and form a brown blotch, chiefly at the tip of the leaf; any injury to the cuticle-as a bruise-will create a similar blotch.

This is the first link in the chain, the primary or predisposing cause of the disease. The haulm and leaf are punctured in many places, their juices withdrawn by insects. An effort is required from the plant to heal the wounds; an exudation arises-all this weakens the constitution of the plant. Should fine weather continue, the blotches merely dry up, the haulm in due season dies down, the tubers ripen, and are turned up free from disease. And this is a good season. But should rainy weather (the second link in the chain, and exciting cause of the disease) supervene in July and August, just when the wounded stems and leaves are healing up (the critical time), when the potatoes are nearly at their full size, or just about to ripen, and more especially should electrical discharges with heavy rainfall supervene, saturate the ground, and induce for several days a muggy condi- 
tion of atmosphere, then a fungus-the third link in the chain-(Botrytis infestans), the true potato disease, is developed with marvellous rapidity.

Now, we know that with regard to the spread and invasion of fungi generally (of which mushrooms, or mould on jam are good types), certain conditions are necessary to their development and propagation. In the shape of spores, or seeds, they are present in numbers, doubtless, everywhere ; but unless warmth and moisture and a still atmosphere be afforded, the mycelium is not developed, no fungi are seen. Furthermore, we know that with regard to living tissues, fungi do not, and probably cannot penetrate, a sound healthy skin ; but, aided by a lesion of surface, or an unduly thin cuticle, they invade and spread rapidly, especially in deteriorated constitutions. This is especially the case in the common ringworm of children. Now, this is the case with the potato plant.

Numerous wounds have been made on its leaves and haulm; exudation has been poured out, its constitution is impaired thereby, the surface is not a healthy, true skin; let warmth and moisture, and a still close atmosphere, especially under the potato haulm when long, be superadded, and in twenty-four hours the first sign of active mischief is visible. A white film of mould appears on the under surface of the brown blotch-not, indeed, on the dry portion, but where the exudation has been poured out at the edge of the green portion of the leaf-a rapid development of mycelia and spores ensues; and in another forty-eight hours, if the atmospheric condition be favourable, the mycelia will spread with marvellous rapidity, attacking the haulm and leaf at numerous 
points, descending through the stem, to the roots and tubers (those at the top are generally the first affected), and thus the three links of the chain are completed.

The first appearance of disease in the tuber is a brown discoloration, going deeper than the cuticle into the starch of the potato, generally, if not always, commencing at an eye, and often at that eye which is connected with the haulm. When a part of the cuticle of the tuber is exuded, by insects or otherwise, the fungus there finds an entrance; or the spores, falling on the tubers above ground, find a weak spot and enter. Or if potatoes be taken up when not yet ripe, and the skins be bruised in doing so, and they are covered with diseased haulm, or lie in its vicinity, these will suffer severely from disease. At this stage, when the white film appears, the only remedy I am aware of is to cut off the haulm, or pull it up, leaving the potatoes well covered with soil ; but this must be done early, a delay of forty-eight hours may prove fatal to the crop.

But during the last two years I have observed an apparent contradiction to the above. I have seen haulm spotted with film abundantly, and yet the crop of tubers when dug has been free from disease generally. How is this? Simply because the tubers were all but ripe, and the haulm all but dry before it was invaded by the fungus. Moreover, the wet lasted but a few days, and was then succeeded by fine sunny weather, which, as the haulm was but short, soon dried up the film, and checked its progress, and the haulm ripening and drying up, the fungus could not invade the tubers. Hence I learn a practical lesson. 
With a falling barometer, at first sight of the film, I adopt extreme measures, and cut off the haulm; with a rising barometer, I trust to fine weather to carry through with a well-ripened crop.

I have now said sufficient, I trust, to stimulate observers in future seasons to watch narrowly these three links, one of which being wanting, there will be no disease; and I am perfectly certain that, though the theory which I now propound may not at once command assent, yet, if fairly, and thoroughly observed, it will not merely stand the test, but will explain the numerous vagaries and eccentricities of the disease, which have done so much to baffle enquiry."

Dr. Wallace goes on to say that he claims no merit himself for this discovery, which is due to the late Dr. Maclean, of Colchester, a most skilful and observant naturalist, who first showed him what he has been describing, who related an experiment which he made many years back, which, crucial as it was, convinced him-then somewhat incredulous-that the matter was worth investigation. He planted two pots with potatoes, and covered the haulm with gauze, kept in situ by means of sticks. From one pot, $A$, he excluded all insects; into the other, B, he introduced in quantity the eupteryx. The pots were placed side by side throughout their growth, and the contents were eventually turned out. In A every tuber was sound; in B every tuber was diseased.

The result of Dr. Wallace's observations on potatogrowing led him to come to the following conclusions :- 
Avoid long-haulmed crops. It is true that you may get large potatoes and heavy crops; but the larger the haulm, the greater the risk of disease, since ventilation near the surface of the ground must be prevented, and a condition of atmosphere after rain favourable to the development of fungi prevail. Large potatoes suffer most from disease. I remember one year growing many very large; one weighed 3lb. I Ioz., and twelve others weighed I 3 lb.; but all these, though at first apparently sound, soon showed signs of disease, and were worthless for keeping purposes.

Avoid red-skinned sorts, since, in digging them up, you cannot so well detect if they are or are not affected by disease.

Give plenty of room between the rows and plants to encourage ventilation.

Well-drained soil is to be preferred, but potatoes from heavy land possess a far superior flavour to those grown on light land.

In most localities, but perhaps not in all, second early potatoes will ripen in good time before harvest, and escape disease; therefore, let the bulk of your crop be then.

I have had most excellent crops from seed saved from a crop infected the previous year by disease. I do not, therefore, believe in any deterioration of the potato.

If possible, dig the crop early in dry weather, directly the skins are set, though the haulms may be green, especially if the disease be prevalent.

If this is not possible when the disease is prevalent, at its first sign (the white film in the leaf), cut off or 
pull up the stems, covering the potatoes with soil, and leave them to ripen. Burn all the diseased haulm.

When this cannot be done in time, dig up your potatoes late; the diseased ones will rot, and only the sound ones will remain. You will then economise labour.

Sets may be preserved of tainted potatoes when only slightly affected, thus,-cut out every trace of disease till no brown discoloration of the starch remains; the remainder may be dried and dusted with lime, and will keep sound if dry.

No kind can claim immunity from disease.

It has often been remarked that, the stray potatoes left in the ground, stragglers, and self-sown ones, invariably turn out the best seed, and it has been observed that, where the spring-planted crop has perished, the self-planted one has escaped, and the question has been asked whether the seed, often the inferior part of a crop, kept in an artificial state during the winter, in a condition very likely to promote the development of the spores from which the fungi Botrytis infestans is developed, would not fare better if put into the ground in autumn, and whether autumn planting ought not to be encouraged.

Of this phase of the subject I have spoken previously, and the whole gist of it appears to depend upon the healthy condition of the haulm, and its power to resist, or throw off disease.

Mr. Moule's Theory.-The Rev. Mr. Moule's theory of the potato disease is, that it is often occasioned by want of silex supplied to the plant, and he observes that the different parasites of the vegetable world are destined to feed upon plants undercertain conditions. 
Thus, the stalk of the wheat plant, and the leaf and unripe fruit of the vine, are quite as much the food and the life of mildew, as the grain of the wheat, and the ripened fruit of the vine, are intended to be the food of man, and that the abundance, and increase of these parasites, are dependent upon a weakened condition of the plant, and their attacks prevail most when the stall is weak, in proportion to the weight it has to sustain, which has been traced chiefly to an insufficient supply of silex, or of silicic acid, and a deficiency of this essential constituent exposes the vine to attacks of mildew ; and the same cause, aggravated at times by stimulating manures (of a kind not specially adapted to the potato) would similarly affect it.

Without having any idea that the potato would be affected by the presence of silex, he caused about an ounce of the manure he terms phospho-silicon to be placed under each tuber when planted, which from the first showed a strong and vigorous growth; the result of this experiment being, unlike others, where luxuriant growth has been attained at the expense of a weakened constitution, although the haulm stood two and a half feet high (the variety being the Early Rose), it kept erect without breaking; and under those whose growth was the most luxuriant, the tubers were the largest, and the most abundant.

Although the blight had affected more or less severely every garden and field in his parish, not a diseased tuber was found amongst the potatoes so treated. Occasionally during the month previous to the digging of the last portion of the crop, the dark spot appeared on a leaf here and there, but it never 
was attended by the withering of the plant or stalk, or even of the leaf itself. This result would seem to point out that the incipient forms of the disease was there, ready to attack a vulnerable part of the plant, but its constitution was strong enough to resist its approaches. In Mr. Moule's schoolmaster's garden, a single line of potatoes was grown with some of this manure, while the rest of the garden had none of it, and although every part of the garden was black, and offensive through the prevalence of the blight, this line appeared to be untouched, and, out of a very large yield, only two tubers were slightly affected by the disease.

Mr. Moule's theory of the potato disease is, that it is owing to the weakness of the frame or structure of the stalk and leaf, that weakness being occasioned by an absence of those constituents in the soil which are necessary to ensure robust health to the plant.

Having observed the slag, or dross from iron-works became pulverised upon exposure to the atmosphere, and proved a good manure for potatoes, upon examination he found, amongst its ingredients, potassium, silicon, and aluminum. Further, that it is well known that the water-meadows of Wilts, Hants, and Dorset, lying in the valley formed by chalk hills, their great fertility is due not so much to the water itself, as to the very minute particles of flint washed down from the hills, which yields silicic acid, that is conveyed to the roots of the grass.

The conclusion to be derived from these, and similar facts is, that, owing to a deficiency of one of the main constituents of its structure, the attacks of the 
fungus, its parasite, will be more or less effective according to the greater or lesser degree of warmth and moisture, and certain electrical conditions of the atmosphere; the exciting cause, or occasion of the disease, being comprised in the susceptibility of the plant to the growth of that fungus, and the evident remedy is to be found in the correction of that susceptibility by strengthening the constitution of the plant, and that silica will make stronger the potatohaulm even as it is found to strengthen the wheatstalk.

Dr. Carpenter's Theory.-Dr. Carpenter's opinion is, that the germs of the potato disease are planted with the seed which come to maturity at their own proper time, whenever concomitant circumstances favour fungus growth; the development of which may be checked by dressing the seed in the same manner that farmers adopt with their corn. The years $\mathrm{r} 843, \mathrm{r} 845$, and 1846 were remarkable for the destructive influence of mildew upon corn crops caused by the fungus Puccinia graminis, which belongs to the order of Coniomycetous fungi, a species having a dust-like appearance; this disease of grain having been materially decreased since farmers have adopted the plan of dressing their seed, and that the same laws which promote the growth of Botrytis infesians are the same as those which give rise to fungus upon corn, whether called by the name of smut, red-rust, red-robin, or bunt, all being various stages in the development of the Puccinia graninis.

Just as these develop themselves more easily upon undressed spring-sown wheat, so Botrytis infestans will more easily find its home upon undressed spring- 
planted potatoes; and there are three material points that need to be observed:-

I. In making choice of the best seed.

2. The removal of mycelium and rusting spores from the seed chosen. Botrytis infestans disappearing rapidly from potato fields that have been moderately drained, as soon as the sun breaks out, and the sky becomes unclouded, proves that it is a fungus which cannot increase in a dry air, and continued bright sunlight. It will be right, therefore, to spread out the seed potatoes upon the surface of the ground to let them dry in the sun, and become green. They may be exposed thus for two or three weeks if they are kept dry. This treatment will destroy the major part of adhering mycelium, or spawn. They should then be gently dipped in a solution of lime and carbolic acid. A pound of quicklime, stirred up in a bucketful of water, to which an ounce of the carbolic acid of commerce has been added, will suffice for a sack of potatoes. The seed should be put in a tub and gently turned about, so that the whole may be covered with the solution, and afterwards dried in the air. By this means all spores and mycelium on the outside of the tubers will be destroyed, the only danger being likely to arise from the presence of some which contain the disease within their substance; but the latter will decay in course of time, and will not affect those which are sound.

3. The seed should be well preserved, without sprouting, and if this cannot be done, from lack of convenience, they should be planted in the autumn ; each potato then separate from its fellow, if diseased, will decompose beneath the surface of the ground; 
then, if the seed is re-dressed with carbolate of lime before planting, no blight will appear, unless the grower has disobeyed manifest rules, such as planting the seed in fields manured with diseased haulms, or in soil in which potatoes have been continuously planted, until it is full of debris of previous crops. It is necessary also that the soil should not contain an excess of manurial matter, or be frequently sodden with moisture.

A keen observer of the potato disease in Ireland since 1846 has pointed out that the practice of storing potatoes there as they are raised, in large pits made in the field where they have been grown, is decidedly injurious. The tubers heat, and absorb the sweat produced by their being heaped together in large quantities, the farmer finding, when he opens his earthen pits in spring, a large proportion in a state of decay, having, without his being aware of it, communicated the taint to many which he considers sound, and from which he selects his seed.

To overcome this, where storing in pits is absolutely necessary, the potatoes recently raised should be left in temporary pits for a short time until the sudorific process has exhausted itself; then the pits should be opened, and the crop carefully picked, so as to remove every suspicious tuber, and the sound portion pitted afresh in soil different. from that on which they were grown. During I846-7, the only sound potatoes the Rev. C. Foot, Rector and Vicar of Knocktopher, county of Kilkenny, ever met with were stored in the way described, who makes this recommendation. The next thing demanding attention is the planting, which should not be later than 
the second week in April. The manure should be mixed with fresh lime, chloralum, soot, \&c., and but a small quantity of manure applied, the ground being as often as can be arranged, such as has not recently produced potatoes. Rich manuring, in this gentleman's opinion, when not compounded with the chemical ingredients alluded to, is one of the predisposing causes of the potato rot, which is precipitated by atmospheric influence, it having been frequently observed in Ireland that, disease made its appearance after thunderstorms, succeeded by foggy nights, which usually occur about the second week in August; but in one year these happened in the last week in July, and the disease existed to an extent unknown since I 846 .

The experience and testimony of the gentlemen I have quoted, while not exactly agreeing with one another as to the exact origin, and method of treatment of the disease, yet are unanimous upon certain points ; and thus Mr. Cuthill's method of drying and greening the seed beforehand is recommended, in a different manner somewhat, by the two gentlemen last referred to; and there is this difference of opinion, that while some attribute the presence of disease to the root, others consider it is communicated to the root by the haulm; but the result of these observations certainly go far to prove that healthy seed which will throw up strong, woody stems, will enable the plant to resist the attacks of disease, beneath which a less healthy one would succumb.

Botrytis is a genus of moulds with which we have lately become very familiar, as it is generally admitted that the decay of the leaves and haulm of the potato 
are certainly due to Botrytis infestans; but there are several other kinds extremely destructive to plants-as Botrytis parasitica, which isoccasionally injurious toturnips, while another species spoils whole crops of onions, and another commits ravages upon tares, and peas.

If the potato-murrain, which was first observed in a serious form in this country in $\mathrm{I} 845$, is not identical with the ravages of Botrytis infestans, it is most probable the latter has some connection with it. In I 845 it was looked upon as being an entirely new disease in England, it having been most disastrous in America in the year preceding ( 1844 ); but according to Gay and Acosta, the potato-murrain has been known for ages on the western coast of America, in Chili, and other places, and it is generally believed to arise more particularly from certain special conditions of the atmosphere.

I have said enough, however, for the reader to form his own conclusions upon the subject, which to a certain extent is somewhat obscure.

Mamures for Potatoes.-In the foregoing I have touched upon the requirements of the tuber, and certain constituents that it is necessary to supply to the soil when growing potatoes; but the common experience is, that the largest crops are realised from the application of manure when it is administered in the shape of farmyard dung; but the chances of disease are greatly increased by its use, so that on the whole it is better to resort to it only in a qualified degree.

On the other hand, while ammoniacal manures tend to promote disease, or rather, to induce such a growth of the plant as will render it more susceptible to the 
attacks of disease, carbonaceous substances are much safer to resort to-such as soot, coal ashes, old tan, and vegetable substances of all sorts. Long, strawy manure will therefore be found to be better suited to this crop than when it is more steeped with the droppings of the stable, and the quality of the long manure may be improved by the addition of some carbonaceous substance or other, such as peat-charcoal. Decomposed sawdust has been recommended by some, but I never found it to answer on my land, having once a good deal to dispose of, upon on occasion when we set a saw to work in the plantation, attached to a portable steam-engine by a band, or strap. The observation of my foreman was that the sawdust appeared to poison the land. It was used chiefly in sandy spots, and there may have been something in the quality of the soil which caused it to be unsuitable. But the case was very different with leaves, which we are able to gather in large quantities. In one portion of my plantation the underwood or coppice consists of Spanish chestnut, and immense quantities of large leaves fall to the ground each year, which enables us to gather a great number of cartloads every autumn. When leaves are used as manure, either by themselves, or mixed with other manures of an appropriate character, I find them very effective. Leaf-mould for the use of our frames and the greenhouse is also a great acquisition to us.

Although disease has done a good deal of damage in our district amongst the crops of neighbouring farmers at different seasons, so that I have been enabled to buy large quantities of potatoes at threepence, and sixpence per bushel, for feeding my pigs, 
which I $b a k e$, instead of boiling, after the plan usually followed, we have not lost any of consequence from disease; here and there there have been a few stray roots, and our neighbours, the farmers, cannot understand why we are so exempt, though we make no secret of the plan we pursue.

Ours being chiefly. sandy, light soil, we have found that lime, though a very valuable application on some lands, produces scab on the skins of potatoes, this being especially the case upon one occasion with two or three acres we grew of Webb's Imperial. We had a good crop, but all disfigured in the way described; and the use of lime generally does not appear either to increase, or diminish liability to disease.

The sulphate of soda, potash, and magnesia, arc generally considered efficacious for potatoes raised upon dry land, where the haulm does not grow too luxuriantly; but on all deep, gravelly soils, nitrates of soda and potash should be avoided, as they are too forcing to the haulm. Superphosphate of lime, while not being so forcing on the haulm, tends to promote the early formation of the root in good numbers, and to force them on to early maturity; and so, by being ready for digging early, they often escape the liability to infection by being hastened on; but it is not suitable for dry, light soils, the same as most of mine consists of. The premature ripening and small tubers are, however, no drawback to those who wish to hurry in early new potatoes to market. But on deep alluvial soils of whatever nature, superphosphate may be employed with excellent effect together with long straw manure, and will both increase the weight of the 
crop as well as promote its early ripening. From these results it will be seen the application of the kind of manure should depend very much upon the nature of the soil; and on those where the tendency is for the haulm to continue green until either early frost or disease lays it low, manure should be used which will stimulate the growth of the root; but, on the other hand, on those dry, light soils where the tubers ripen prematurely (unless wanted to do so) manures that are calculated to strengthen the growth of the hauln are to be recommended.

Sulphate of ammonia, guano, and rape-cake are all capital manures for potatoes, with respect to ensuring a heavy crop ; but, unfortunately, these all appear to exercise a predisposing influence in subjecting it to the attacks of disease.

I have tried guano alone upon potatoes, but the roots were very small, but came early ; and this result will be doubtless experienced on all dry soils, though on rich deep ones the premature ripening would not be so marked, but the liability to disease increased.

Rape-calke has been successfully used in healthy seasons, and some heavy crops of potatoes have been grown from it; but in seasons when disease has been prevalent, the crop so treated has been the worst in the district, invariably acting slowly, but steadily, upon the growth of the potato all through the season, keeping the tops green till the end of October, unless cut off by the early frosts or disease.

Rape-cake mixed with guano has brought an earlier crop than where the former has been used alone, but it has turned out a lighter one; while sulphate of ammonia produces similar results to guano in stimulating 
the growth of the tops and early maturity, combined with a small crop. If, however, mixed with farm-yard manure, the bulk of the crop is considerably increased, as well as its liability to become diseased. In these instances a choice is offered, as it were, to growers, whether they will choose a small sound crop, or take the chance of having a large diseased one.

For my part, I have a capital use for diseased potatoes, and my method of disposing of them profitably I shall afterwards describe; but to many persons diseased potatoes are next door to worthless, as may be guessed, when I sometimes buy them at threepence per bushel, as I have just stated.

When a good deal of stock is kept upon a farm, and the great bulk of the manure is in a highly ammoniacal condition, the plan of manuring the land intended for potatoes in autumn, or winter, is to be recommended. Instances are recorded where cut potatoes have been placed upon fresh dung, when they became uniformly rotten, while those which had their sides covered with skin placed in direct contact with the manure turned out sound, and sent forth vigorous shoots. This fact would seem to point out the desirability of always using whole potatoes for seed when fresh farm-yard manure has to be employed.

I, however, am never troubled with those considerations myself, for, as I have stated before, I always leave my seed potatoes in the ground till I am ready to use them. Their condition can always be ascertained by digging up a root or two at any time.

Raising the Crop and Storing:--The cheapest mode of taking up potatoes upon a large scale is by means of the double mould-board plough; but the single is 
far preferable, for, put at the full depth, it turns the tubers over without cutting them, while the double plough is apt to bruise them a good deal.

The best way, however, is to dig them with a fork, both as lifting the crop more thoroughly, and at the same time getting the land into good order; but if the double mould-board is used in ploughing them up, it is spread to the extent of the drills, and is run through the centre of the space between them, returning through the next row but one, so as to give time to the pickers, and not throw the loose earth upon the unpicked drills, returning in the row between the two others.

In digging them up with a fork, the latter should have four stout flat prongs, about an inch broad by fifteen inches long, with an inch division betwixt each prong, so as to allow the soil to become separated from the roots while the ends of the prongs should be rounded, and not pointed, in order to avoid injuring the potatoes.

When dug up, they should be allowed to lie on the surface of the ground to get seasoned and thoroughly dry before being stored up. They must also be quite ripe, otherwise the risk of heating is very much increased.

When the haulm is cut down through disease or frost, about a fortnight should be allowed to elapse before digging, in order to permit the skins to become firm and set, and a good deal of trouble is saved if the potatoes are sorted at the time of lifting, by passing them through an inch and three-quarter riddle.

If a crop is only slightly diseased, the infected 
tubers may be easily picked, out during the process of riddling, and put aside; but if the whole crop should unfortunately turn out diseased, it is best to cart the whole produce to some dry place, and separate the good from the bad, sorting them into three lots, the sound large ones, the small potatoes, and the diseased tubers.

Unripe potatoes are more apt to become heated than fully matured ones, and when they are sorted, the sound tubers can be stored in the way I have previously referred to, the main object being to keep them dry and cool, and sufficiently protected from frost. Some growers have kept their potatoes very well in permanent pits sunk in the ground and lined with brickwork covered.with a thatch. When heaped up, the potatoes should remain uncovered for a time, except with the dead tops, straw, dried fem, or other litter, so as to allow the gases to escape. A tarpaulin cover should be used at night, and when raining, so as to guard against the risk of their getting wetted. These sunk pits are very useful for other purposes at times, when not being applied to the use for which they are specially designed.

Use of Diseased Potatoes.-Diseased potatoes make capital food for pigs when steamed, and mixed aftcrwards with a little bran, or pea or barley meal, according to the rate at which they require to be fed.

As soon as the potatoes are taken up, they should be steamed, and packed in sugar hogsheads, and pressed closely down, with some salt strewn amongst them. Or bricked pits, with air- and water-tight walls sunk four or five feet in the ground, into which the potatoes are well trodden down; will keep them 
well. After being rammed in hard between these walls, and brought up to a sharp conical roof, it is then covered over with earth, and well beaten with the back of the spade, jso as to thoroughly exclude air and wet.

Cooked and stored in this way, the potatoes will keep good for almost any length of time. It is true they will get sour, but the pigs will eat them readily, and will get fat upon them when mixed with a little meal. This method of storing, also, enables one to dispose of a large quantity, which, if not dealt with at once, would often become a great nuisance.

In some parts of the country diseased potatoes are sold to the owners of starch mills; but there are plenty of ways of profitably disposing of all kinds of produce upon a mixed farm where stock is kept.

Baking Diseased Potatoes.-The plan, however, which I have found to answer best in dealing with diseased potatoes is to bake them. With this object in view, I have built a small kiln at a trifling expense with a place for a fire below a plate of iron half-aninch or so thick. Upon this plate we spread the diseased potatoes, and bake them thoroughly. The moist diseased part is dried up by the operation of baking, and the pigs eat them as greedily as they would corn; and there is no expensive food required to be mixed with the potatoes when given in this way. Diseased potatoes, where kept in large quantities, often get very offensive, and gradually become a mass of corruption; and although I have not had occasion to deal with any of my own growing, I have used large quantities in this way, having a neighbour or two who do not "believe in" pigs, and could never make them 
answer; while I generally have about forty, which, as may be supposed, get through a very large amount of food, and I am always ready to take my neighbours' diseased potatoes. When rainy days occur, and they sort them over, I often have a cartload or two brought to me, and we quite understand how to turn them to profitable account; the last method I have indicated being, in my opinion, decidedly the best, as we receive them from time to time during the winter.

Of the profitable management of pigs, however, I have spoken before, and merely refer now in a cursory manner to the best methods of dealing with diseased potatoes, while speaking of potato cultivation.

Of the minor diseases of the potato, such as the curl, which is known from the leaves of the stem becoming shrivelled, and the tubers ultimately turning rotten; the disease of Martius, to which the name of $d r y$-rot has been given, and others, it is hardly necessary to speak, the minor diseases being all swallowed up, as it were, in the more formidable one with which we are all now familiar, called, par excellence, the potato disease, which every one deprecates. 


\section{CHAPTER VII.}

\section{HOP-GROWING.}

Preliminary-Soil and Situation-Varieties-Cultivation-Poling Hop-picking-Drying the Hops-Bagging-Raising Hops from Sced-Male Plants-Clearing up the Hop-gardens-The Hops' Enemies, \&c.

As I have previously mentioned, when I first commenced farming, I had not the least idea of the method of cultivating hops; and only had a sort of superstitious dread of having anything to do with them, being told that large sums of money were often lost, and that hop-growing was a species of gambling.

As the five acres of hops adjoined our small kitchen garden, I used to watch the process of cultivation followed during the time $I$ had not yet taken them into my own hands, together with the ten acres of arable land ; and chatting with the men at different times, our gossip enlivened with a few jugs of beer, as they were giving over work for the day, I soon got to know all that was needed to be known, and drew my own conclusions respecting the business.

A great deal of money was spent in manure, woollen rags, when they were to be obtained, being a very favourite application; but this kind of manure is now no longer obtainable; for, by improved processes and improved machinery in the manufacture 
of shoddy, the Yorkshire cloth-manufacturers now use up almost everything, and utilise all the rags, for which they can afford to pay a good price; leaving but a small residuum in the shape of a moist mass, resembling wet dust, that bears but an infinitesimal proportion to the bulk used.

The hop-land became in time desirable to me, both because I saw that I stood in a much more advantageous position with respect to its cultivation than my neighbours; and, also, abutting my grounds, I could see what an ornamental effect I could produce by adding the hop-field to my possessions, by striking out paths and walks through it, with grass alleys over which the hops might be trained, so as to make long ornamental bowers.

Our kitchen-garden, too, was ridiculously small, as is often the case with many country houses, and I resolved to give up the whole of this to my wife for a flower-garden; and make sufficient space for growing vegetables, and currants, and gooseberries, \&c., out of the borders of the hop-field, by taking up the outside row of hops, and running paths across the centre of the field, here and there, according to fancy.

This I eventually did, and I can safely say the most unalloyed happiness I ever experienced in my life was enjoyed by me in making the necessary improvements, and alterations I contemplated. I made a good broad path all round the field to begin with, in some parts having to cut through some stiff clay soil which adjoined a neighbouring plantation, and these precipitous banks I laid out tastefully with suitable shrubs and plants.

There were two principal circumstances in my 
favour which placed me in a better condition to cultivate the hops economically than the farmer who previously had taken to them. My plantation furnished me with plenty of hop-poles, having both Spanish chestnut coppice, as well as an ash plantation which grew at the bottom of my five acres of plantation, which sloped towards a watercourse, down which a good deal of surface-water used to run in rainy weather, so I had plenty of ash and chestnut poles, which my neighbours had to buy, but which were growing up in readiness for my use during the time I had hesitated upon taking to the hops.

Then, again, I had found out for myself how to make pigs pay, and as we kept a great many, we accumulated vast quantities of manure; so I foresaw I could manage without having occasion to buy any; and I believe I am the only person in our neighbourhood who has never purchased manure for his hops.

The hops in our district do not bring such heavy crops as some hop-gardens within a mile or two of us, the soil being somewhat light and sandy, being on the confines of Surrey and adjoining Hampshire; yet the hops are of the best quality, and rank as what are termed "Farnham country" hops, being actually the same in quality as those which are grown in Farnham.

Accordingly, upon taking possession, our kitchengarden was turned into a flower-garden, and a gap was cut in the hedge which divided it from the hopgarden, and a gate hung, so that we might walk out from one to another. Our kitchen-garden afterwards consisted of six or eight feet of the border, or outeredge of the hop-field, in which we have always grown 
an abundance of capital vegetables, which are easy to cultivate, and lie directly beneath our view, as it were, as we walk in the hop-garden.

Right down the centre of the hop-field I removed other rows of hops, and made a path, each side of which I planted espalier apple-trees, and currant and gooseberry bushes, all of which, on account of the capital condition of the ground, soon established themselves in the most satisfactory manner.

I also laid down a grass path or two, in appropriate situations, over which we trained the hops to grow on stout cords, making a most beautiful appearance and shady walks in the summer-time, which we used highly to appreciate. It was, in short, a great addition altogether, and added much to the appearance of our residence. By removing the rows of hopplants we somewhat diminished our crop of hops; but this I made amends for, eventually, by planting two acres of arable land, which stood in an enclosure by itself, surrounded by a broad straggling hedge which took up a great deal of room. In fact, on one side of the field, there were two great hedges; for a road had been formed there leading up to a cottage, in which my foreman lived; and this centre hedge I grubbed up, and grew a very large quantity of potatoes upon the site it occupied, but I will speak of the method of hop-planting hereafter.

My hops have paid me very well on the whole, but I do not consider they would have done so had I not been differently circumstanced to my neighbours. The land not being of very good quality, our yield is not heavy, not often being more than five hundredweight per acre, eight hundredweight being 
an unusually good crop for us, and one year I only got three hundredweight of hops off the whole five acres. I certainly received an exceptionally high price for this handful, viz., $£$ I 5 per hundredweight; but there was a heavy loss that year as a matter of course, about $£^{6}$ per hundredweight being, perhaps, an average rate; in abundant years not more than $£ 5$ being realised per hundredweight. The expense of cultivating an acre of hops, and making good wornout poles every year, is supposed to be, in round numbers, about $£ 20$ per annum; but as I grew my own poles and made abundance of manure, it never cost me, in money out of pocket, any more than the cultivation of the rest of my arable land stood in, and the bad year I have spoken of occasioned me to depart from the system that is invariably pursued by thorough hop-growers, of not raising anything else whilst hops are growing. For, ever afterwards, when from appearances there are signs that the hop-crop is likely to become a failure, I make a practice of planting something else between every other row of hops, and thus secure a good crop of something or other; but this is a very difficult conclusion to arrive at, inasmuch as some years, when almost a total failure has been predicted, by a fortunate change of weather the hops have taken a sudden turn, and have recovered themselves, and we have had a fair crop after all. With all its drawbacks it is, however, a most interesting crop to cultivate, and its risks are diminished by the course I have adopted, though it exposes me to the sneers of my neighbours. When, however, the crop has partly failed, and I have been recompensed by a heavy crop of mangolds or turnips, 
which I have got from every other row throughout my hop-garden, I have put up very complacently with my neighbours' jokes upon the point, whose professional feelings are averse to my plan.

Soil and Sitnation.-Hops were not brought into cultivation in England until about the year 1524, and according to a distich in "Baker's Chronicle"-

" Turkeys, Carps, Hops, Piccarel, and Beer, Came into England all in one year."

By beer, must be understood the liquor now commonly brewed from malt and hops; for ale brewed from malt was known at a much earlier period, but ground-ivy was used for preserving it.

Hops can only be successfully grown upon good land that is specially suited for the plant, which depends mainly upon the nature of its subsoil; the bulk of those produced in England being cultivated in the counties of Surrey, Kent, and Sussex, Hampshire, Worcestershire, and Herefordshire, though a few are grown in the counties of Nottingham, Essex, and Suffolk.

The peculiarities of each district are chiefly dependant upon its geological characteristics, and this circumstance rules the estimation in which they are held by hop merchants and factors, some brewers refusing to buy hops altogether upon their own judgment, depending upon that of their hop factor. Thus, in the vicinity of Canterbury, and throughout the greater part of East Kent, the plantations are upon a deep, loamy, rich surface, with a subsoil of loamy brickearth, the whole lying above a stratum of chalk, the hops being of a strong and bitter flavour, which causes them to be in request by porter brewers. 
The hops in the neighbourhood of Farnham are chiefly grown upon the out-crop of the upper greensand, and on a deep alluvial loam lying beneath-the London clay being said to end about this district ; and much of the soil consists of a mellow hazel mould, or of a deep siliceous loam, rather strong, dry, friable, and very deep, lying upon a calcareous, or marly subsoil. The hops produced on such land are of a bright, lively, pale colour, very fragrant and bitter, held in great estimation for brewing pale ale.

The grounds around Maidstone, extending through the district on the rag-stone rock, or "stone brash" which lies below the chalk hills on the borders of the weald of Kent, in some years yield great crops of hops; but of an inferior quality to those grown in East Kent; for though of larger size, and having a larger leaf, they contain less quantity of the farina or "condition," as it is provincially called, which constitutes the chief recommendation in hops. The best East Kent hops are grown, perhaps, in the neighbourhood of Canterbury ; the best Mid Kents, on either side of the river Medway, in the neighbourhood of Maidstone.

In the weald of Kent and Sussex, hops chiefly grow upon the Hastings sand of the wealden formation ; and in the Worcester district, upon the marls of the new red-sandstone. In the valleys of the weald of Kent and Sussex district, where the soil has been deeply drained, the best crops are grown ; and in the valleys of Eastern Sussex, some of the brook meadow-land which has been drained and converted into hopgardens is of a very fertile description, and at times brings crops of even thirty and forty cwt. per acre growing the largest average crops. 
Speaking generally, the soil best fitted for the site of a hop plantation is one consisting of a fresh, rich, dark loam, interspersed with friable sandstone, and lying upon an absorbent calcareous base. The duration of a hop-garden depends entirely upon the nature of the land, for although many rich soils will grow a crop of good hops, the land will not support it for any length of time if it is destitute of a calcareous subsoil. The strong lands in the weald of Kent often become unprofitable after ten or twelve years; while on the strong rich loams of the Maidstone district, and around Farnham, which rest on rock and calcareous rubble, hop-gardens have existed which have always grown hops as long as the people in the neighbourhood can remember them.

Varieties.-In my little hop-garden there are two varieties of hops, of the kind usually grown in our neighbourhood, which I suppose were originally chosen to suit the peculiarities of the soil, being mostly sandy, but in one part consists of a stiff clay. These are the "Farnham Whitebine," and the "Golding," the latter being somewhat stronger than the former, but not so finely flavoured.

In the ordinary way, these kinds require the longest poles, varying from fourteen to twenty feet in the most prolific gardens; but we seldom have occasion to use poles of a greater length than fifteen feet. The main roots of these strike very deeply into the ground.

The species called "Canterbury Grape," is chiefly grown on the rich soils of East Kent, the "Mayfield, and the "Whitebine" on the dry limestone land, and the "Golden Tips" on the weald of Kent and Sussex which are remarkable for their resistance to blight, but 
some of the hops produced in the latter district are coarse and inferior in quality.

The "Grapes," of which there are several sub-divisions, grow in clusters somewhat resembling grapes, hence their name, their bines being small, taking poles from ten to fourteen feet long. Another species, the "Jones's," are better adapted to light and inferior land, and poles of eight to ten feet long are generally sufficient for them, those which have broken off at the ends-the refuse poles-re-sharpened at the bottoms, being generally long enough for this variety. The kind termed "Colegates" is a hardy variety, suitable to stiff soils, which will clothe a tall pole, but is not much esteemed; for though producing heavy crops, it is more liable to be injured by mould than some others, and is late in ripening.

On the other hand, the "Flemish Redbine" is a coarse species, is much hardier than other sorts, which will grow on light siliceous soils, and often escapes the aplis, or black blight, that they have earned for themselves the sobriquet of "Never-blacks;" on this account they are much grown by those whose land lies under a bleak exposure; but they produce a poor thin hop, the only recommendation in their favour being their tendency to escape the aplits blight. There is also a species of hop that is much esteemed for the delicacy of its flavour, which is chiefly produced in the counties of Hereford and Worcester.

Cultivation.-In giving an account of the general cultivation of hops, perhaps it would be as well for me to commence at the beginning, and describe the first formation of a hop-garden. 
The ground should first be trenched soon after Michaelmas, which is the best course to get the land into proper order, or should be subsoil-ploughed. The latter is resorted to in order to save expense; but trenching the ground all over two spit deep with the spade causes the manure to be more regularly, and intimately mixed with the soil, which is also made loose and open, so as to allow it to be easily penetrated by the roots of the hops whilst they are young and tender; and they obtain a good hold of the ground by the time they arrive at maturity, it taking three years for them to arrive at perfection. On rich land, in favourable seasons, the bine sometimes produces a small quantity of flowers during the first year, and occasionally a moderate crop in the second.

When the ground has been got into order, the hops are planted in squares, or triangles, at equal distances, from five feet to seven feet apart. In the neighbourhood of Farnham, six feet is the most common distance employed. To fix correctly the position of the hills, a common land measuring chain is used, in the links of which, bits of rag are fixed, to mark where the sets are to be planted, which are indicated by pieces of short stick. In very luxuriant grounds the distance is increased yet more, in rare cases as great a space as nine feet having been allowed.

The plants are procured by cutting off the layers, or shoots of the preceding year, which are bedded out in March, in well manured and trenched ground, and the following Michaelmas they become what are termed nursery-plants, or bedded sets.

The cuttings are sometimes planted out the same year, which is done mostly to save the expense of the 
sets; but it is not a good plan to follow, and is often proved to be false economy, as in a dry spring there is often great risk in their dying off. "Naked sets" are cut from the crown of the root when the hop hills are opened, which operation will afterwards be described; but they are less quick at arriving at a proper condition for planting than nurslings, and are a year later in arriving at maturity and becoming productive.

When the positions of the hills have been marked out, the earth is dug out to the depth of a couple of feet, and the same width, and a compost of well rotted dung and earth or fine mould filled in. One, two, or three plants are then inserted, the latter being the most common number; but when cuttings are used, it is safest to plant five to each hill, dibbled round one as a centre, leaving sufficient earth between each. The holes made by the dibble should be in a slanting direction outward, so that the roots may grow in the inclined position in which the poles are afterwards placed, in order to prevent the bines from intermingling. The plants should be raised above the level of the ground, so that the hop may rise high enough to form a hillock, and the roots have a greater depth of earth below them.

During the first year, the ground must be kept perfectly clean, and free from weeds, and the soil be well stirred, so as to supply the young plants with fresh pulverised earth to feed on (and digging with a fork is a good plan with this end in view), the finest earth being placed by hand round the hills. The more frequently this is done, the stronger the young plants become. 
As soon as the young shoots make their appearance above the hills, slender poles, or stout sticks are used, in accordance with the length it is expected the young bines will run, and when they have attained the height of a couple of feet or so, women are employed to tie, or twist the hop-plants separately around them. In a good season, and upon strong plants, a few hops will grow, but they are never gathered, and they seldom bear till the second year. Early in November the ground is dug all over, and carefully turned towards the plants, where it is afterwards left in a rough condition to stand all the winter exposed to the beneficial influences of the frost.

In the second year, during dry and fine weather, either in February or the beginning of March, according as the season serves, the hills are opened, so as to allow the lower part of the last year's shoots to be got at, which now require pruning.

This operation is performed in our neighbourhood by an implement called a "beck" (the operation requiring the exercise of some care), which is a double tool, on one side having a strong! hoe, and on the other a fork or "spane" with a couple of stout prongs, which are flat and broad, so that when the spanes will not penetrate into the ground, the beck is turned, and the hoe used.

This "beck" is a very handy implement, and gentlemen who have visited me upon occasions, who take an interest in husbandry operations, coming from different parts of the country, have quite fallen in love with it, and have caused me to procure them a few for the use of their own men. No doubt it was the 
original invention of some local grower, who saw the desirability of some such implement.

When the hop-hills are opened, the vine is cut off with a sharp pruning-knife to within an inch or two of the main stem, together with all the suckers quite close to it. The soil is then replaced just enough to cover the mounds, so as to prevent the air from affecting the plants just as they are about to spindle, but is left rather bare around them. During the whole of the second summer, the land is well stirred, and kept quite clean either by the use of the hand-hoe, horse-hoeing, or the spade or fork.

In the spring of the third year the hills are again opened, the earth of which, taken away in the first spring, has been replaced in the succeeding autumn, and the young suckers are again pruned as before. Good farm-yard manure at the rate of twenty to twenty-five loads per acre is. applied; or double that quantity, if made into compost with mould, having been brought on to the land previously during frosty weather, and the hills are dressed in the month of March. It is afterwards regularly spread upon the ground, and dug in with a fork, which both mixes the manure more intimately with the soil than a spade, and there is less danger in its use of cutting the roots of the hop-plant. In every succeeding year the hills are opened in the same manner, and the crown of the plants pruned.

Any poles which want renewing, as well as the manure, should be taken on the land during frosty weather, to prevent the trampling down of the soil, one main object in hop-growing being to keep it as open, and light as possible. 
Poling.-After the hops have been duly pruned in April, the poles should be set up. And here the exercise of a good deal of sound judgment is required, for if a hop-garden is over poled, that is, supplied with longer poles than are necessary, the crop will be much diminished. Of course, in an established hop-plantation, the height of the poles is generally well understood that may be required, while under-poling is equally to be avoided. If the poles are of too great a length, the roots become impoverished, and thereby sustain an injury that cannot very well be remedied; but in the case of under-poling, an auxiliary pole can be provided. It is better to pole rather sparingly in a new hop-ground than run to the other extreme, for if too long poles are used, the fact is soon manifested by the weakness of the bine ; and it is better to have fewer poles in number, than too many.

Three poles are usually set up to each hill in our part of the country, there being about $I, 200$ hills to the acre. In round numbers, we reckon about 3,000 poles are required per acre, ours not being very long poles. When very long poles are used, it is sometimes customary to use two to each hill, when they are sixteen feet poles, and three to every third hill. About June the plants should be inspected, and any changes that may be called for made, an extra pole being put to the strongest hills, taking off a vine from each of the other poles to furnish them with. In established hop-gardens, the weak hills are marked with a stick at cutting time, so that they may be poled accordingly.

The poles are put into the ground by means of an iron bar called a "hop-pitcher," or hop-bar, somewhat 
like, only larger than, the implement used for making holes for the stakes which support hurdles in sheepfolds. The poles are pitched into the holes with the full force of the man's strength after the end has been sharpened and dipped into tar, or some other preparation for preserving it from rotting in the ground. It is necessary the pole stands firmly, for when clothed with bine and hops, it offers a full mark for the wind, which often commits great havoc in a hop-garden. The poles should be put up at equal distances from each other around the hill, about a foot from it, the tops inclining outwards, as when leaning in that direction, they give more room, air, and sunshine to the bine, which causes it to yield more hops than when they are made to stand upright. The usual number of vines trained to each pole is three, selected according to their present appearance and probable future luxuriance; but the very strong and rank ones are rejected if there is an appearance of there being sufficient without them.

The bines shoot from the plant about the beginning of May, being ten days or so earlier in new grounds than in old ones; and as soon as they will reach the poles, they must be tied up, as they become injured by lying on the ground and getting twisted together ; at the same time, they must be sufficiently long to be attached to the pole without straining them too "taut" or slanting them too much from the root. The hop follows the course of the sun in its winding round the pole, and this inclination must be observed, and the bine not twisted in the contrary direction.

The bines are tied to the poles by women, with either rushes or old matting, and they go regularly 
over the ground from time to time, till every pole gets its due quantity of bines, one woman being able to superintend about two acres and a half, the heads of those bines which have been tied sometimes being blown away by the wind. In very rich grounds, only two bines are trained to a pole occasionally, and these will come to maturity earlier than the others, but there is a risk attending the practice which can only be followed in exceptional cases. More than three bines must never be suffered to remain.

The surplus bines are allowed to remain by most growers until midsummer, with the object of keeping the ground moist, while others cause them to be pulled out by the tyers, leaving one here and there in case of accident.

I must not omit to say that immediately after the poling in dry weather, the ground should be pared over with the hoe, as during a mild winter, a good deal of chickweed, groundsel, \&c., will be found, the hoeing to be followed by a second digging, or running the horse-nidgel through it, which is a kind of narrow scarifier, or cultivator, having handles like a plough, which is made for the purpose of breaking up the ground between the rows of hops, a boy leading the horse, or horses, while the man holds the handles. Some use the "beck" for this purpose, but I always have mine dug with the fork.

During the first three weeks in June, the hills should be carefully inspected, and where the vines look weakly, and do not seem as if they would run up the poles, they should be taken down, and shorter ones put in their place. The large poles thus taken away should be put up against the strong hills, which 
give signs of extra luxuriance, and supplied with two bines each, one being taken from each of the two nearest poles, and crossed over to the extra one. The hills are earthed up about a foot and a half high, for the double purpose of keeping the crown of the hill in a growing condition, as well as of keeping down the young shoots, which would otherwise sprout from the hill, and take away from the strength of the plant; which needs to be concentrated in the bines growing round the poles.

The surplus bines that are cut off, are collected and made into fodder; and if ricked in good order, they are quite equal to the best clover hay in quality. The plantation can now be seen how it is progressing, when the hilling, or earthing up is completed; and all the weak plants should receive an extra dose of manure, or mending, as it is sometimes termed. As there will be a difficulty in getting bulky manures upon the land, this is best done by portable artificials, as guano, muriate, or sulphate of ammonia, or nitrate of potash, mixed with equal quantities of superphosphate of lime; or ground rape-cake. The effects of this application will be visible, in a few days, in imparting vigour to the bine.

After the hilling is done, the earth should be kept pulverised, either by digging, or the nidgel, this time only drawn by one horse, if two have been employed before; and the ground should be continually well stirred, especially in dry weather. The beck I find sufficient for my purpose, as my transactions are but upon a small scale; and after the ground has been stirred in a dry season, we find the plants put on the same appearance (except in the washing of their leaves), 
and have the fresh look they wear after a shower of rain. On the other hand, in a wet season, the hoe must be briskly plied to keep down the weeds, which will be indefatigable in springing up; one of the main principles in hop-growing being, to keep the land thoroughly clean.

In our neighbourhood, and I believe in most others, it is customary to shave the poles-take off their bark before using them-the practice, doubtless, owing its origin to the avoidance of a ragged skin, or bark, at times; when its covering peels off, and the poles are said to last longer, when the bark is stripped off; but, it has been exceptionally said, its removal deprives the pole of a certain degree of softness and warmth, which has been considered usefuil to the growth of the plant; in the case of maplepoles, it having been observed that when the mornings were cold, the sensitive leader of a tender, fresh-poled bine reclined its head lovingly against the velvet bark of the maple, while others held theirs aloof from the more chilly, smooth-barked poles.

Women generally shave the poles, which are rested upon a couple of crutches of convenient height, fixed in the ground; the knife being rapidly drawn along the poles; for which $1 s$. per hundred is commonly paid; the ends being afterwards sharpened by men, ready for insertion in the ground, who are paid rod. or $\mathrm{I} s$. per hundred. When the lower portions are not dipped into some solution, in order to preserve them, they are sometimes imperfectly charred by holding them over the smoke of a strong fire.

In those instances where, as I have before related, I have trained hops across a green path from the 
tops of the poles; we usually get an extra heavy crop, the hops hanging from the bines overhead in the most beautiful manner, which gives rise to the supposition that, hops so cultivated, would be unusually productive; as in the overhanging, which, in the common manner, spoils each other by being crowded together, they are by this means separated, and held firmly by the cords passing across at the top. The extra yield doubtless pays more than the cost of the labour in tying the cords, and every portion of the bine; and hop-bunches receive their due share of air, sunshine, and moisture; whether from dews or fertilising showers. I adopted the plan merely with a view of forming a beautiful natural arbour; but the experiment convinces me that it would be a profitable method of growing hops, if made a regular matter of business in carrying out this arrangement throughout an entire hop-plantation.

Hop-poles are made of larch and spruce fir, of which there are a good many plantations in some of the sandy districts of Surrey; ash, chesnut, maple, and the more substantial willows. Some of the best kind are said to last twenty years; beginning as tall poles and ending as short ones, for they generally break at the bottom.

Hop-picking.-The time when the hops become ripe depends very much upon the season, and there is great emulation amongst hop-growers to get the first hops to market, which generally realise a fancy price. Sometimes these may be gathered at the end of August, but the most usual time is the beginning, and middle of September.

Careful growers sometimes pick off those which 
are ripe first, and that come early; which is ascertained when the seed begins to change from a pale straw-colour, to a light brown, and to emit a fragrant smell, feel firm, and be easily rubbed to pieces. No time should be lost when they are fully ripe, and the hop may be considered so when it becomes hard, and crisp to the touch, and the kernel, or seed, feels hard like a nut.

Colour is a great point with the finer kind of hops ; and although where it has attained a light brown shade, no real injury to its quality will have ensued, its marketable value will not be so great as when of a pale primrose colour.

Strong rough frames are made, called "bins," or "cribs," about nine feet long, and four wide; standing upon legs about three feet high, so as to afford room for pickers to stand on each side; and over the frame a coarse hessian cloth is fastened to the inside of the frame, so as to form a deep bag, into which the hops are stripped off the poles.

A family, perhaps consisting of a woman and her children, or a party of friends, will make up what is called a "set," together with the man who collects the poles, and the pole-picker, or bin-man, as he is called, has to hold up the bag for the man who measures the hops that are placed in it; which are paid for, so much a bushel; the price depending upon whether the season is a plentiful one or not, being commonly at the rate of $\mathrm{I} s$. the basket of five bushels; but the price varies according to the quantity grown, and the owners of the hop-gardens, in a certain district, generally agree amongst themselves what the rate is to be for the season. 
The bin-man with his pickers, in Kent, is placed to a certain number of hills, and remains with them until they are all picked, one hundred hills generally forming a set (which afterwards forms a stack of poles), which, when finished with, they all proceed to another set, this sort of arrangement preventing confusion, and systematising the work.

The account of the number of bushels picked by each set is kept by means of the contrivance called a double-tally, which is a simple device formed of two pieces of wood, neatly planed, and accurately fitted together by means of a shoulder on the principal part, or tally, which is three inches longer than the secondary part, or check, the two when joined together making the double-tally, generally a foot long by an inch and a half square. One of these is given to each set, who receives the check part, the tally being kept by the foreman, who, as the baskets are delivered, cuts a notch at the same time upon both, by joining them together.

It is a matter of pride with my men to exclude all strangers from being admitted as pickers of our hops, and they collect their families and friends together, and do the job between them without hurry, and my hops are generally picked carefully, without leaves, which strangers are sometimes apt to pluck with the hops.

When the pickers are ready to commence work, the bine is cut from two, to three feet from the ground; for if separated lower, it is likely to injure the root by the profuse bleeding which it occasions; and the pole is then forcibly lifted from the earth by an implement specially made for the purpose, called a "hop-dog," 
which consists of a strong tapering stick, about three inches in diameter, and five feet long; at the distance of nearly a foot from the larger end a small bar of iron, about a foot long, is clenched, and being bent in the middle into an acute angle, the inside having been made rough, like teeth, by the blacksmith; when fastened upon the lower end of the pole, hold it fast, and it is then prized up.

The poles are then laid horizontally across the frames, so that the bunches of hops are readily got at, and if there can be any choice exercised in reference to the weather, that which is neither very sultry nor very moist is to be preferred; for if the sun is hot and scorching, it is apt to shrivel and discolour the hops before they can be got off the poles; and if they are gathered in a moist condition, or too early in the morning, when the dew is on them, they become musty ; and a good deal of attention is required upon these little points, which, apparently trivial, yet exercise a considerable influence upon the successful ingathering of the crop in first-rate condition.

To prevent injury from the sun, the pole-pullers take down no more than the pickers can gather the hops off in a short time; and should, from press of time, it become obligatory to begin picking before the dew is off the hops, the pole is shaken to and fro, in order to throw off as much moisture as possible.

When carefully picked by one's own hands, it is usual to begin at the bottom of the pole, and pick the hops without bunches, long tails, or leaves; sorting those that are of a proper degree of ripeness by themselves, those which are full and fair being kept in a bin separate; those somewhat inferior and of second 
quality in another basket; three different parcels being sometimes thus made. With Farnham hops, however, unripe hops are better than over-ripe ones, and the worst sample is supposed to consist of those which are defective in their form, or have received a check in some stage of their growth.

As they should be dried as soon as possible after they have been picked, and they are apt to heat, and spoil, if kept too long in the baskets in which they have been brought from the grounds, they are taken at once to the kiln, or oast-house, where the drying process is continued night and day, till the entire crop is bagged up ready for market.

Drying Hops.-The operation of drying the hops is a very delicate one, and requires great nicety of treatment. In our part of the world we aim at turning them out a bright primrose colour, though country brewers, who look for strength in their hops, and porter brewers, are not so particular about the colour. We always use brimstone with ours, but I am told that some of the Farnham growers object to its use for their best hops. It is generally admitted to confer a double benefit-in the first place by its bleaching properties, diminishing the brown colour of the petals when the hops are fully ripe, (when gathered somewhat unripe the occasion for its use is removed on this ground), and the sulphurous acid, having a great affinity for water, dries up the vapour of the hop, and so materially hastens on the operation. Its use requires judgment, and should only be applied in small quantities at a time. But in every hop-growing district there is generally some old man or other, of great experience, who has earned for himself a name 
as the possessor of peculiar skill, and aptitude, for this business, to whom the matter may be safely entrusted.

As the kiln fires are kept burning all night, my people often make a little merry-making over this job, and an accordion is brought out, and some songs are sung, which I do not object to, so that the mirth is kept within proper bounds, and does not get "too fast and furious ;" for it is rather a tiresome job for the poor fellow who has to see to the drying, and that it is done gently, without hurry.

The kilns, or oast-houses, differ very much in their form and construction, but the principle is very similar to that of a hop-kiln. The hops are laid in parcels of twenty-five to thirty bushels upon a horse-hair cloth, spread about five or six inches thick, the kiln having been previously heated, the temperature being regulated to one uniform moderate standard, in order that the hops do not dry too fast, at which they are kept until the upper portion appears to have felt the fire, when, the lower part being considered dry, the heap is turned. Before that is done, however, the heat should be somewhat lowcred, and restored when the turning has taken place.

The thickness of the heap must depend upon the state of the hops; for should they be in a somewhat moist condition, they should be spread upon the kiln very thin, otherwise the steam arising from them will make them cake; and when hops are thus seen coming out of a pocket, an experienced judge can tell there has been a fault in the method of drying. The chief object with the experienced hop-drier is to get rid of the vapour, or reek, from the green hops as quickly as possible ; and this is best done by currents 
of heated air passing rapidly through the hops; so the space above the hops is kept hot, and the lower parts of the kiln cold, which forces the rarefied air above, in combination with the vapour of the hops, through the apertures or cowls upon the top of the hop-kiln, or oast-house. Many improvements have been made in these drying-houses of late years, but one has mostly to put up with the premises and buildings attached to the'farm, unless he grows hops upon a sufficiently large scale to make it worth while having buildings and appliances specially constructed for him. The hops have to be removed from the horse-hair cloth immediately the moisture has been sufficiently expelled from them, and upon this judgment and general knowledge of the man who attends to the drying, a good deal hinges, generally taking about ten or twelve hours in the drying process. The fuel used is generally coke, or charcoal, as being the least likely to communicate a disagreeable smell, which might injure the aroma of the flower.

I make my own charcoal, having plenty of wood to burn, and this operation is one full of interest to us, the charcoal-burners (my own men) rigging up a rough hut in the plantation to watch the fires at night, which are banked over, forming a weird and picturesque scene, which gives change and variety to my ordinary business life in London.

The hops, when dry, are shovelled off with a broad flat shovel to an adjoining store-room, called the "stowage-room," in which they are bagged up, but this does not take place until a few days after they have been dried, as when they first leave the kiln they are extremely brittle, and would breals if imme- 
diately handled, and the "sample" would become deteriorated.

They are therefore left on the floor in heaps, in order that they may acquire that degree of toughness, and tenacity, which a moderate degree of sweating will confer upon them; and when this is effected they are put up into either bags or pockets. The first picking being the best sample and the brightest colour, are generally put into pockets, the weight of which average a hundredweight and a quarter, or a hundredweight and a half; and the late pickings, of inferior colour, are packed in bags about seven and a half feet in length, and eight in circumference, which usually weigh two and a half hundredweight.

These bags are generally supplied by some local draper, who makes it a special part of his business to supply them, upon which are stamped some distinguishing mark or sign. The Kent bags are distinguished by the rampant horse, while in our district a bell is the insignia used.

Bagging. - The bagging is usually performed through a circular hole which is made in one corner of the floor of the stowage-room. A hoop rather larger than the circumference of the hole is made use of to stretch out the bag by means of hooks on the outer side of it, the hoop either resting on the floor above the hole, or on a frame of wood over it, made for the purpose, so that the bag is suspended firmly in the air beneath the floor of the room, and nearly touching the ground, perhaps, on the floor beneath. A few hops are tied tightly in the lower corners of the bag, in order that, when full, the bag may be caught hold of and lifted easily, else, as will 
afterwards be seen, a bag of hops would be a rather awkward parcel to handle.

When the bag is thus stretched out and let down the opening, the "feeder" throws in a few shovelsful of hops, and the "bagster" jumps into the bag with leather socks or slippers on his feet, made for the purpose, with broad, flat soles, and treads them carefully and regularly down, especially towards the sides, so as to pack them in the bag as evenly and tightly as possible; more hops are then thrown down and pressed as before, and this is continued until the bag is filled; the tighter and closer the better, for the closer they are packed the longer will the hops keep. The necessity for employing a very strong material for making the bag with will be seen from the strain that is put upon it. The hoop is then loosened, and the bag let down to the lower floor; more hops are tied into the upper corners, and it is sewed up with a packing-needle and string as closely as possible, the whole job generally taking about an hour to perform.

Raising Hops from Seed.-After the lapse of years, in old grounds hop-plants at times die off, run out, become small and of a bad colour, and in such cases it is worth while trying the experiment of raising some plants from seed.

In selecting plants from which the seed is taken, care must be used to procure them from a situation in which male plants have been grown, the stigma, or burr of the female plant, needing to be inoculated by the flower, or pollen from the male, without which, the seed will not possess its proper vitality. It is this impregnation which gives great weight to the hop, imparting the aromatic bitter to the production of the 
vine, and more particularly so to the seed, the petal, or leaf of the flower, containing but little of the astringent quality of the hop.

Those plants raised from seed, excel those grown from cuttings, both in luxuriant growth, and in their power to withstand the effects of blight. They are found to have a seed at the bottom of every petal of the flower, of a most pungent, and aromatic flavour, and these seeds not only add greatly to the weight of the produce, but constitute its real vitality, condition, or strength of the hop, where there is the most seed, there being also the most condition, as it is technically termed.

They should be sown early in the spring, in a mixed soil of chalk, clay, and sand, the latter predominating, and be set out in rows towards the end of autumn, where they should be allowed to remain until their sexual distinction can be ascertained, which will be discovered by noticing the leaf and forwardness of the plant. The next year the males will exhibit a rough leaf when the females are only just breaking out of the ground. When the distinction of sexes is made apparent, at the latter end of the second year they may be planted in the ground where they are intended to remain, and may be poled the third year. In congenial soil, and a propitious season, they will bear hops the third year. Those who advocate the raising of hops from seed, and duly appreciate the advantage of the presence of the male plant, consider that one male should stand with fifty females; but this is a much higher proportion than is generally assigned, one hill in two hundred, or six to an acre, being commonly considered sufficient. As this is a 
point that is frequently overlooked, the subject is worthy of a special paragraph.

Male Plants.-The "buck," or "cock hop," is often unmercifully rooted up out of many hop-gardens as an useless cumberer of the ground. A common practice, that may be traced to the times when the sexual distinctions of plants were an unknown subject.

The grand object in hop-growing ought to be to get as much seed as possible, for the reasons already stated, and for the extra weight obtained. Indeed, the fructification of the plant cannot be complete without the impregnation of the male bloom; but some old-fashioned growers turn a deaf ear to all that is said about the male plants, and care nothing for them, and make some such answer to the representations that are made to them on this score, that their forefathers got on very well without male hops, and it was always their practice to root them up; and as they made money by their system, they don't see any reason why they should change it, and so on.

But it is a most important point that there should be plenty of male plants in a hop-garden, as those which possess a good quantity are always the most prolific, and reach maturity earlier, as well as the hops being of a better quality. My man always regarded the buck hops as idle cumberers of the ground, and used mercilessly to root them out; and at first I knew no better, until I met with an account of a plantation which was arranged in the espalier fashion, trained horizontally on poles five feet high and three apart, with a long pole fixed on top across them, to keep them steady, with the male plants growing upon upright poles of the full height, so that their farina, or 
pollen, might fall uninterruptedly upon the females beneath. This method has also been recommended, if I remember rightly, by Arthur Young.

Mr. Lance, of Lewisham, wrote a tract called the "Golden Farmer," published in I83I, in which it is related that a specimen of the hops grown at Lewisham, cxhibited at the Malling Agricultural Meeting, where great attention had been paid to this point, were allowed by all judges to be the best sample in the booth. The weight of hop-seeds without the leaves having been accurately ascertained, those grown at Lewisham, being the fourth year from the sowing of the seed, grown with a male plant close to them, weighed at the rate of thirty-six pounds per bushel, and the same quantity (by old measure) from Mr. Love's ground at Shoreham, raised from cuttings, and grown near male plants, weighed at the rate of thirty-five pounds per bushel. The hop leaves, without seed, from Mr. Jordan's grounds at Oxford, where the male plants are always eradicated, weighed at the rate of twenty-two pounds per bushel when closely pressed.

Hop-seeds being severally put into rain-water, most of those produced by plants raised from seeds, and grown near male plants, sunk in the water, while the majority of those grown in grounds that had not any male plant near them, and which had been raised from cuttings, swam on its surface.

Upon reading these and similar accounts, as there is a hedge all round my hop garden, I made a point ever after, of encouraging male plants to grow in it at all points of the compass, so that whichever way the wind might happen to blow, the pollen of the males 
may be wafted to the females, which bear the hops, and become duly impregnated. I am convinced, that to this plan I am indebted for the full price I can always obtain for my hops through the factor in the Borough, who sells for me. A good many of my neighbours sell their hops at Weyhill Fair, and take a good deal of trouble sometimes with them before they get sold, being anxious to obtain as much as possible; but I never have the least trouble with mine, and they are always sold for me at the top price that is realised for "Farnham Country" hops, and my cheque is sent to me without any deductions or complaints of any kind, excépt one, and that is, that I only grow so mall a quantity.

Clearing up the Hop-Garden.-In October, the bines should be stripped from off the poles as quickly as possible, and carefully put together, when, at all events, it will serve as an excellent substitute for straw. Young stock will pick it over, and eat a good deal, and I resort to all sorts of economical contrivances in feeding my young stock, and take advantage of every occasion in this way which presents itself. The haulm or bine should be stacked in ricks, and cut out when wanted, like hay. There is a large amount of mineral, and organic properties in the bine, which is the means of forming most excellent manure; it being one of the best for potatoes, which like to feed upon vegetable substances. When applied for this purpose, it is spread over the surface of the land, where it is allowed to lie during the winter, when, during the course of it, the leaves drop off, which are afterwards dug or trenched in, the stalks which remain being otherwise disposed of. It is also a capital manure 
foroats, and should never beburned, or wasted, the same as I have seen hop-growers carelessly do at times. The poles, in some parts of the country, when stripped, are stacked throughout the hop-plantations, each stack containing about four hundred or five hundred poles. Three narrow mounds of earth are raised, upon which the poles are rested, the tops of the poles meeting each other, and being brought into the middle of the stack, leaving the butt-ends outwards at each end of it, which is thus formed into a square compact form. Upon the mounds of earth are laid a few old pieces, in the first place, to keep the poles from contact with the damp earth, the mounds of earth which support the pile being about a foot and a half high.

The most ustal method of dealing with the poles in our part of the country, is to set them up vertically upon their butt-ends, in four parcels of a hundred poles each, inclining inwards towards the top, in the form of a cone, the tops meeting together and forming its apex. This is considered the better method of the two, as it allows the poles to dry thoronghly in less time than the other. It gives also a more picturesque appearance to the grounds, resembling somewhat the tents, or encampment of an army.

Throughout the winter months, when there are no pressing jobs on hand, the poles should be looked over and sorted. Many will be found to be fractured at the butt-ends, and these should be chopped off, and the poles re-pointed, which will answer for those hops that only require a short pole, taking them away from the others, which should be hiled up afresh, as it is called, the parcels containing only those which are fit for the ground upon which they stand. 
If any surface-water is noticed standing upon the ground, the drainage should be looked to, for which there is every facility, as the hops stand in straight rows. Drains in hop-gardens ought not to be less than five feet deep, and they should be laid thickly, for even surface-water from adjoining lanes and roads, in the spring of the year, when the plant is in its tenderest state, often causes a good deal of damage, and perhaps make the roots to rot, in which case the bines then canker off.

When the earth is bound with frost, in the months of January and February, the occasion should be taken advantage of to carry what new poles may be wanted on the ground, and to cart manure on it. Digging with a fork may be done whenever the weather is open and dry. This is usually done with a three-spaned fork, or spud, as it is sometimes calleda handy tool, the spanes being about a foot longwhich will enable the ground to be dug thoroughly, eight or nine inches perpendicularly. A pound an acre is the price paid for this work with us: and the land being light, any extra hands whom we may take on at piece-work are quite satisfied with their rate of earnings; although we take care to see that it is thoroughly well done, for it is the foundation of all the subsequent labour during the season.

The Hop's Enemies.-Hops are subject to the attacks of numerous enemies, several of which are very persistent, and destructive, the safety of the crop being often threatened in one form or another by them. Both the yellow, and black wire-worm will, in the first place, turn their attention to its root, being found most abundantly in those new grounds which have been 
formed on the site of meadow, or pasture-land. A1though a troublesome method, the most effectual one is to remove the earth round the plant, and pick them out by hand, and this should be done every week till they are destroyed.

A slice of potato placed by the side of the hill has been found efficacious in attracting them; and a plan for destroying them is mentioned by Mr. Charnock, in the Fournal of the Royal Agricultural Society, who recommends five cwt. per acre of rape-cake, crushed into lumps about the size of half-inch bones, ploughed or harrowed in. The wire-worms congregate on these lumps of cake, which they devour with avidity, and become glutted, and perish either from repletion, or the peculiar qualities of the cake, or perhaps a conjunction of both causes. Throughout a farm whereon the wire-worm prevailed, by adopting this remedy, the land became perfectly freed, without any further recurrence of the evil. A solution of guano, or sulphate of ammonia, mixed with soot, will get rid of them; but it must be applied carefully, and not in too large quantities.

In March, a little skipping beetle, called "the flea," often commits the most serious ravages-so much so, that a diminution of half the crop has followed its visitation. They eat up the young shoots as fast as they make their appearance above ground, and sometimes, to all appearance, will entirely arrest the progress of vegetation for more than a month. Sometimes, when the bine has grown eight or nine inches long, they will devour the head, and every leaf off the bine, causing it to present a shrivelled appearance, as if scorched by fire. This fly is named Altica concinna, 
and is distinct from another, which is, par excellence, the "fly" of the hop-garden, Aphis lummuli, or plant louse, the young of which are termed "nits."

These are long-winged flies, which make their first appearance about the middle of May, the first arrivals being followed by fresh battalions, at intervals throughout the whole summer. No effectual remedy has been discovered for the extirpation of these two pests, though fumigation and other expedients have been resorted to with varying success ; but fortunately they themselves are assailed by numerous enemies, foremost amongst which is the lady-bird, with other beneficial insects. There seems to be a singular change in the economy of these insects, which are said to be viviparous in the spring, and in the autumn become oviparous. Thus, as soon as the aphides make their appearance upon the hops, they begin to suck the under side of the leaves, and immediately deposit their young, which is the aphis louse. The lice, too, are viviparous, and they are said to have the faculty of propagating their species a few hours after birth; and in this way generations are produced without the intervention of the fully formed aphis fly, so that millions of lice are both born and die, without either parents, or issue, ever attaining the development of the perfect insect.

This multiplication of insect life is so rapid that, the hop-leaves become entirely covered by them, and living upon and abstracting the juices of the bine, the leaf assumes a sickly brown hue, curls up, ceases to grow, and ultimately falls from the pole, the lice remaining till they die from want of food, when usually severe blights prevail, and the crop is destroyed, 
unless a favourable change takes place in the weather.

As these vermin are, however, very susceptible to atmospheric changes, especially those of an electrical nature, as if by magic, when a favourable turn in the weather takes place, they will perish by myriads in a night, and the bines throwing out their lateral branches, when there is time for them to do so, a recovery will often take place, so that the case is never regarded as hopeless, while there is a chance of this occurring, there being many instances of extraordinary recoveries. when a stench had begun to arise from the plantations, which sufficiently indicated the severity of the depredations which had been committed.

The useful labours of the lady-birds, or coccinella, are readily recognised, for the aphis fly is their natural prey, and during their first incursions they destroy great numbers, and when the aphides are not too numerous, they will soon clear the plantations of them; but generally the flies have time to deposit some of their young on the under side of the leaves before the lady-birds can clear them off, especially in dull and cloudy weather, when they are sluggish.

But these also deposit their eggs on the under side of the leaves, which are yellow in colour, and usually in clusters of about twenty in number. These eggs of the lady-birds are soon hatched, and out of them proceeds the "serpent" or "black nigger," which are sometimes erroneously supposed to belong to the tribe of depredators. They are not so, however; for as soon as they are hatched, they commence to destroy the lice, which are their peculiar food. Viewed under a microscope, they are ferocious-looking monsters, 
somewhat resembling the form of a lizard, and when the lice are not too numerous, they also, at times, clear the plants of the vermin ; but if the latter are too many for them, they gorge themselves with their prey, and then, attaching themselves to the leaves of the hop, after remaining dormant for a few days in their larva condition, they throw off their outer skin and change into the perfectly developed lady-bird, and still continue to wage war upon the enemies of the hop.

When a favourable change is about to take place, the small leaves and tops of the bines may be seen densely covered with lice. The collecting together of these enormous multitudes appear to threaten the very existence of the plant; but a favourable turn has been taken in the tide of events, and the large leaves at the bottom of the bine, and the leaves next the stem, are becoming clean; the "serpents" meanwhile capturing all the stragglers that are left, and pressing upwards in chase of the remainder, till at length most of the lice drop from the tops of the bine, and there is an end of them.

The growth of the vine should be stimulated with manure during these crises, when it may be seen to resume its erect position and recommence its upward growth-guano, perhaps, being one of the best, applied at the rate of four, to eight hundredweights per acre, according to circumstances, and the ground should be continually stirred. By taking these precautions, a large crop of hops has been sometimes grown after a very severe early blight, the chief danger with late ones being not sufficient time, owing to the advanced season, for the plant to throw out fructifying branches. When the aphis blight comes late in the year, during 
the months of August and September, although it has no effect in diminishing the growth of the bine, it yet exerts a very deleterious influence upon the hops, by crawling into the hop itself, and leaving excrementitious particles, gives the hop a dirty appearance, and compels the grower to gather his crop before it is ripe, in order to escape further injury.

Another enemy to the hop is the "hop-frog-fly," Amblycephalus intermptus, which is similar to, if not identical with, that enveloped in a frothy substance, called "cuckoo spittle," which is often observed on strawberry-beds, on hawthorn-hedges, and potatofields. They are very injurious, and begin to appear about the middle of May, soon after the young hops are tied to the poles, and generally infest old plantations, being seldom found to any extent in newlymade hop-gardens.

The pupa of these insects may be seen jumping about the hop-hills like sand-flies on the 'sea-coast, and they do a great deal of mischief by puncturing the most succulent parts of the vine, for the purpose of sucking its juices, and thus exhausts the plant by the exudations that are caused, which, when dried up, leaves a whitish deposit upon the leaves, which may be often seen in old plantations. When once they establish themselves, their attacks each year increase in intensity, and the only remedy, perhaps, is to catch them. This is done by means of a sheet of thin iron, about four feet long and two feet wide, with turned-up edges, resembling in shape a dripping-pan, the bottom of which is covered with gas-tar. Two women carry it by its handles (which are generally formed of string put through two holes at each end), and is held by 
them on the ground below each pole of hops. Another woman strikes the pole sharply with a hammer, on an unclothed part, which jerks the insects off, which will mostly fall into the tray, if carefully held on the leeward side.

This operation must be performed before the end of July, for they then attain their fully developed state, and are furnished with wings, when it is not possible to catch them, which ought to be attempted as soon as they are first discovered.

Mould, or mildew is caused by the attack of a vegetable parasitical fungus, which in its first stage wears the characteristics of an Oidium, but when mature takes that of an Erysiphe, usually making its appearance in wet seasons, and in damp situations.

As there is no known remedy for it, and it steadily progresses after having first made its appearance, it is much dreaded by the hop-grower. Its presence may often be attributed to carelessness and slovenly methods of cultivation, the predisposing causes being dampness, and an absence of the free circulation of air and light. The object should always be to 1et into the plantation as much of these as possible, by grubbing up old dense hedges, and removing any cause which obstructs the free play of sunshine, and the action of the elements.

As soon as this disease appears, it spreads in every direction, its first aspect taking the form of a small white speck upon the upper side of the leaf, gradually increasing in size till it reaches the diameter of about one-eighth part of an inch; below this white spot, on the corresponding portion of the under side of the leaf, a similar indentation 
appears, which shows the presence of mould to be unmistakable.

It is supposed that, the seeds of this parasitical fungus are blown in every direction from the spots on the surface of the leaves, and it thus becomes spread; the minutest particle of this white dust, when it settles upon another leaf, becoming a speck of mould. Hopgardens that are too crowded, or where an excessive growth of bine has been stimulated, are causes which tend to predispose the hop-plants to this disease, by depriving them of their necessary supply of air and light; and attention ought to be paid to pulling off the suckers frequently, as they spring from the hills during the summer months, for the mould commencing near the ground, they invariably take it the first. Every blossom that is touched by it perishes; and when it makes its first appearance, it is well to pull off at once every leaf that is found affected by it. But as it is scarcely possible to do this in large plantations, preventive measures should be resorted to, and it is found to be more fatal in those grounds which are low, moist, and sheltered, than in those that are high and open.

The fire-blast, which usually occurs in the month of July, sometimes scorches up whole plantations, especially when a hot gleam of sunshine has followed immediately after rain, chiefly on thin, inferior soils, the leaves first acquiring dark blotches, and then turn yellow and brown, and afterwards fall off.

An insufficient supply of manure, and the want of frequent stirring of the soil, are the predisposing causes of the fire-blast ; and it is usual to employ a mixture of manures to the soil, in accordance with the 
best devised method of routine hop-growing; the first year farmyard dung being put in the land at the rate of twenty to twenty-five bushels to the acre, or twenty-five hundred-weights of crushed rape-cake, to give a supply of carbonaceous matter ; succeeded in the next year by dry nitrogenous applications, such as woollen rags, wool waste, shoddy, \&c. (but which, as before stated, are now very difficult to procure), horn shavings, \&c. ; and the third year animal refuse, such as fish, sheep's hoofs, trotters, \&c., which need all to be dug in at the first digging of the ground.

Over manuring proves sometimes as injurious as under manuring, overdoses of ammonia developing too much leaf, and will retard the ripening of the hops, so that in the application of manures the previous condition of the soil must be taken into account, though it is safer to err on the liberal side in their treatment, rather than in the opposite direction.

Red-rust is caused by a small red mite, and only makes its appearance in dry seasons, being somewhat limited and partial in its attacks, which, when severe, causes the leaves to turn brown, shrivel up, and fall from the bines. As this blight does not attain its full vigour till towards the end of August, the mites attack the flowers as well as the leaves, inducing premature ripeness, and causing the hops to turn red, their quality becoming greatly injured.

Constant digging and stirring of the soil is the best permanent practice that can be resorted to in 
184 ROOT GROWING \& CULTIVATION OF HOPS. the cultivation of hops. Fresh pabulum, or plant food, is found for the roots by a thorough pulverization of the land, and no labour is paid for so well by increased fertility, and additional weight of crops.

THE END. 
II, HENRIETTA Street, COVENT GARDEN, W.C. AUGUST, 1888.

A

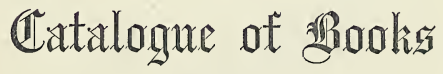
PUBLISHED BY

\section{CHAPMAN \& HALL,} LIMITED.

\section{FOR}

Drawing Examples, Diagrams, Models, Instruments, eto., ISSUED UNDER THE AUTHORITY OF

THE SCIENCE AND ART DEPARTMENT, SOUTH KENSINGTON,

FOR THE USE OF SCHOOLS AND ART AND SCIENCE CLASSES, See separate Illustrated Catalogue. 


\section{NEW PUBLICATIONS.}

By T. WEMYSS REID.

THE LIFE OF THE RT. HON. W. E. FORSTER. By T. WEMYss REID. Fourth Edition. 2 vols, Demy 8vo. With Portraits, 328.

By PERCY FITZGERALD.

THE CHRONICLES OF BOW STREET POLICE OFFICE. With an Account of the Magistrates, "Runners," and Police ; and a Selection of the most interesting Cases. By PERcy FrTzGerdi.D. With aumerous Illustrations. 2 vols. Demy 8vo, ars.

By the AUTHOR of "THE BROKEN VOW:"

THE CHILD OF STAFHERTON. By CANON KNOX LITTLE, Author of "The Broken Vow." Crown 8vo, as, 6d.

\section{By FREDERICK HAWKINS.}

THE FRENCH STAGE IN THE EIGHTEENTH CENTURY. By Frederick Hawkins. With Portraits. 2 vols. Demy 8vo, 305.

By ANDREW A. ANDERSON.

TWFNTY-FIVE YEARS IN A WAGGON: Sport and Travel in Sonth Africa. By Andrew A. ANDerson. With lllustrations and Map. A New Edition in one volume. Demy 8vo, 12.5

$$
\text { By EDWARD BURGESS. }
$$

ENGLISH $\triangle N D$ AMERICAN YACHTS. Illustrating and Describing the most famons Yachts now sailing in English and American Waters. With a Treatise upon Yachts and Yachting. By EDWARD BuRGess. Illustrated with 50 Beautiful Photogravure Engravings. Oblong folio, 42 s.

\section{By COUNT GLEICHEN.}

WITH THE CAMEL CORPS UP THE NILE. ByCOUNT GLIICHEN, Grenadier Guards. With numerous Sketches by the Author. Second Edition. Large crown 8 vo, gs.

ATCTRTAN By WRASER RAE.

AUSTRIAN HEALTH RESORTS;

Waters of Hungary. By W. FRAser RAE. Crown 8vo, 5 s.

and the Bitter

By EDWARD KENNARD.

NORWEGIAN SKETCHES: FISHING IN STRANGE WATIERS. By EDWARD KENNARD. Illustrated with 30 beautiful Sketches printed by The Automatic Ingraving Co. Second Edition. Oblorig folio, 2xs, A Set of Six Hand-coloured Plates, 2IS. ; in Oak Frames, 428.

$$
\text { By ATHOL MAUDSLAY. }
$$

HIGHWAYS AND HORSES. By ATHoL MAUDSLAY. With numerous Illustrations, Demy $8 \mathrm{vo}, 21 \mathrm{~s}$

$$
\text { ILLUSTRATED WITH PORTRAITS AND VIEWS. }
$$

A GIRL'S LIFE EIGHTY YFARS AGO. Selections from the Letters of ELIZA SOUTHGATE Bowns. With an Introduction by Clarence COOK. Illustrated with Portraits and Vicws. Fcap. 4to, ras.

$$
\text { By COLONEL G. B. MALLESON, C.S.I. }
$$
PRINCE FUGENE OF SAVOY. By Colonel G. B. MAlleson,
C.S.I. With Portrait and Maps. Crown 8vo, 6s.

$$
\text { BY PROPESSOR WRIGHTSON. }
$$

THE PRINCIPLES OF AGRICULTURAL PRACTICF AS AN INSTRUCTIONAL SUBJECT. By Prof, J. WRIGHTSON, M.R.A.C., F.C.S. etc.; Examiner in Agriculture to the Science and Art Department; Professor of Agriculture in the Normal School of Science and Royal School of Mines; President of the College of Agriculture, Downton, near Salisbury, etc. With Geological Map. Crown 8vo, 5s.

$$
\text { BY PROFESSOR J. LE CONTE. }
$$

EVOLUTION AND ITS RELATIONS TO RELIGIOUS THOUGHT. By J. LE CONTE, Professor of Geology and Natural History in the University of Californin. Crown 8vo, 6 s. 


\title{
B O O K S
}

\author{
PUBLISHED BY
}

\section{CHAPMAN \& HALL, LIMITED.}

ABLETT (T. R.)-

WRITTEN DESIGN. Oblong, sewed, 6d.

ABOUT (EDMOND)-

HANDBOOK OF SOCIAL ECONOMY; OR, THE WORKER'S A B C. From the French. With a Biographical and Critical Introduction by W. FRASER RAE. Second Edition, revised. Crown 8vo, 4s.

AFRICAN FARM, STORY OF AN. By OLIVe Schreiner (Ralph Iron). New Edition, Crown \&vo, cloth, 25.

ANDERSON (ANDREW $\left.A_{+}\right)$-

TWENTY-FIVE YEARS IN A WAGGON IN THE, GOLD REGIONS OF AFRICA. With Illustrations and Map. Second Edition. Demy 8vo, Izs.

AGRICULTURAL SCIENCE (LECTURES ON), AND OTHER PROCEEDINGS OF THE INSTITUTE OF AGRICULTURE, SOUTH KENSINGTON, $x 88_{3-4}$. Crown 8vo, sewed, 2s.

AVELING (EDWARD), D.SC, Fellow of University College, London-

MECHANICS AND EXPERIMENTAL SCIENCE. As required for the Matriculation Examination of the University of London.

MECHANICS, With numerous Woodeuts. Crown 8vo, $6 \mathrm{~s}$.

Key to Problems in ditto, crown Bvo, $35.6 \mathrm{~d}$.

MAGNETISM AND ELECTRICITX. Crown 8vo.

LIGHT AND HEAT. Crown 8vo.

BADEN-POWELL (GEORGE)-

STATE AID AND STATE INTERFERENCE. Illustrated by Results in Commerce and Industry. Crown 8 vo, 95.

BARKER (G. F. RUSSELL) and DAUGLISH (M. G.), of Lincoln's Inn, Barristers-at-Law-

HISTORICAL AND POLITICAL HANDBOOK. Second Edition. Crown 8vo, 25. 6d.

$B A R T L E Y$ (G. C. T.)-

A HANDY BOOK FOR GUARDIANS OF THE POOR. Crown 8ve, cloth, 3 s. 
BAYARD: HISTORY OF THE GOOD CHEVALIER, SANS PEUR ET SANS REPROCHE. Compiled by the LoYaL SERviteUr. With over zoo Illustrations, Royal 8vo, zis.

BEATTY-KINGSTON (W.)-

A WANDERER'S NOTES. 2 vols. demy 8vo, $24 \mathrm{~s}$.

MONARCHS I HAVE MET. 2 vols. demy 8vo, $24 \mathrm{~s}$.

MUSIC AND MANNERS: Personal Reminiscences and Sketches of Character. 2 vols. demy $8 \mathrm{vo}$, zos.

BELL (FAMES, Ph.D., Esc), Principal of the Somerset House Laboratory-

THE CHEMISTRY OF FOODS. With Microscopic Illustrations.

PART 1. TEA, COFFEE, COCOA, SUGAR, ETC. Large crown 8vo, 2s. 6d. PART II. MILK, BUTTER, CHEESE, CEREALS, PREPAKED STARCHES, ETC. Large crown $8 \mathrm{vo}, 3^{\mathrm{s}}$.

$B E N S O N(W)-$.

UNIVERSAL PHONOGRAPHY. To classify sounds of Human Speech, and to denote them by one set of Symbols for casy Writing and Printing. 8vo, sewed, $x$ s.

MANUAL OF THE SCIENंCE OF COLOUR. Coloured Frontispiece and Illustrations. $12 \mathrm{mo}$, cloth, 2s. $6 \mathrm{~d}$.

PRINCIPLES OF THE SCIENCE OF COLOUR. Small 4 to, cloth, 155 .

BINGHAM (CAPT. THE HON, D.)-

A SELECTION FROM THE LETTERS AND DESPATCHES OF THE FIRST NAPOLEON. With Explanatory Notes.
3 vols, demy Bvo, $\ell^{2}$ 2s.

THE BASTILLE. With Illustrations. 2 vols, demy 8 vo, $3^{2 a s}$.

BIRDWOOD (SIR GEORGE C. M.), C.S.I.-

THE INDUSTRIAL ARTS OF INDIA. With Map and ${ }_{74}$ Illustrations. New Edition, Demy 8vo, 24.

BLACKIE (FOHN STUART), R.R.S.E.-

THE SCOTTISH HIGHLANDERS AND THE LAND. LAWS. Demy 8vo, 9s.

ALTAVONA: FACT AND FICTION FROM MY LIFE IN THE HIGHLANDS. Third Edition. Crown $8 \mathrm{vo}, 6 \mathrm{~s}$.

BLATHER WICK (CHARLES)-

PERSONAL RECOLLECTIONS OF PETER STONNOR, Esq. With Illustrations by JAMES GUTHRIE and A. S. Boyd, Large crown 8vo, 65.

BLOOMFIELD'S (BENJAMIN LORD), MEMOIR OFMISSION TO THE COURT OF BERNADOT'TE. Edited by GFORGIANA, BARON ESS BLOOMFIFL, Author of "Reminiscences of Court and Diplomatic Life," With Portraits. 2 vols, demy 8 vo, 28 s. 
BOULGER (DEMETRIUS C.)-

GENERAL GORDON'S LETTERS FROM THE CRIMEA, THE DANUBE, AND ARMENIA. and Edition. Crown 8vo, 5 s. BRACKENBURY (COL. C. B.)-

FREDERICK THE GREAT. With Maps and Portrait. Large crown $8 \mathrm{vo}^{4} 4 \mathrm{~s}$,

BRADLEY (THOMAS), of the Royal Military Academy, Woolwich-

ELEMENTS OF GEOMETRICAL DRAWING. In Two Parts, with Sixty Plates. Oblong folio, half bound, each Part $x 68$.

$B R A Y$ (MRS.)-

AUTOBIOGRAPHY OF (born ${ }_{7} 899$, died $188_{3}$ ).

Edited by Jomn A. Krempe. With Portraits. Crown 8vo, ros. 6d.

\section{MRS. BRAY'S NOVELS AND ROMANCES.}

New and Revised Editions, with Frontispieces. 3s. $6 d$. each.

THE WHITE HOODS; a Romance of Flanders.

DE FOIX; a Romance of Bearn.
THE TALBA; or, The Moor of Portugal. THE PROTESTANT; a Tale of the Times of Queen Mary.

\section{NOVELS FOUNDED ON TRADITIONS OF DEVON AND CORNWALL.}

FITZ OF FITZFORD; a Tale of Destiny. WARLEIGH; or, The Fatal Oak, HENRY DE POMEROY; or, the Eve of

St. John.

TRELAWNY OF TRELAWNE; or, a

COURTENAY ÓF WALREDDON ; a Romance of the West.

HARTLAND FOREST AND ROSE-

Romance of the West. TEAGUE.

\section{MISCELLANEOUS TALES.}

A FATHER'S CURSE AND A DAUGHTER'S SACRITICE.

TRIALS OT THE HEART.

BRITISH ARMY, THE. By the Author of "Greater Britain," "The Present Position of European Politics," etc. Demy 8vo, 12s,

$B R O A D L E Y(A . M)-$.

HOW WE DEFENDED ARABI AND HIS FRIENDS. A Story of Egypt and the Egyptians. Illustrated by Frederick Villiers. Demy 8vo, 125.

BROMLEY-DAVENPORT (the late W.), M.P.-

SPORT: Fox Hunting, Salmon Fishing, Covert Shooting, Deer Stalking. With numerous Illustrations by General CrzaLock, C.B. New Cheap Edition. Post 8vo, 3s, 6d.

Small 4 to, 2 rs.

BUCKLAND (FRANK)-

LOG-BOOK OF A FISHERMAN AND ZOOLOGIST.

With numerous Illustrations, Fifth Thousand. Crown Bvo, 5s. 
BURCHETT (R.)-

DEFINITIONS OF GEOMETRY. New Edition. 24mo, cloth, 5d.

LINEAR PERSPECTIVE, for the Use of Schools of Art. New Edition. With Illustrations. Post 8vo, cloth, 7 s.

PRACTICAL GEOMETRY : The Course of Construction of Plane Geometrical Figures. With 137 Diagrams, Eighteenth Edition. Post 8vo, cloth, 55.

BURGESS (EDWARD)-

ENGLISH AND AMERICAN YACHTS. Illustrating and Describing the most famous Yachts now sailing in English and American Waters. With a treatise upon Yachts and Yachting. Illustrated with so Beautiful Photogravure Engravings. Oblong folio, 425 .

BUTLER (A. \%.)-

COURT LIFE IN EGYPT. Second Edition. Illustrated. Large crown 8vo, ras.

CAMPION (\%. S.).-

ON THE FRONTIER. Reminiscences of Wild Sports, Personal Adventures, and Strange Scenes. With Illustrations. Sccond Edition. Demy 8vo, $16 s$.

ON FOOT IN SPAIN. With Illustrations. Second Edition. Demy 8vo, r6s.

CARLYLE (THOMAS), WORKS BY.-See pages 29 and 30.

THE CARLYLE BIRTHDAY BOOK. Compiled, with the permission of Mr. Thomas Carlyle, by C. N. Wrulinmson. Second Edition. Small fcap. 8 vo, 3 s.

CHALDAEAN AND ASSYRIAN ART-

A HISTORY OF ART IN CHALDAA AND ASSYRIA. By Grorges Perrot and Charles Chiprez. Translated by Walter Arastrong, B,A, Oxon. With 452 Illustrations, 2 vols, Imperial 8 vo, 425 ,

CHARNAY (DÉSIRÉ)-

THE ANCIENT CITIES OF THE NEW WORLD. Being Travels and Explorations in Mexico and Central America, r857-r882. Translated from the French by J. Gonino and Helen S. Conant. With upwards of soo Illustrations. Super Royal 8vo, 3xs. 6d.

CHURCH (PROFESSOR A. H.), M.A., Oxon.-

FOOD GRAINS OF INDIA. With numerous Woodcuts. Small ${ }_{4} t_{0}, 6 s$.

ENGLISH PORCELAIN. A Handbook to the China made in England during the Eighteenth Century, as illustrated by Specimens chicfly in the National Collection. With numerous Woodcuts. Large crown
8 vo, 35.

ENGLISH EARTHENWARE. A Handbook to the Wares made in England during the 17 th and 18 th Centuries, as illnstrated by Specimens in the National Collections. With numerons Woodcuts. Large crown $8 \mathrm{vo}, 3 \mathrm{~s}$.

PLAIN WORDS ABOUT WATER. Illustrated. Crown 8 vo, sewed, $6 \mathrm{~d}$. 
CHURCH (PROFESSOR A. H.)., M.A., Oxon. (Continued)-

FOOD : Some Account of its Sources, Constituents, and Uses. Sixth Thoasand. Large Crown 3vo, cloth, 3 s.

PRECIOUS STONES : considered in their Scientific and Artistic Relations. With a Catalogue of the Townsend Collection of Gems in the South Kensington Museum. With a Coloured Plate and Woodeuts. Large crown 8 vo, 25. 6d.

CLINTON $(R . H)-$.

A COMPENDIUM OF ENGLISH HISTORY, from the Earliest Times to A.D. $x 872$. With Copious Quotations on the Leading Events and the Constitutional History, together with Appendices. Post Bvo, 75, 6d.

COBDEN, RICHARD, LIFE OF. By the Right HoN. JoHN MokL.EY, M.P. With Portrait. Fourth Thousand. 2 vols. Demy 8vo, 328.

New Edition, with Portrait. Crown 8vo, 7s. 6d.

Popular Edition, with Portrait, 4to, sewed, Is.; cloth, 2s.

COOKERY -

THE PYTCHLEY BOOK OF REFINED COOKERY AND BILLS OF FARE. By Major L-. Second Edition. Large crown 8vo, 8 8.

BREAKFASTS, LUNCHEONS, AND BALL SUPPERS. By Major L-. Crowa 8vo. $4^{\text {s. }}$

OFFICIAL HANDBOOK OF THE NATIONAL TRAINING SCHOOL FOR COOKERY. Containing Lessons on Cookery; forming the Course of Instruction in the School, Compiled by "R. O. C. Eighteenth Thousand. Large crown 8vo, 6s.

BREAKFAST AND SAVOURY DISHES. By "R. O. C." Seventh Thousand. Crown $8 \mathrm{vo}$, Is.

HOW TO COOK FISH. Compiled by "R. O. C." Crown 8vo, sewed, 3 d.

SICK-ROOM COOKERY. Compiled by "R. O. C." Crown 8vo, sewed, $6 \mathrm{~d}$.

THE ROYAL CONFECTIONER: English and Foreign. A Practical Treatise. By C. E. FrancatzLLi. With numerous Illustrations. Fifth Thousand. Crown 8vo, ss.

THE KINGSWOOD COOKERY BOOK. By H. F. WICKEN. Crown 8vo, $2 s$.

COOPER-KING (LT,-COL.)-

GEORGE WASHINGTON. Large crown 8vo. With Portrait and Maps.

COURTNEY (W. L.), M.A., LL.D., of New College, Oxford-

STUDIES NEW AND OLD. Crown 8vo, 6s.

CONSTRUCTIVE ETHICS: A Review of Modern Philo. sophy and its Three Stages of Interpretation, Criticism, and Reconstruction. Demy 8vo, ras. 
CRAIK (GEORGE LILLIE)-

ENGLISH OF SHAKESPEARE. Illustrated in a Philological Commentary on his "Julius Crsar." Seventh Edition. Post 8vo, clotb, 5s.

OUTLINES OF THE HISTORY OF THE ENGLISH LANGUAGE. Tenth Edition. Post 8vo, cloth, 2s, 6d.

CRAWFURD (OSWALD)-

BEYOND THE SEAS; being the surprising Adventures and ingenious Opinions of Ralph, Lord St. Keyne, told by his kinsman, Humphrey St. Keyne. Second Edition. Crown Bvo, 35. 6d,

CRIPPS (WILFRED JOSEPH), M.A., F.S.A.-

COLLEGE AND CORPORATION PLATE. A Handbook for the Reproduction of Silver Plate. [/n the South Kensington Museum, from celebrated English collections.] With numerous Illustrations. Large crown $8 \mathrm{vo}$, cloth, 25. 6d.

DAIRY FARMING-

DAIRY FARMING. To which is added a Description of the Chief Continental Systems. Witb numerous Illustrations. By JAMES LoNG. Crown 8vo, gs,

DAIRY FARMING, MANAGEMENT OF COWS, \&c. By Arthur Roland, Edited by Whliam ABLETt. Crown 8vo, 55.

$D A L Y$ (J. B.), LL.D.-

IRELAND IN THE DAYS OF DEAN SWIFT. Crown $8 \mathrm{vo}, 5$ s.

DAUBOURG (E.)-

INTERIOR ARCHITECTURE. Doors, Vestibules, Staircases, Anterooms, Drawing, Dining, and Bed Rooms, Libraries, Bank and News. paper Officcs, Shop Fronts and Interiors. Half-imperial, cloth, $6=12 \mathrm{~s}$. $6 \mathrm{~d}$.

DAVIDSON (ELLIS A.)-

PRETTY ARTS FOR THE EMPLOYMENT OF

LEISURE HOURS. A Book for Ladies. With Illustrations. Demy $8 \mathrm{vo}, 6 \mathrm{~s}$.

DAVITT (MICHAEL)-

LEAVES FROM A PRISON DIARY; or, Lectures to a Solitary Audience. Crown $8 \mathrm{vo}, 6 \mathrm{~s}$

Cheap Edition. Ninth Thousand. Crown 8vo, sewed, 15. 6d.

$D A Y($ WILLIAM) -

THE RACEHORSE IN TRAINING, with Hints on Racing and Racing Reform, to which is added a Cbapter on Shoeing. Fifth
Edition. Demy 8 vo, $9 \mathrm{~s}$.

DAS (DEVENDRA N.)-

SKETCHES OF HINDOO LIFE. Crown 8vo, $5 \mathrm{~s}$.

DE AINSLIE (GENERAL)-

A HISTORY OF THE ROYAL REGIMENT OF DRAGOONS. From its Formation in $166 \mathrm{r}$ to tbe Present Day. With Illustrations,
Demy 8vo, 215 . 
DE CHAMPEAUX (ALFRED)-

TAPESTRY. With numerous Woodcuts. Cloth, 2s. 6d.

DE FALLOUX (MEMOIRS OF THE COUNT). Edited by C. B. Prtman, 2 vols. Demy 8 vo.

D'HAUSSONVILLE (VICOMTE)-

SALON OF MADAME NECKER. Translated by H. M. TroLlope, 2 vols. Crown 8 vo, $x 8 \mathrm{~s}$.

$D E K O N I N C K\left(L . L_{+}\right)$and DIETZ (E.)-

PRACTICAL MANUAL OF CHEMICAL ASSAYING, as applied to the Manufacture of Iron, Edited, with notes, by RoвrRT MALLET. Post 8vo, cloth, 6s.

DE LESSEPS (FERDINAND)-

RECOLLECTIONS OF FORTY YEARS. Translated from the French by C. B. Piturax. 2 vols. Demy 8 vo, 245 .

DE LISLE (MEMOIR OF LIEUTENANT RUDOLPH), R.N., of the Naval Brigade. By the Rev. H. N. Oxenhas, M.A. Third Edition. Crown 8vo, 78, 6d.

DE LUSIGNAN (THE PRINCESS)-

SCRAPS : PoEms. Crown 8vo, is.

DE MANDAT-GRANCEY (BARON E.)-

PADDY AT HOME; OR, IRELAND AND THE Irish at rhe Prisent Trare, as seen ay A Frenchass. Translated from the French. Fourth Edition. Crown svo, as.

DICKENS (CHARLES), WORKS BY-See pages $3 \mathrm{I}-3^{8}$.

THE LETTERS OF CHARLES DICKENS. Two vols. uniform with "The Charles Dickens Edition" of his Works. Crown 8vo, 8s.

THE LIFE OF CHARLES DICKENS-See "Forster."

THE CHARLES DICKENS BIRTHDAY BOOK. With Five Illustrations. In a handsome fcap. 4 to volume, 128.

THE HUMOUR AND PATHOS OF CHARLES DICKENS. By Chardes Kent. With Portrait. Crown 8vo, 6s.

DOUGLAS (JOHN)

SKETCH OF THE FIRST PRINCIPLES OF PHYSIOGRAPHY. With numerous Illustrations. Crown 8vo.

DOWN WITH ENGLAND. Translated from the French. With Maps. Crown 8 vo, $1 \mathrm{~s}$.

DRAYSON (MAJOR-GENERAL A. W.), Late R.A., F.R.A.S.-

EXPERIENCES OF A WOOLWICH PROFESSOR during Fifteen Years at the Royal Military Academy. Demy 8vo, 8s.

THE CAUSE OF THE SUPPOSED PROPER MOTION OF THE FIXED STARS. Demy 8 vo, cloth, Ios.

PRACTICAL MILITARY SURVEYING AND SKETCHING. Fifth Edition. Post 8vo, cloth, 45. 6d. 
DRAGE (GEOFFREY)-

CRIMINAL CODE OF THE GERMAN EMPIRE. Translated with Prolegomena, and a Commentary, by G. DRAGs. Crown 8vo, 8s. DREAMS BY A FRENCH FIRESIDE. Translated from the German by Mary O'Callaghas. Illustrated by Fred Roe. Crown 8vo, 7s.6d. DUFFY (SIR CHARLES GAVAN), K.C.M.G.-

THE LEAGUE OF NORTH AND SOUTH. An Episode in Irish History, $1850-1854$. Crown $8 v o, 83$.

DYCE (WILLIAM), R.A.-

DRAWING-BOOK OF THE GOVERNMENT SCHOOL OF DESIGN ; OR, ELEMENTARY OUTLINES OF ORNAMENT. Fifty
selected Plates. Folio, sewed, 55, ; mounted, r8s.

ELEMENTARY OUTLINES OF ORNAMENT. Plates I. to XXII, containing 97 Examples, adapted for Practice of Standards I, to IV. Small folio, sewed, 25 . $6 \mathrm{~d}$.

SELECTION FROM DYCE'S DRAWING BOOK. ${ }_{5}$ Plates, sewed, $x$.6d.; mounted on cardboard, 6s. $6 \mathrm{~d}$.

TEXT TO ABOVE. Crown 8vo, sewed, 6d.

EDWARDS (H. SUTHERLAND)-

FAMOUS FIRST REPRESENTATIONS. Crown 8vo, 6 s.

EGYPTIAN ART-

A HISTORY OF ART IN ANCIENT EGYPT. By G. PERrot and C. Chuprez. Translated by WALTER ARMstrong. With over
600 Illustrations. 600 Illustrations. 2 vols. Imperial $8 \mathrm{vo}, \mathcal{L}_{2} 25$.

ELLIS (A. B., Major Ist West India Regiment)-

WEST AFRICAN STORIES. Crown 8vo.

THE TSHI-SPEAKING PEOPLES OF THE GOLD COAST OF WEST AFRICA: their Religion, Manners, Customs, Laws,
Language, \&c. With Map. Demy $8 \mathrm{vo}$, ros. $6 \mathrm{~d}$.

SOUTH AFRICAN SKETCHES. Crown 8vo, 6s.

WEST AFRICAN ISLANDS. Demy 8vo, r4s.

THE HISTORY OF THE WEST INDIA REGIMENT. With Maps and Coloured Frontispiece and Title-page. Demy 8vo, I8s.

THE LAND OF FETISH. Demy 8vo, I2s.

ENGEL $(C A R L)-$

MUSICAL INSTRUMENTS. With numerous Woodcuts. Large crown 8vo, cloth, 25. 6d.

ESCOTT (T. H. S.)-

POLITICS AND LETTERS. Demy 8vo, 9s.

ENGLAND. ITS PEOPLE, POLITY, AND PURSUITS. New and Revised Edition. Sixth Thousand. 8vo, 8s.

EUROPEAN POLITICS, THE PRESENT POSITION OF. By the Author of "Greater Britain." Demy 8vo, 12s. 
FANE (VIOLET)-

QUEEN OF THE FAIRIES (A Village Story), and other Poems. Crown 8vo, 6s.

ANTHONY BABINGTON : a Drama. Crown 8vo, 6s.

FARR (WILLIAM) and THRUPP (GEORGE A.)-

COACH TRIMMING. With 6o Illustrations. Crown 8vo.

FIFE-COOKSON (LIEUT-COL, J. C.)-

TIGER-SHOOTING IN THE DOON AND ULWAR, AND LIFE IN INDIA. With numerous Illustrations by E. HosDAY, R.H.A. Large crown 8vo, ros. 6 d.

FITZGERALD (PERCY), F.S.A.-

THE CHRONICLES OF BOW STREET POLICE OFFICE, with an Account of the Magistrates, "Runners," and Police ; and a Selection of the most interesting Cases. With numerous Illustrations. 2 vols. Demy 8vo, 2 Is.

FLEMING (GEORGE), F.R.C.S.-

ANIMAL PLAGUES: THEIR HISTORY, NATURE, AND PREVENTION. 8vo, cloth, 15 s.

PRACTICAL HORSE-SHOEING. With 37 Illustrations. Fifth Edition, enlarged. Bvo, sewed, 25.

RABIES AND HYDROPHOBIA: THEIR HISTORY, NATURE, CAUSKS, SYMPTOMS, AND PREVENTION. With 8 Illustrations. $8 \mathrm{vo}$, cloth, $\times 53$.

FORSTER ( $F O H N)-$

THE LIFE OF CHARLES DICKENS. Uniform with the Illustrated Library Edition of Dickens's Works. 2 vols. Demy 8vo, 2os.

THE LIFE OF CHARLES DICKENS. Uniform with the Library Edition. Post 8vo, xos, 6d,

THE LIFE OF CHARLES DICKENS. Uniform with the "C. D." Edition. With Numerouts Illustrations, 2 vols. 7 s.

THE LIFE OF CHARLES DICKENS. Uniform with the Household Edition. With Illustrations by F. Barnard. Crown 4 to, cloth, $5^{\mathrm{s}}$.

WALTER SAVAGE LANDOR : a Biography, I775-1864. With Portrait. A New and Revised Edition. Demy 8vo, 12s.

FORSTER, THE LIFE OF THE RIGHT HON. W. E. By T. Wemyss ReId. With Portraits. Fourth Edition. a vols. Demy 8vo. 32s. FORTESCUE (THE HON. JOHN)-

RECORDS OF STAG-HUNTING ON EXMOOR. With $x_{4}$ full page Illustrations by EDcar Ginerne, Large crown 8vo, 168 .

FORTNIGHTLY REVIEW-

FORTNIGHTLY REVIEW.-First Series, May, 1865 , to Dec. 1866.6 vols. Cloth, 13 s, each.

New Series, $x 867$ to $x_{7} 2$. In Half-yearly Volumes. Cloth, 135. each.

From January, 1873 , to the present time, in Half-yearly Volumes. Cloth, 16 s, each.

CONTENTS OF FORTNIGHTLY REVIEW. From the commencement to end of 1878 . Sewed, 28 . 
FORTNUM (C. D. E.), F.S.A.-

MAIOLICA. With numerous Woodcuts. Large crown $8 \mathrm{vo}$, cloth, 2s. 6d. BRONZES. With numerous Woodcuts. Large crown
$8 \mathrm{vo}$, cloth, $2 \mathrm{~s}$. $6 \mathrm{~d}$,

FOUQUÉ (DE LA MOTTE)-

UNDINE : a Romance translated from the German. With an Introduction by JULiA CARTwright. Illustrated by Heywood Sumner. Crown 4 to. 5 s.

FRANCATELLI (C. E.) -

THE ROYAL CONFECTIONER: English and Foreign. A Practical Treatise. With Illustrations. Fifth Edition. Crown 8vo, 5.

FRANCIS (FRANCIS), JUNR.

SADDLE AND MOCASSIN. 8vo, ras.

FRANKS (A. W.)-

- JAPANESE POTTERY. Being a Native Report, with an Introduction and Catalogue. With numerous Illustrations and Marks. Large
crown 8vo, cloth, 2s, $6 \mathrm{~d}$.

FROBEL, FRIEDRICH ; a Short Sketch of his I,ife, including Fröbel's Letters from Dresden and Leiprig to his Wife, now first Translated into English. By EMILy SHIRrefr. Crown 8vo, 2s.

GALLENGA (ANTONIO)-

ITALY: PRESENT AND FUTURE. 2 vols. Dmy. 8vo, 2 rs.

EPISODES OF MY SECOND LIFE. 2 vols. Dmy. 8 vo, $28 \mathrm{~s}$.

IBERIAN REMINISCENCES. Fifteen Years' Travelling Impressions of Spain and Portugal. With a Map. 2 vols. Demy 8vo, 325.

GASNAULT (PAUL) and GARNIER (ED.)-

FRENCH POTTERY. With Illustrations and Marks. Large crown 8vo, 35 .

GILLMORE (PARKER)-

THE HUNTER'S ARCADIA. With numerous Illustrations. Demy 8vo, ros. 6d.

GIRL'S LIFE EIGHTY YEARS AGO (A). Selections from the Letters of Eliza Southgate Bowne, with an Introduction by Clarence Cook. Illustrated with Portraits and Views. Crown 4 to, 12s.

GLEICHEN (COUNT), Grenadier Guards-

WITH THE CAMEL CORPS UP THE NILE, With numerous Sketches by the Author. Second Edition. Large crown 8vo, 95.

GORDON (GENERAL)-

LETTERS FROM THE CRIMEA, THE DANUBE, AND ARMENIA. Edited by Demetraus C. Boulger. Second Edition.
Crown 8vo, 5s.

'VORST (SIR F. E.), Q.C., M.P.-

An ELECTION MANUAL. Containing the Parliamentary Elections (Corrupt and Illegal Practices) Act, 1883 , with Notes. Third Edition. Crown 8vo, rs. $6 \mathrm{~d}$

GOWER (A.R.), Royal School of Mines-

PRACTICAL METALLURGY. With Illustrations. Crown 8vo, 3 s.

GRAHAM (SIR GERALD), V.C., K.C.B.-

LAST WORDS WITH GORDON. Crown 8vo, cloth, Is. 
GRESWELL (WILLIAM), M.A., F.R.C.I,-

OUR SOUTH AFRICAN EMPIRE. With Map. 2 vols Crown 8vo, 2xs.

GREVILLE (LADY VIOLET)-

MONTROSE. With an Introduction by the EARL of Ashdurnhas. With Portraits. Large crown $8 \mathrm{vo}, 7 \mathrm{5}$, 6a.

GRIFFIN (SIR LEPEL HENRY), K.C.S.I.-

THE GREAT REPUBLIC. Second Edition. Crown 8vo, 45. $6 \mathrm{~d}$.

GRIFFITHS (MAYOR ARTHUR), H,M. Inspector of Prisons-

FRENCH REVOLUTIONARY GENERALS. Large crown 8vo.

CHRONICLES OF NEWGATE. Illustrated. New Edition. Demy 8vo, r6s,

MEMORIALS OF MILLBANK: or, Chapters in Prison History. With Illustrations by R. Goff and Author. New Edition. Demy 8vo, I25.

GRIMBLE (AUGUSTUS)-

DEER-STALKING. A New Edition, revised and enlarged. Imperial ${ }_{4}$ to, ${ }^{315}$. $6 \mathrm{~d}$. With 18 Full-page Illustrations.

HALL (SIDNEY)-

A TRAVELLING ATLAS OF THE ENGLISH COUNTIES. Fifty Maps, coloured. New Edition, including the Railways, corrected up to the present date. Demy 8vo, in roan tuck, ros. 6 d.

HARDY (LADY DUFFUS)-

THROUGH CITIES AND PRAIRIE LANDS, Sketches of an American Tour. Demy 8vo, 1 /5.

HATTON (FOSEPH) and HARVEY (REV, M.) -

NEWFOUNDLAND. The Oldest British Colony. Its History, Past and Present, and its Prospects in the Future. Illustrated from Photographs and Sketches specially made for this work. Demy 8 vo, $x 8 s$.

HA WKINS (FREDERICK)-

THE FRENCH STAGE IN THE EIGHTEENTH CENTURY. With Portraits. a vols. Demy 8vo, jos.

ANNALS OF THE FRENCH STAGE: FROM ITS ORIGIN TO THE DEATH OF RACINE. 4 Portraits. 2 vols. Demy 8 vo, $28 \mathrm{~s}$.

HILDEBRAND (HANS), Royal Antiquary of Sweden-

INDUSTRIAL ARTS OF SCANDINAVIA IN THE PAGAN TIME. With numerous Woodcuts. Large crown 8vo, 25. 6d. HILL (MISS G.) -

THE PLEASURES AND PROFITS OF OUR LITTLE POULTRY FARM. Small 8vo, 35.

HOLBEIN-

TWELVE HEADS AFTER HOLBEIN. Selected from Drawings in Her Majesty's Collection at Windsor. Reproduced in Autotype, in portfolio. $\delta$ I 16 s.

HOLLINGSHEAD (FOHN)-

FOOTLIGHTS, Crown 8vo, 7 s. $6 \mathrm{~d}$. 
HOPE (ANDRÉE)-

CHRONICLES OF AN OLD INN; or, a Few Words about Gray's Inn. Crown 8vo, 5 s.

HOVELACQUE (ABEL)-

THE SCIENCE OF LANGUAGE: LINGUISTICS, PHILOLOGY, AND ETYMOLOGY. With Maps. Large crown 8vo, cloth, 55. HOZIER (H. M.) -

TURENNE. With Portrait and Two Maps. Large crown 8vo, 4 s.

HUMPHRIS (H. D.)-

PRINCIPLES OF PERSPECTIVE. Illustrated in a Series of Examples. Oblong folio, half-bound, and Text 8vo, cloth, $6 \mathrm{I}$ Is.

HUNTLY (MARQUIS OF) -

TRAVELS, SPORTS, AND POLITICS IN THE EAST OF EUROPE. With Illustrations by the Marchioness of Huntly. Large
Crown 8vo, I2s.

I.D.B. ; or, the Adventures of Solomon Davis on the Diamond Fields and Elsewhere. By W. T. E. Crown 8vo, 6s.

INDUSTRIAL ARTS: Historical Sketches, With numerous Illustrations. Large crown Bvo, 35 .

INTERNATIONAL POLICY : Essay on the Foreign Relations of England. By Frepgric Harrison, Prop. Bezsley, Richard Congreve, and others. New Edition. Crown Bvo, 2s. 6d.

IRELAND IN THE DAYS OF DEAN SWIFT. By J. B. DALY, LL.D. Crown Bvo, 5 s.

IRISH ART OF LACEMAKING, A RENASCENCE OF THE. Illustrated by Photographic Reproductions of Irish Laces, made from new and specially designed Patterns. Introductory Notes and Descriptions. By A. S. C. Demy 8vo, 2s. 6 d.

IRON (RALPH), (OLIVE SCHREINER)-

THE STORY OF AN AFRICAN FARM. Third Edition. Crown 8vo, cloth, 25.

IACKSON (FRANK G.), Master in the Birmingham Municipal School of Art-

DECORATIVE DESIGN. An Elementary Text Book of Principles and Practice. With numerous Illustrations. Crown 8vo, 7s.6d.

JAMES (HENRY A.)-

HANDBOOK TO PERSPECTIVE. Crown 8vo. 2s, 6d.

FARRY (GENERAL)-

OUTPOST DUTY. Translated, with TREATISES ON MILITARY RECONNAISSANCE AND ON ROAD-MAKING. BY MajorGen. W. C. E. NAPIRr. Third Edition. Crown 8vo, 5 s.

FEANS (W.T.)

CREATORS OF THE AGE OF STEEL. Memoirs of Sir W. Siemens, Sir H. Bessemer, Sir J. Whitworth, Sir J. Brown, and othey Inventors. Second Edition. Crown 8 vo, 75 . $6 \mathrm{~d}$.

YOHNSON (DR. SAMUEL)-

LIFE AND CONVERSATIONS OF DR. SAMUEL JOHNSON. By A. MAns, Crown 8vo, ros. 6d, 
FONES (CAPTAIN DOUGLAS), R.A.-

NOTES ON MILITARY LAW. Crown 8vo, 4s.

JONES. HANDBOOK OF THE JONES COLLECTION iN THE SOUTH KENSINGTON MUSEUM, With Portrait and Woodcuts, Large crown $8 \mathrm{vo}, 25.6 \mathrm{~d}$.

KENNARD (EDWARD)-

NORWEGIAN SKETCHES : FISHING IN STRANGE

WATERS. Illustrated with 30 beantiful Sketehes printed by The Automatic Engraving Co. Second Edition. Oblong folio, 2Is. A Set of Six Hand-coloured Plates, aIs, ; in Oak Frames, 425.

KENT (CHARLES)-

HUMOUR AND PATHOS OF CHARLES DICKENS. Crown 8vo, 65 .

KLACZKO (M. $\mathcal{F U L I A N ) - ~}$

TWO CHANCELLORS : PRINCE GORTCHAKOF AND PRINCE BISMARCK. Translated byMrs. TArr. New and cheaper Edition, $6 s$. KNOLLYS (MAJOR HENRY), R.A.-

SKETCHES OF LIFE IN JAPAN. With Illustrations. Large crown 8vo, 125 .

LACEMAKING, A RENASCENCE OF THE IRISH ART OF. Illustrated by Photographic Reproductions of Irish Laces, made from new and specially designed patterns. Demy $8 \mathrm{vo}^{2}, 2 \mathrm{~s}, 6 \mathrm{~d}$.

LACORDAIRE'S JESUS CHRIST; GOD; AND GOD AND MAN. Conferences delivered at Notre Dame in Paris. New Edition. Crown 8vo, 6 s.

LAING $(S$.$) -$

MODERN SCIENCE AND MODERN THOUGHT.

With a Supplementary Chapter on Gladstone's "Dawn of Creation" and Drummond"s

"Natural Law in the Spiritual World." Fifth Edition. Demy 8vo, 3s, 6d.

LAVELEYE (EMMILE DE)-

THE ELEMENTS OF POLITICAL ECONOMY. Translated by W. Pollard, B.A., St. John's College, Oxford. Crown 8vo, 6s.

LANDOR (W.S.)-

LIFE AND WORKS. 8 vols.

Vol, 1 . WALTER SAVAGE LANDOR, A Biography in Eight Books. By

Vot. 2. Out of print.

Vot. 3. CONVERSATIONS OF SOVEREIGNS AND STATESMEN, AND FIVE DIALOGUES OF BOCCACCIO AND PETRARCA. Demy $8 \mathrm{vo}^{2} \mathbf{x} 4 \mathrm{~s}$.

Vol. 4. DIALOGUES OF LITERARY MEN. Demy $8 \mathrm{vo}, x_{4}$.

Vol. 5. DIALOGUES OF LITERARY MEN (contiracd). FAMOUS WOMEN. LETTERS OF PERICLES AND ASPASIA. And Minor Prose Pieces, Demy 8vo, $1_{4} \mathrm{~s}$.

Vot. 6. MISCELLANEOUS CONVERSATIONS. Demy 8vo, 145 ,

Vol, 7. GEBIR, ACTS AND SCENES AND HELLENICS. Poems. Demy 8vo, r4s:

VOL. 8. MISCELLANEOUS POEMS AND CRITICISMS ON THEO. CRITUS, CATULLUS, AND PETRARCH. Demy 8vo, $x_{4} 4 \mathrm{~s}$.

LE CONTE (JOSEPH), Professor of Geology and Natural History in the University of California-

EVOLUTION AND ITS RELATIONS TO RELIGIOUS THOUGHT. Crown 8vo, 6s. 
I.EFÈ VRE (ANDRE)-

PHILOSOPHY, Historical and Critical. Translated, with an Introduction, by A. W. KEANE, B.A. Large crown 8vo, 7s. 6d.

LESLIE (R. C.)-

A SEA PAINTER'S LOG. With I 2 Full-page Illustrations by the Author. Large crown 8vo, ras,

LETOURNEAU (DR. CHARLES)-

SOCIOLOGY. Based upon Ethnology. Translated by Henky M. Trollope. Large crown 8 vo, ros.

BIOLOGY. Translated by William MacCall. With Illustrations, Large crown 8vo, 6s.

LILLY $(W . S$.

CHAPTERS ON EUROPEAN HISTORY. With an Introductory Dialogue on the Philosophy of History. 2 vols. Derny 8vo, 2rs.

ANCIENT RELIGION AND MODERN THOUGHT: Third Edition, revised, with additions. Demy $8 \mathrm{vo}, 125$.

LITTLE (THE REV. CANON KNOX)-

THE CHILD OF STAFFERTON: A Chapter from a Family Chronicle. Crown 8vo, 2s. $6 \mathrm{~d}$.

THE BROKEN VOW. A Story of Here and Hereafter. Third Edition. Crown $8 \mathrm{vo}, 2 \mathrm{~s}, 6 \mathrm{~d}$.

LLOYD (COLONEL E.M.), R.E., late Professor of Fortification at the Royal Military Academy, Woolurich-

VAUBAN, MONTALEMBERT, CARNOT: ENGINEER STUDIES. With Portraits, Crown $8 v 0,5 s$.

LONG (JAMES)-

DAIRY FARMING. To which is added a Description of the Chief Continental Systems. With numerous Illustrations. Crown $8 v 0$, gs.

LOW (C. R.)-

SOLDIERS OF THE VICTORIAN AGE. 2 vols. Demy 8 vo, 6I Ios.

LOW (WILLIAM)-

TABLE DECORATION. With I9 Full Illustrations Demy 8vo, 6s.

LYTTON (ROBERT, EARL)-

POETICAL WORKS-

FABLES IN SONG. 2 vols. Fcap 8 vo, r2s.

THE WANDERER. Fcap. 8vo, 6s.

POEMS, HISTORICAL AND CHARACTERISTIC, Fcap, 6s, 
MACDONALD (FREDERIKA)-

PUCK AND PEARL: THE WANDERINGS AND WONDERiNGs of Two kinglish CHILdRen in India. By Frederika Macdonald, With Illustrations by Mrs. IRviNo Graftam. Second Edition. Crown 8vo, 55 .

MALLESON (COL. G. B.), C.S.I.-

PRINCE EUGENE OF SAVOY. With Portrait and Maps, Large crown $8 \mathrm{vo}, 6 \mathrm{~s}$,

LOUDON. A Sketch of the Military Life of Gideon Ernest, Freicherr von Loudon, sometime Generalissimo of the Austrian Forces. With Portrait and Maps, Large crown 8vo, $4^{5}$.

MALLET (ROBERT)-

PRACTICAL MANUAL OF CHEMICAL ASSAYING, as applied to the Manufacture of Iron. By L. L. De Koninck and E. DiETz. Edited, with notes, by RoBErT MALLET. Post 8 vo, cloth, $6 \mathrm{~s}$.

MASKELL (ALFRED)-

RUSSIAN ART AND ART OBJECTS IN RUSSIA. A Handbook to the Reproduction of Goldsmiths' Work and other Art Treasures, With Illustrations. Large crown 8 vo, 4 s. $6 \mathrm{~d}$.

MASKELL (WILLIAM)-

IVORIES: ANCIENT AND MEDIAEAL. With numerous Woodcuts. Large crown 8vo, cloth, 2s. 6d.

HANDBOOK TO THE DYCE AND FORSTER COLLECTIONS. With Illustrations. Large crown 8vo, cloth, 25, 6d.

MAUDSLAY (ATHOL)-

HIGHWAYS AND HORSES. With numerous Illustrations. Demy 8 vo, 2rs. Bound in white and red, gilt top, and uncut edges, $6 x_{35} 6 \mathrm{~d}$.

\section{GEORGE MEREDITH'S WORKS.}

A New and Uniform Edition. Crown 8vo, Six Shillings each.

DIANA OF THE CROSSWAYS.

EVAN HARRINGTON.

THE ORDEAL OF RICHARD FEVEREL.

THE ADVENTURES OF HARRY RICHMOND.

SANDRA BELLONI. Originally EMILIA IN ENGLAND.

VITTORIA.

RHODA FLEMING.

BEAUCHAMP'S CAREER.

THE EGOIST.

THE SHAVING OF SHAGPAT: AN ARABIAN ENTERTAINMENT; AND FARINA.

MERIVALE (HERMAN CHARLES)-

BINKO'S BLUES. A Tale for Children of all Growths. Illustrated by EDGAR GIBERNB. Small crown 8vo, 5 s.

THE WHITE PILGRIM, and other Poems. Crown 8vo, 9s. 


\section{MILITARY BIOGRAPHIES-}

FREDERICK THE GREAT. By Col، C. B.BRACKENBURY. Witb Maps and Portrait. Large crown 8vo, 45 .

LOUDON. A Sketch of the Military Life of Gideon Emest, Freicherr yon Loudon, sometime Generalissimo of the Austrian Forces. By CoL. G. B. MALLESON, C.S.I. With Portrait and Maps. Large crown $8 \mathrm{vo}, 45$.

TUREnNe. By H. M. Hozrer. With Portrait and Two Maps. Large crown 8 vo, 45 .

PARLIAMENTARY GENERALS OF THE GREAT CIVIL WAR, By Major Walford, R.A. With Maps, Large crown 8vo, 45.

PRINCE EUGENE OF SAVOY. By Col, G. B. Malleson, C.S.I. With Portrait and Maps. Large crown 8vo, 6 s.

GEORGE WASHington. By Lieut,-Col. Cooper King. Large crown 8 vo. With Portrait and Maps.

FRENCH REVOLUTIONARY GENERALS. By MAJOR AxthuR GRTpiths. Lange crown 8vo.

MOLESWORTH (W. NASSAU)-

HISTORY OF ENGLAND FROM THE YEAR I830 TO THE RESIGNATION OF THE GLADSTONE MINISTRY, 8874 . Twelfth Thousand, 3 vols, Crown 8 vo, $18 \mathrm{~s}$.

ABRIDGED EDITION. Large crown, 7s, 6d.

MOLTKE (FIELD-MARSHAL COUNT VON)-

POLAND : AN HISTORICAL SKETCH. An Authorised Translation, with Biographical Notice by E. S. Buchнex . Crown 8vo, 4s, 6d.

MORLEY (THE RIGHT HON. FOHN), M.P.-

RICHARD COBDEN'S LIFE AND CORRESPON. DENCE. Fourth Tbousand. 2 vols, Demy 8 vo. 6 I I25.

Crown 8vo Edition, with Portrait, 7s. $6 \mathrm{~d}$.

Popular Edition. With Portrait. 4to, sewed, Is. Cloth, 2s.

MUNTZ (EUGENE)-

RAPHAEL: his Life, Works, and Times. Illustrated with about 200 Engravings, A new Edition, revised from tbe Second French Edition by W. Armstrong, B.A. Oxon. Imperial 8vo, 255.

MURRAY (ANDREW), F.L.S.-

ECONOMIC ENTOMOLOGY. APtera. With numerous_Illustrations. Large crown $8 \mathrm{vo}^{2}, 75,6 \mathrm{~d}$, 
NAPIER (MAף.-GEN. W.C.E.) -

TRANSLATION OF GEN. JARRY'S OUTPOST DUTY. With TREATISES ON MILITARY RECONNAISSANCE AND ON ROAD-MAKING, Third Edition. Crown $8 \mathrm{vo}, 5 \mathrm{~s}$.

NAPOLEON. A Selection from the Letters and Despatches of the First Napoleon. With Explanatory Notes by Captain the Hon. D. Bragharr. 3 vols. Demy 8vo, $\varnothing_{2} 2 \mathrm{~s}$.

NECKER (MADAME)-

THE SALON OF MADAME NECKER. By VICOMTE D'Haussonville. Transiated by H. M. Trollore, 2 vols. Crown $8 \mathrm{vo}, \mathrm{r} 8 \mathrm{~s}$.

NESBITT (ALEXANDER)GLASS. With numerous Woodcuts. Large crown 8vo,
cloth, $25.6 \mathrm{~d}$.

NEVINSON (HENRY)-

A SKETCH OF HERDER AND HIS TIMES, With a Portrait. Demy 8vo, I4s.

NEWTON (E. TULLLEX), F.G.S.-

THE TYPICAL PARTS IN THE SKELETONS OF A CAT, DUCK, AND CODFISH, being a Catalogue with Comparative Description arranged in a Tabular form. Demy 8vo, cloth, 35.

NILSEN (CAPTAIN)-

LEAVES FROM THE LOG OF THE "HOMEWARD BOUND"; or, Eleven Months at Sea in an Open Boat. Crown 8vo, Is.

NORMAN (C. B.)-

TONKIN; OR, FRANCE IN THE FAR EAST. With Maps. Demy 8vo, r4s.

O'GRADY (STANDISH)-

TORYISM AND THE TORY DEMOCRACY. Crown $8 \mathrm{vo}, 5 \mathrm{~s}$.

OLIVER (PROFESSOR), F.R.S., \&

ILLUSTRATIONS OF THE PRINCIPAL NATURAL ORDERS OF THE VEGETABLE KINGDOM, PREPARED FOR THE SCIENCE AND ART DEPARTMENT, SOUTH KENSINGTON, With rog Plates. Oblong 8vo, plain, 165 ; coloured, $6 \mathrm{x} 6 \mathrm{~s}$.

OXENHAM (REV. H. N.)-

MEMOIR OF LIEUTENANT RUDOLPH DE LISLE, R.N., OF THE NAVAL BRIGADE. Third Edition, with Illustrations. Crown 8vo, 75. 6d.

SHORT STUDIES, ETHICAL AND RELIGIOUS. Demy 8vo, 125.

SHORT STUDIES IN ECCLESIASTICAL HISTORY AND BIOGRAPHY. Demy 8vo, 125. 
PERROT (GEORGES) and CHIPIEZ (CHARLES)-

A HISTORY OF ANCIENT ART IN PHCNICIA AND ITS DEPENDENCIES. Translated from the French by WALter Armstrong, B.A. Oxon. Containing 6.44 Illustrations in the text, ond xo Steel and Coloured Plates, 2 vols. Imperial 8vo, $42 \mathrm{~s}$.

A HISTORY OF ART IN CHALDEA AND ASSYRIA. Translated by WALTER ARMstrong, B.A. Oxon. With $45^{2}$ Illustrations. 2 vols. Imperial 8vo, 425.

A HISTORY OF ART IN ANCIENT EGYPT. Translated from the French by W, ARMstrong, B.A. Oxon. With over 6oo lllustrations. 2 vols. Imperial $8 \mathrm{vo}, 425$.

PETERBOROUGH (THE BARL OF)-

THE EARL OF PETERBOROUGH AND MONMOUTH (Charles Mordaunt): A Memoir. By Colonel Frank Russsl, Royal Dragoons With Illustrations. 2 vols, demy 8 vo. 325 .

PHERICIAN ART-

A HISTORY OF ANCIENT ART IN PHCENICIA AND its DEPENDENCIES. By Georges Perrot and Charles Chipiez. Translated from the French by WALTER Armstrong, B.A. Oxon. Containing 644 Illustrations in the text, and ro Steel and Coloured Plates, 2 vols. Imperial $8 \mathrm{vo}, 425$.

PILLING (WILLIAM)-

ORDER FROM CHAOS: a Treatise on Land Tenure. Large crown 8vo. 25, 6d.

PITT TAYLOR (FRANK)-

THE CANTERBURY TALES. Selections from the Tales of Grofragy ChAucer rendered into Modern English, with close adherence to the language of the Poet. With Frontispiece. Crown 8vo, 6s.

POLLEN (F. H.)-

GOLD AND SILVER SMITH'S WORK. With numerous Woodcuts. Large crown 8vo, cloth, 2s, 6d.

ANCIENT AND MODERN FURNITURE AND WOODWORK. With numerous Woodcuts. Large crown 8vo, cloth, 2s. 6d.

POOLE (STANLEY LANE), B.A., M.R.A.S.-

THE ART OF THE SARACENS IN EGYPT. Published for the Committee of Council on Education. With xo8 Woodcuts. Large crown $8 \mathrm{vo}, 4 \mathrm{~s}$. 
POYNTER (E. F.), R.A.-

TEN LECTURES ON ART. Third Edition. Large crown 8vo, 95 .

PRINSEP (VAL), A.R.A.-

IMPERIAL INDIA. Containing numerous Illustrations and Maps. Second Edition. Demy 8vo, \&I Is.

RADICAL PROGRAMME, THE. From the Fortnightly Reoicw, with additions. With a Preface by the Right HoN. J. Chamberlans, M.P. Thirteenth Thousand. Crown 8vo, 25. $6 \mathrm{~d}$.

RAE (W. FRASER)-

AUSTRIAN HEALTH RESORTS : and the Bitter Waters of Hungary. Crown 8vo, 55 .

RAMSDEN (LADY GWENDOLEN)-

A BIRTHDAY BOQK. Illustrated. Containing 46 Illustrations from Original Drawings, and numerous other Illustrations, Royal 8vo, 2IS.

RAPHAEL: his Life, Works, and Times. By Eugene MunTz. Illustrated with about 200 Engravings. A New Edition, revised from the Second French Edition. By W. Armstrong, B.A. Imperial 8vo, 255.

RRDGRAVE (GILBRRT)-

OUTLINES OF HISTORIC ORNAMENT. Translated from the German. Edited by GuLBERT REDGRAvE. With numerous Illustrations. Crown 8 vo, 45 .

REDGRAVE (GILBERT R.)-

MANUAL OF DESIGN, compiled from the Writings and Addresses of RichazD Rrdgrave, R.A. With Woodcuts. Large crown 8vo, cloth, 25. $6 \mathrm{~d}$,

REDGRAVE (RICHARD)-

ELEMENTARY MANUAL OF COLOUR, with a Catechism on Colour, 24mo, cloth, gd.

REDGRAVE (SAMUEL)-

A DESCRIPTIVE CATALOGUE OF THE HISTORICAL COLLECTION OF WATER-COLOUR PAINTINGS IN THE SOUTH KENSINGTON MUSEUM. With numerous Cliromo-lithographs and other Illustrations. Royal $8 \mathrm{vo}, \ell_{1}$ Is.

$R E I D(T, W E M Y S S)-$

THE LIFE OF THE RIGHT HON. W. E. FORSTER. With Portraits. Fourth Edition. 2 vols, demy 8vo, 325 , 
RENAN (ERNEST)-

HISTORY OF THE PEOPLE OF ISRAEL TILL THE TIME OF KING DAVID. Translated from the French by C. B. PitMan. Demy $8 \mathrm{vo}^{\mathrm{I}}$ I4s.

RECOLLECTIONS OF MY YOUTH. Translated from the original French, and revised by MADAMe Rzwan. Crown $8 \mathrm{vo}$, 8s.

REYNARDSON (C. T. S. BIRCH)-

SPORTS AND ANECDOTES OF BYGONE DAYS in England, Scotland, Ireland, Italy, and the Sunny South. With numerous Illustrations in Colour. Second Edition. Large crown 8vo, 12s.

DOWN THE ROAD: Reminiscences of a Gentleman Coachman. With Coloured Illustrations. Large crown 8vo, res.

RIANO ( $7 U A N$ F.) -

THE INDUSTRIAL ARTS IN SPAIN. With numerous

Woodcuts. Large crown $8 \mathrm{vo}$, cloth, $4 \mathrm{~s}$.

RIBTON-TURNER (C. J.)-

A HISTORY OF VAGRANTS AND VAGRANCY AND BEGGARS AND BEGGING. With Illustrations. Demy 8vo, 2rs.

ROBINSON ( 7 AMES F.)-

BRITISH BEE FARMING. Its Profits and Pleasures. Lange crown $8 \mathrm{vo}, 5 \mathrm{~s}$.

ROBINSON (7. C.)-

ITALIAN SCULPTURE OF THE MIDDLE AGES AND PERIOD OF THE REVIVAL OF ART. With so Engravings. Royal $8 \mathrm{vo}$, cloth, $7 \mathrm{~s} .6 \mathrm{~d}$.

ROBSON (GEORGE)-

ELEMENTARY BUILDING CONSTRUCTION. Illustrated by a Design for an Entrance Lodge and Gate. $x_{5}$ Plates. Oblong folio, sewed, 8 s.

ROBSON (REV. F. H.), M.A., LL.M.-

AN ELEMENTARY TREATISE ON ALGEBRA.

Post $8 \mathrm{vo}, 6 \mathrm{~s}$.

ROCK (THE VERY REV. CANON), D.D.-

TEXTILE FABRICS. With numerous Woodcuts. Large crown 8 vo, cloth, 25. 6d.

ROOSE (ROBSON), M.D., F.C.S.-

THE WEAR AND TEAR OF LONDON LIFE.

Crowa 8vo, sewed, is.

INFECTION AND DISINFECTION. Crown 8vo, sewed. 
ROLAND (ARTHUR)-

FARMING FOR PLEASURE AND PROFIT, Edited by William Ablett. 8 vols. Crown 8 vo, 5 s, each.

DAIRY-FARMING, MANAGEMENT OF COWS, \&c.

POULTRY-KEEPING.

TREE-PLANTING, FOR ORNAMENTATION OR PROFIT.

STOCK-KEEPING AND CATTLE-REARING.

DRAINAGE OF LAND, IRRIGATION, MANURES, \&c.

ROOT-GROWING, HOPS, \&c.

MANAGEMENT OF GRASS LANDS, LAYING DOWN GRASS, ARTIFICIAL GRASSES, \&c.

MARKET GARDENING, HUSBANDRY FOR FARMERS AND GENERAL CULTIVATORS.

RUSDEN (G.W.), for many years Clerk of the Parliament in Virtoria-

A HISTORY OF AUSTRALIA. With a Coloured Map. 3 vols. Demy Bvo, 5os.

A HISTORY OF NEW ZEALAND. With Maps. 3 vols. Demy 8vo, 5os.

RUSSELL (COLONEL FRANK), Royal Dragrons-

THE EARL OF PETERBOROUGH AND MON. south (Charles Mordatint): A Memoir. With lllustrations, a vols, demy $8 \mathrm{vo}, 325$,

"RUSSIA'S HOPE," THE; OR, BRITANNIA NO LONGER RUles the Waves. Showing how the Muscovite Bear got at the British Whale, Translated from the original Russian by CHarles James Cooke. Crown 8vo, is.

SCIENCE AND ART: a Journal for Teachers and Scholars. Issued monthly. 3d. Sec page 39 .

SCOTT (MAJOR-GENERAL A. DE C.), late Royal Engineers-

LONDON WATER : a Review of the Present Condition and Suggested Improvements of the Metropolitan Water Supply. Crown 8vo, sewed, as,

$\operatorname{SCOTT}(L E A D E R)-$

THE RENAISSANCE OF ART IN ITALY : an Illustrated Sketch. With upwards of 200 Illustrations. Medium quarto, I8s.

SCOTT-STEVENSON (MRS.)-

ON SUMMER SEAS. Including the Mediterranean, the FEgean, the Ionian, and the Euxine, and a voyage down the Danube. With a Map. Demy 8vo, $16 s$.

OUR HOME IN CXPRUS. With a Map and Illustrations. Third Edition. Demy 8 vo, I4s. OUR RIDE THROUGH ASIA MINOR. With Map.

$S B R M A N(0)-$.

THE MYTHOLOGY OF GREECE AND ROME, with Special Reference to its Use in Art. From the German. Edited by G. H. BLANCHI, 64 Illustrations, New Edition. Crown 8vo, $5 \mathrm{~s}$.

SHEPHERD (MAJOR), R.E.-

PRAIRIE EXPERIENCES IN HANDLING CATTLE AND SHEEP. With Illustrations and Map. Demy 8vo, 10s. 6d. 
SHIRREFF (EMILY)-

A SHORT SKETCH OF THE LIFE OF FRIEDRICH FROBEL; a New Edition, including Fröbel's Letters from Dresden and Leipzig to his Wife, now first Translated into English. Crown 8vo, 2s.

HOME EDUCATION IN RELATION TO THE KINDERGARTEN. Two Lectures. Crown 8vo, rs. 6d.

SHORE (ARABELLA)-

DANTE FOR BEGINNERS : a Sketch of the "Divina Commedia." With Translations, Biographical and Critical Notices, and Illustrations. With Portrait. Crown 8vo, $6 s$.

SIMMONDS (T. L.)-

ANIMAL PRODUCTS: their Preparation, Commercial Uses, and Value. With numerous Illustrations. Large crown 8vo, 7s. 6d.

SINGER'S STORY, A. Related by the Author of "Flitters, Tatters, and the Counsellor." Crown 8vo, sewed, $x$ s.

SINNETT (A.P.)-

ESOTERIC BUDDHISM. Annotated and enlarged by the Author. Sixth and cheaper Edition. Crown 8vo, 3s, 6d.

KARMA. A Novel. New Edition. Crown 8vo, 3s. 6d.

SINNETT (MRS.)-

THE PURPOSE OF THEOSOPHY. Crown 8vo, $3 \mathrm{~s}$.

SMART (HAWLEY)-

A FALSE START. Crown 8vo, 3s. $6 \mathrm{~d}$.

SADDLE AND SABRE. Crown 8vo, 3s. 6d.

SMITH (ALEXANDER SKENE)-

HOLIDAY RECREATIONS, AND OTHER POEMS.

With a Preface by Rev. Puinctral CaIrns, D.D. Crown 8vo, 5 .

SMITH (MAFOR R. MURDOCK), R.E.-

PERSIAN ART. With Map and Woodcuts. Second Edition. Large crown 8vo, 25.

STOKES (MARGARET)-

EARLY CHRISTIAN ART IN IRELAND. With Io6 Woodcuts, Demy Bvo, 75, 6d.

$\operatorname{STORY}(W . W)-$.

ROBA DI ROMA. Seventh Edition, with Additions and Portrait. Crown 8vo, cloth, ros, 6d.

CASTLE ST. ANGELO. With Illustrations. Crown $8 \mathrm{vo}$, ros. $6 \mathrm{~d}$.

SUTCLIFFE (FOHN)-

THE SCULPTOR AND ART STUDENT'S GUIDE

to the Proportions of the Human Form, with Measurements in feet and inches of Full-Grown Figures of Both Sexes and of Various Ages. By Dr. G. ScHadow, Member of the Academies, Stockholm, Dresden, Rome, \&c. \&cc. Translated by J. J. WRTGHT. Plates reproduced by J. SUTCLIFre, Oblong folio, 315. 6d. 
TAINE (H. A.)-

NOTES ON ENGLAND. Translated, with Introduction, by W. Fraskr RAE. Eighth Edition. With Portrait. Crown 8vo, ss.

TANNER (PROFESSOR), F.C.S.-

HOLT CASTLE; or, Threefold Interest in Land. Crown $8 \mathrm{vo}, 45.6 \mathrm{~d}$.

JACK'S EDUCATION; OR, HOW HE LEARNT FARMING. Second Edition. Crown 8vo, 3s. 6d.

TEMPLE (SIR RICHARD), BART., M.P., G.C.S.I.-

COSMOPOLITAN ESSAYS. With Maps. Demy 8vo, x6s. THRUPP (GEORGE A.) and FARR (WILLIAMI)-

COACH TRIMMING. With 60 Illustrations. Crown 8 vo, 25, 6d.

TOPINARD (DR. PAUL)-

ANTHROPOLOGY. With a Preface by Professor Paul Brocs. With numerous Illustrations. Large crown 8vo, 75. 6d.

TOVEY (LIEUT.-COL., K.K.)-

MARTIAL LAW AND CUSTOM OF WAR; or, Military

Law and Jurisdiction in Troublous Times. Crown 8 vo, 68 .

TRAILL (H. D.)-

THE NEWW LUCIAN. Being a Series of Dialogues of the Dead. Demy 8vo, rzs,

TROLLOPE (ANTHONY)-

THE CHRONICLES OF BARSETSHIRE. A Uniform

Edition, in 8 vols., large crown $8 \mathrm{vo}$, handsomely printed, each vol. containing Frontispiece, 6s, each.

THE WARDEN and BAR-

CHESTER TOWERS. 2 vols.

DR. THORNE.

FRAMLEY PARSONAGE.
THE SMALL HOUSE AT

ALLINGTON. 2 vols.

LAST CHRONICLE OF BARSET, 2 vols,

LIFE OF CICERO. 2 vols. 8vo. Ex 4 s.

VERON (EUGENE)-

ÆSTHETICS. Translated by W. H. ArMstrong. Large crown $8 \times 0,7 \mathrm{~s}, 6 \mathrm{~d}$.

WALE (REV. HENRY FOHN), M.A.-

MY GRANDFATHER'S POCKET BOOK, from r $70 x$ to ${ }^{7796 .}$ Author of "Sword and Surplice," Demy 8vo, 12s,

WALFORD (MAJOR), R.A.-

PARLIAMENTARY GENERALS OF THE GREAT CIVIL WAR. With Maps. Large crown 8vo, is.

WALKER (MRS.)-

EASTERN LIFE AND SCENERY, with Excursions to Asia Minor, Mitylene, Crete, and Roumania, 2 vols., with Frontispiece to each vol. Cruwn 8vo, 21s. 
WARING (CHARLES)-

STATE PURCHASE OF RAILWAYS. Demy 8vo, $5 \mathrm{~s}$. WATSON (WILLIAM)-

LIFE IN THE CONFEDERATE ARMY: being the Observations and Experiences of an Alien in the South during the American Civil
War, Crown 8 vo, $6 \mathrm{~s}$.

WHIST HANDBOOKS. By AquARIUS-

THE HANDS AT WHIST. 32mo, cloth gilt, Is.

EASY WHIST. 32mo, cloth gilt, Is.

ADVANCED WHIST. 32mo, cloth gilt, Is.

WHITE (WALTER)-

A MONTH IN YORKSHIRE. With a Map. Fifth Edition. Post 8vo, 45 .

A LONDONER'S WALK TO THE LAND'S END, AND A TRIP TO THE SCILLY ISLES. With 4 Maps. Third Edition. Post 8vo, 4 s.

WILL-O'THE-WISPS, THE. Translated from the German of Marie Petersen by CharLotte J. Hart. With Illustrations. Crown 8vo, $75.6 \mathrm{~d}$.

WORKING MAN'S PHILOSOPHY, A. By "ONE OF THE Crown." Crown 8vo, 35.

WORNUM (R. N.)-

ANALYSIS OF ORNAMENT: THE CHARACTERISTICS OF STYLES. An Introduction to the History of Ornamental Art. With many Illustrations. Ninth Edition. Royal 8vo, cloth, 8s.

WRIGHTSON (PROF. FOHN), M.R.A.C., F.C.S., E-C.; Examiner it Agriculture to the Science and Art Department; Professor of Agriculture in the Normal School of Science and Royal School of Wines; President of the College of Agricullure, Dowonton, near Salisbury; late Commissioner for the Royal Agricultural Society of England, E 6 ., \&c.

PRINCIPLES OF AGRICULTURAL PRACTICE AS AN INSTRUCTIONAL SUBJECT. With Geological Map. Crown 8vo, 5.

WORSAAE (F. F.A.)-

INDUSTRIAL ARTS OF DENMARK, FROM THE EARLIEST TIMES TO THE DANISH CONQUEST OF ENGLAND. With Maps and Woodcuts. Large crown 8 vo, 3s. 6d.

YEO (DR. F. BURNEY)-

CLIMATE AND HEALTH RESORTS. New Edition. Crown $8 v 0$, xos. 6d.

YOUNGE (C. D.)-

PARALLEL LIVES OF ANCIENT AND MODERN HEROES. New Edition. 12mo, cloth, 4s. 6d. 


\section{SOUTH KENSINGTON MUSEUM SCIENCE AND ART} HANDBOOKS.

Handsomely printed in large crown 8vo. Published for the Committer of the Council on Education.

EARLY CHRISTIAN ART IN IRELAND. By MARGARET STokes. With xo6 Woodcuts. Crown 8 vo, 45.

A Library Edition, demy 8vo, 75. 6d.

FOOD GRAINS OF INDIA. By Pror. A. H. Church, M.A., F.C.S., F.I.C. With Numerous Woodcuts, Small 4 to. $6 \mathrm{~s}$.

THE ART OF THE SARACENS IN EGYPT. By STANLEX LANz Pooles, B.A., M.A.R.S. With ro8 Woodcuts. Crown 8vo, 45 .

ENGLISH PORCELAIN : A Handbook to the China made in England during the 18 th Century, as illustrated by Specimens chiefly in the National Collections. By Pror. A. H. CHurch, M.A. With numerous Woodcuts. 3 s.

RUSSIAN ART AND ART OBJECTS IN RUSSIA: A Handbook to the reproduction of Goldsmiths' work and other Art Treasures from that country in the South Kensington Museum. By ALIRED MAskell. With Illustrations. $4 \mathrm{~s}, \mathrm{Gd}$.

FRENCH POTTERY. By Paul Gasnault and Edouard GARNIER, With Illustrations and Marks, 35 .

ENGLISH EARTHENWARE: A Handbook to the Wares made in England during the 17 th and 18 th Centuries, as illustrated by Specimens in the National Collection. By Prop. A. H. Church, M.A. With numerous Woodcuts, 35 .

INDUSTRIAL ARTS OF DENMARK. From the Earliest Times to the Danish Conquest of England. By J. J. A. Worsase, Hon. F.S.A., \&c. \&c. With Map and Woodcuts. 35, 6d.

INDUSTRIAL ARTS OF SCANDINAVIA IN THE PAGAN TIME. By Hass Hildebrand, Royal Antiquary of Sweden. With numerous Woodcuts. 25. 6d.

PRECIOUS STONES: Considered in their Scientific and Artistic relations, with a Catalogue of the Townsend Collection of Gems in the South Kensington Museum. By Prof. A. H. Crurcr, M.A. With a Coloured Plate and Woodcuts. 25. $6 \mathrm{~d}$.

INDUSTRIAL ARTS OF INDIA. By Sir George C. M. BirdWood, C.S.I., \&c. With Map and Woodcuts. Demy \&vo, x4s.

HANDBOOK TO THE DYCE AND FORSTER COLLECTIONS in the South Kensington Museum. With Portrats and Facsimiles, 2s. 6d.

INDUSTRIAL ARTS IN SPAIN. By JUAN F. RIAÑo. With numerous Woodeuts. $4^{5}$.

GLASS. By Alexander Nesbitt. With numerous Woodcuts. 2s. $6 \mathrm{~d}$.

GOLD AND SILVER SMITHS' WORK. By JOHN HUNGERFord POLLEN, M.A. With numerous Woodcuts. 2s, 6d.

TAPESTRY. By Alfred de Champeaux, With Woodcuts. 2s. 6d.

BRONZES. By C. Drury E. Fortnum, F.S.A. With numerous Woodcuts. 2s. 6d. 
SOUTH KENSINGTON MUSEUM SCIENCE \& ART HANDBOOKS-Continued.

PLAIN WORDS ABOUT WATER. By A. H. Church, M.A., Oxon. With Illustrations. Sewed, 6d.

ANIMAL PRODUCTS : their Preparation, Commercial Uses, and Value. By T. L. Srmosns. With lllustrations. $78.6 \mathrm{~d}$.

FOOD: Some Account of its Sources, Constituents, and Uses. By Pronessor A. H. Church, M.A. Oxon. Sixth Thousand. 3s.

ECONOMIC ENTOMOLOGY. By ANdrew Murray, F.L.S. APTBRA. With Illustrations. 75. 6d.

JAPANESE POTTERY. Being a Native Report. With an Introduction and Catalogue by A. W. FRANKS, M.A., F.R.S., F.S.A. With Iilustrations and Marks. 2s. 6d.

HANDBOOK TO THE SPECIAL LOAN COLLECTION of Scientific Apparatus. 3 s.

INDUSTRIAL ARTS: Historical Sketches. With Numerous 1llustrations. $3^{\text {s. }}$

TEXTILE FABRICS. By the Very Rev. Danier Rock, D.D. With numerous Woodcnts, 2s. $6 \mathrm{~d}$.

JONES COLLECTION IN THE SOUTH KENSINGTON MUSEUM. With Portrait and Woodcuts. 2s, 6d.

COLLEGE AND CORPORATION PLATE. A Handbook to the Reproductions of Silver Plate in the South Kensigton Museum from Celebrated English Collections. By WILFred Josepr Criprs, M.A., F.S.A. With Illustrations, 25, 6d.

IVORIES: ANCIENT AND MEDIEVAL. By WILLIAM Maskelt. With numerous Woodeuts. 25. $6 \mathrm{~d}$.

ANCIENT AND MODERN FURNITURE AND WOODWORK. By JoHn Huscerarord Pollen, M.A. With numerous Woodents,
25. бd.

MAIOLICA. By C. DRuRY E. Fortnum, F.S.A. With numerous Woodcuts, as, $6 \mathrm{~d}$.

THE CHEMISTRY OF FOODS. With Microscopic Illustrations. By JAMrs BrLL, Ph, D, \& $c_{\text {, }}$ Principal of the Somerset House Laboratory. Part I.-Tea, Coffee, Cocoa, Sugar, \&ec. 25. 6d.

Part II,-Milk, Butter, Cheese, Cereals, Prepared Starches, \&c. 35.

MUSICAL INSTRUMENTS. By CARL ENGEL. With numerous Wooricuts. 2s, 6d,

MANUAL OF DESIGN, compiled from the Writings and Addresses of Richard Redgrave, R.A. By Gilmert R. Rederave, With Woodcuts. 2s, $6 \mathrm{~d}$.

PERSiAN ART. By Major R. Murdock Smith, R.E. With Map and Woodcuts. Scoond Edition, enlarged. 2s. 


\section{CARLYLE'S (THOMAS) WORKS.}

\section{THE ASHBURTON EDITION.}

An entirely New Edition, handsomely printed, containing all the Portraits and Illustrations, in Seventeen Volumes, demy $8 \mathrm{vo}, 8 \mathrm{~s}$. each.

THE FRENCH REVOLUTION AND PAST AND PRESENT. 2 vols. SARTOR RESARTUS; IIEROES AND HERO WORSHIP. $₫$ vol. LIFE OF JOHN STERLING-LIFE OF SCHILLER. I vol.

LATTER-DAY PAMPHLETS-EARLY KINGS OF NORWAYESSAY ON THE PORTRAIT OF JOHN KNOX, I vol,

LETTERS AND SPEECHES OF OLIVER CROMWELL. 3 vols.

HISTORY OF FREDERICK THE GREAT. 6 vols,

CRITICAL AND MISCELLANEOUS ESSAYS. 3 vols.

\section{CHEAP AND UNIFORM EDITION. \\ 23 vols., Crown 8vo, cloth, $\$ 75$ s.}

THE FRENCH REVOLUTION : A History. 2 vols., 125.

OLIVER CROMWELL'S LET. TERS AND SPEECHES, with Elucidations, \&c. 3 vols, 185 .

LIVES OF SCHILLER AND JOHN STERLING. I vol., $6 \mathrm{s.}$

CRITICAL AND MISCELLANEOUS ESSAYS. 4 vols, 6I 4 s.

SARTOR RESARTUS AND LECTURES ON HEROES. I vol., 6s,
LATTER-DAY PAMPHLETS. $I$ vol., $6 \mathrm{~s}$.

CHARTISM AND PAST AND PRESENT. $x$ vol, $6 \mathrm{~s}$,

TRANSLATIONS FROM THE GERMAN OF MUSAES, TIECK, AND RICHTER, I vol., $6 \mathrm{~s}$.

WILHELM MEISTER, by Göethe. A Translation. 2 vols, r25,

HISTORY OF FRIEDRICH THE SECOND, called Frederick the Great. 7 vols., $t_{3}$ gs.

\section{LIBRARY EDITION COMPLETE.}

Handsomely printed in 34 vols., demy 8 vo, cloth, 2133 s.

SARTOR RESARTUS. With a Portrait, 7 s. 6d.

THF, FRENCH REVOLUTION. A History. 3 vols., each 9 s.

LIFE OF FREDERICK SCHILLER AND EXAMINATION OF HIS WORKS. With Supplement of 1872 . Portrait and Plates, 95.

CRITICAL AND MISCELLANEOUS ESSAYS. With Portrait. 6 vols, each 95 .

ON HEROES, HERO WORSHIP, AND THE HEROIC IN HISTORY. 75. 6d.

PAST AND PRESENT. 9s, 
CARLYLE'S (THOMAS) WORKS.-IIBRARY EDITION-Continued. OLIVER CROMWELL'S LETTERS AND SPEECHES. With Portraits. 5 vols, each 9 s.

LATTER-DAY PAMPHLETS. 9s.

LIFE OF JOHN STERLING. With Portrait, 9s.

HISTORY OF FREDERICK THE SECOND. Io vols., each 9 s.

TRANSLATIONS FROM THE GERMAN. 3 vols., each 9 s.

EARLY KINGS OF NORWAY; ESSAY ON THE PORTRAITS OF JOHN KNOX; AND GENERAL INDEX. With Portrait Illustrations. 8vo, cloth, 95.

\section{PEOPLE'S EDITION.}

Messrs. Chapman \& HALL are now issuing at a Cheap Rate in a popular form, a complete Edition of CARLYLE'S WORKS. The volumes are handsomely printed and bound in cloth, and published at One Shilling each.

SARTOR RESARTUS. With Portrait of Thomas Carlyle.

FRENCH REVOLUTION. A History. 3 vols.

OLIVER CROMWELL'S LETTERS AND SPEECHES. 5 vols. With Portrait of Oliver Cromwell.

ON HEROES AND HERO WORSHIP, AND THE HEROIC IN HISTORY.

PAST AND PRESENT.

CRITICAL AND MISCELLANEOUS ESSAYS. 7 vols.

THE LIFE OF SCHILLER, AND EXAMINATION OF HIS WORKS. With Portrait.

LATTER-DAY PAMPHLETS.

WILHELM MEISTER. 3 vols.

LIFE OF JOHN STERLING, With Portrait.

HISTORY OF FREDERICK THE GREAT. IO vols,

TRANSLATIONS FROM MUSEUS, TIECK, AND RICHTER. 2 vols,

THE EARLY KINGS OF NORWAY; Essay on the Portraits of Knox; and General Index.

\section{CHEAP ISSUE.}

THE FRENCH REVOLUTION. Complete in I vol. With Portrait. Crown Bvo, 25.

SARTOR RESARTUS, HEROES AND HERO WORSHIP, PAST AND PRESENT, AND CHARTISM. Complete in I vol. Crown $8 \mathrm{vo}, 25$.

OLIVER CROMWELL'S LETTERS AND SPEECHES. Crown 8vo, 2s. $6 \mathrm{~d}$.

\section{SIXPENNY EDITION. $4^{\text {to, }}$ sewed.}

SARTOR RESARTUS. Eightieth Thousand.

HEROES AND HERO WORSHIP.

ESSAYS: Burns, Johnson, ScotT, The Diamond Necklace.

The abovie in $\mathrm{I}$ vol., cloth, 2s. 6 d. 


\section{DICKENS'S (CHARLES) WORKS.}

ORIGINAL EDITIONS.

In demy svo.

THE MYSTERY OF EDWIN DROOD. With Illustrations by S. L. Fildes, and a Portrait engraved by Baker. Cloth, 7s. $6 \mathrm{~d}$.

OUR MUTUAL FRIEND. With Forty Illustrations by Marcus Stone. Cloth, $\delta \mathrm{Is}$.

THE PICKWICK PAPERS. With Forty-three Illustrations by Seymoux and Phiz. Cloth, $£$ x xs.

NICHOLAS NICKLEBY. With Forty Illustrations by Phiz. Cloth, ¿I rs.

SKETCHES BY "BOZ." With Forty Illustrations by George Cruikshank. Cloth, $\ell_{\mathrm{I}}$ Is.

MARTIN CHUZZLEWIT. With Forty Illustrations by Phiz. Cloth, $6 \mathrm{I}$ Is.

DOMBEY AND SON. With Forty Illustrations by Phiz. Cloth, 6 I Is.

DAVID COPPERFIELD. With Forty Illustrations by Phiz. Cloth, $\delta$ I Is.

BLEAK HOUSE. With Forty Illustrations by Phiz. Cloth, 6I Is.

LITTLE DORRIT. With Forty Illustrations by Phiz. Cloth, £x xs.

THE OLD CURIOSITY SHOP. With Seventy-five Illustrations by George Cattermole and H. K. Browne. A New Edition. Uniform with the other volumes, $\delta \times 15$.

BARNABY RUDGE: a Tale of the Riots of 'Eighty. With Seventy-eight Illustrations by George Cattermole and H. K. Browne, Uniform with the other volumes, $f_{\mathrm{x}}$ Is.

CHRISTMAS BOOKS: Containing-The Christmas Carol ; The Cricket on the Hearth; The Chimes; The Battle of Life; The Haunted House. With all the original lllustrations. Cloth, r2s.

OLIVER TWIST and TALE OF TWO CITIES. In one volume. Cloth, EI xs.

OLIVER TWIST. Separately. With Twenty-four Illustrations by George Cruilkshank. Cloth, Irs.

A TALE OF TWO CITIES. Separately. With Sixteen Illustrations by Phiz. Cloth, 9 s.

* * The remainder of Dickens's Works were not originally printed in demy $8 v 0$. 


\section{DICKENS'S (CHARLES) WORKS.-Continued.}

\section{LIBRARY EDITION.}

In post 8vo. With the Original Illustrations, 30 vols., cloth, £II.

\begin{tabular}{|c|c|c|c|c|c|c|c|c|}
\hline PICKWICK PAPERS ... & $\cdots$ & $\cdots$ & $\cdots$ & ... 43 & 政 & , 2 vols. & $\begin{array}{l}s . \\
16\end{array}$ & d. \\
\hline NICHOLAS NICKLEBX & $\cdots$ & $\cdots$ & $\cdots$ & ... 39 & $n$ & 2 vols. & 16 & \\
\hline ARTIN CHUZZLEWIT & $\cdots$ & $\cdots$ & $\ldots$ & ... 40 & $n$ & 2 vols. & I6 & \\
\hline OLD CURIOSITY SHOP \& R & EPR & NTED & PIEC & $\operatorname{Es} 3^{6}$ & ", & 2 vols. & I6 & \\
\hline BARNABY RUDGE and HAI & RD T & IMES & $\ldots$ & $\cdots 3^{6}$ & $"$ & 2 vols. & I6 & \\
\hline LEAK HOUSE... & $\cdots$ & $\cdots$ & $\cdots$ & ... 40 & $"$ & 2 vols, & \pm 6 & \\
\hline ITTLE DORRIT & $\cdots$ & $\cdots$ & $\cdots$ & ... 40 & $"$ & 2 vols. & 16 & \\
\hline DOMBEY AND SON $\quad \ldots$ & $\cdots$ & $\cdots$ & $\cdots$ & $\cdots 3^{8}$ & $"$ & 2 vols. & I6 & \\
\hline DAVID COPPERFIELD & $\cdots$ & $\cdots$ & $\cdots$ & a. $3^{8}$ & w & 2 vols. & 16 & \\
\hline OUR MUTUAL FRIEND & $\cdots$ & $\cdots$ & $\cdots$ & ... 40 & $"$ & 2 vols. & I6 & \\
\hline SKETCHES BY "BOZ" & $\cdots$ & $\cdots$ & $\cdots$ & ... 39 & s & I vol. & 8 & \\
\hline PLIVER TWIST & $\cdots$ & $\cdots$ & $\cdots$ & $\ldots 24$ & " & & 8 & \\
\hline CHRISTMAS BOOKS ... & $\cdots$ & $\cdots$ & $\cdots$ & $\ldots$ I7 & $n$ & I vol. & 8 & \\
\hline A TALE OF TWO CITIES & $\cdots$ & $\cdots$ & $\cdots$ & $\ldots 16$ & $"$ & I vol. & 8 & \\
\hline GREAT EXPECTATIONS & $\cdots$ & $\cdots$ & $\cdots$ & ... 8 & $"$ & I vol. & 8 & \\
\hline PICTURES FROM ITALY \& & $\mathrm{AME}$ & RICAN & NOT & ES 8 & " & I vol. & 8 & \\
\hline UNCOMMERCIAL TRAVEI & LLER & $\ldots$ & $\cdots$ & .. 8 & $"$ & I vol. & 8 & \\
\hline CHILD'S HISTORY OF EN & GLA & & $\cdots$ & ... 8 & $"$ & I vol. & 8 & \\
\hline EDWIN DROOD and MISC & ELL & NIES & $\cdots$ & ... 12 & $"$ & I vol. & 8 & \\
\hline HRISTMAS STORIES fro & & & & & & I vo & 8 & \\
\hline
\end{tabular}

THE LIFE OF CHARLES DICKENS. By JOHN FORSTER. With Illustrations. Uniform with this Edition. Ios. 6 d.

A NEW EDITION OF ABOVE, WITH THE ORIGINAL ILLUSTRATIONS, IN CROWN 8vo, 30 VOLS. IN SETS ONLY. 


\section{DICKENS'S (CHARLES) WORKS.-Continued.}

\section{THE "GHARLES DICKENS" EDITYON.}

In Crown 8vo. In aI vols, cloth, with Illustrations, $\$ 3.3 \mathrm{Ibs}$.

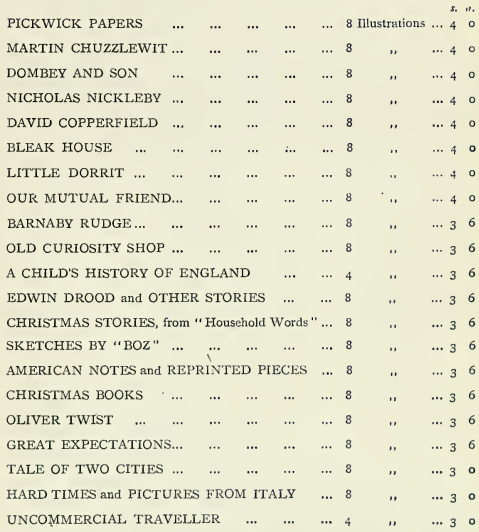

THE LIFE OF CHARLES DICKENS. Numerous Illistrations. 2 vols, 7 。 THE LETTERS OF CHARLES DICKENS $\quad \ldots \quad \ldots \quad \ldots 2$ vols, 8 。 


\section{DICKENS'S (CHARLES) WORKS.-Continued.}

\section{THE ILLUSTRATED LIBRARY EDITION. (WITH LIFE.)}

Complete in 32 Volumes. Demy 8vo, ros. each; or set, fir

This Edition is printed on a finer paper and in a larger type tban has been employed in any previous edition. The type bas been cast especially for it, and the page is of a size to admit of the introduction of all the original illustrations.

No such attractive issue has been made of the writings of Mr. Dickens, which, various as have been tbe forms of publication adapted to the demands of an ever widely-increasing popularity, have never yet been worthily presented in a really handsome library form. preserve.

The collection comprises all the minor writings it was Mr. Dickens's wish to

SKETCHES BY "BOZ." With 40 Illustrations by George Cruikshank.

PICKWICK PAPERS. 2 vols. With 42 Illustrations by Pbiz.

OLIVER TWIST. With 24 Illustrations by Cruiksbank.

NICHOLAS NICKLEBY. 2 vols. Witb 40 Illustrations by Phiz.

OLD CURIOSITY SHOP and REPRINTED PIECES. $a$ vols. With Illustrations by Cattermole, \&c.

BARNABY RUDGE and HARD TIMES, 2 vols. With Illustrations by

Cattermole, \&c.

MARTIN CHUZZLEWIT, 2 vols. Witb 40 Illustrations by Phiz.

AMERICAN NOTES and PICTURES FROM ITALY. $x$ vol. With

8 Illustrations.

DOMBEY AND SON. 2 vols. Witb 40 Illustrations by Phiz.

DAVID COPPERFIELD. 2 vols. With 40 Illustrations by Phiz.

BLEAK HOUSE, 2 vols. With 40 Illustrations by Phiz.

LITTLE DORRIT. 2 vols. With 40 Illustrations by Phiz.

A TALE OF TWO CITIES. With 16 Illustrations by Phiz.

THE UNCOMMERCIAL TRAVELLER. With 8 Illustrations by Marcus Stone. GREAT EXPECTATIONS. With 8 Illustrations by Marcus Stone.

OUR MUTUAL FRIEND. 2 vols. With qo Illustrations by Marcus Stone.

CHRISTMAS BOOKS. With $x_{7}$ Illustrations by Sir Edwin Landseer, R,A,

Maclise, R.A., \&c. \&c.

HISTORY OF ENGLAND. With 8 Illustrations by Marcus Stone.

CHRISTMAS STORIES. (From "Household Words" and "All the Year

Round.") With $x_{4}$ Illustrations.

EDWIN DROOD AND OTHER STORIES With I2 Illustrations by

S. L. Fildes.

LIFE OF CHARLES DICKENS. By John Forster. Witb Portraits, 2 vols, (not separate.) 
DICKENS'S (CHARLES) WORKS.-Continued.

\section{THE POPULAR LIBRARY EDITION OF THE WORKS OF CHARLES DICKENS,}

In 30 Vols., large crown 8vo, price $£ 6$; separate Vols. 4 s. each.

An Edition printed on good paper, each volume containing 16 full-page Illustrations, selected from the Household Edition, on Plate Paper.

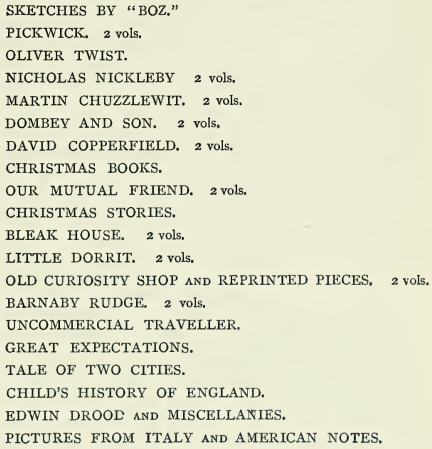




\section{DICKENS'S (CHARLES) WORKS.-Continued.}

\section{HOUSEHOLD EDITION.}

In 22 Volumes. Crown 4 to, cloth, $£ 48 s, 6 d$.

MARTIN CHUZZLEWIT, with 59 Illustrations, cloth, $5^{\text {s. }}$

DAVID COPPERFIELD, with 60 Illustrations and a Portrait, cloth, $5 \mathrm{~s}$.

BLEAK HOUSE, with $6 x$ Illustrations, cloth, $5^{5}$.

LITTLE DORRIT, with $5^{8}$ Illustrations, cloth, 5 s.

PICKWICK PAPERS, with 56 Illustrations, cloth, 5 s.

OUR MUTUAL FRIEND, with $5^{8}$ Illustrations, cloth, $5^{5}$.

NICHOLAS NICKLEBY, with 59 Ilinstrations, cloth, 5 s.

DOMBEY AND SON, with $6 x$ Illustrations, cloth, 5 s.

EDWIN DROOD; REPRINTED PIECES ; and other Stories, with 30 Illustrations, cloth, $5 \mathrm{~s}$.

THE LIFE OF DICKENS. Br JoHn Forster. With 40 Illustrations, Cloth, $5^{\mathrm{s}}$.

BARNABY RUDGE, with 46 Illustrations, cloth, 45 .

OLD CURIOSITY SHOP, with $3^{2}$ Illustrations, cloth, 4 s.

CHRISTMAS STORIES, with 23 Illustrations, cloth, 45.

OLIVER TWIST, with 28 Illustrations, cloth, $3^{\text {s. }}$

GREAT EXPECTATIONS, with 26 Illustrations, cloth, 35 .

SKETCHES BY "BOZ," with 36 Illustrations, cloth, 35 .

UNCOMMERCIAL TRAVELLER, with 26 Illustrations, cloth, $3 \mathrm{~s}$.

CHRISTMAS BOOKS, with 28 Illustrations, cloth, $3^{5}$.

THE HISTORY OF ENGLAND, with I5 Illustrations, cloth, 3 s.

AMERICAN NOTES and PICTURES FROM ITALY, with 88 Illustrations, cloth, $3^{5}$.

A TALE OF TWO CITIES, with 25 Illustrations, cloth, 3 s.

HARD TIMES, with 20 Illustrations, cloth, 25. $6 \mathrm{~d}$. 


\section{DICKENS'S (CHARLES) WORKS.-Continued.}

\section{THE CABINET EDITION.}

In 32 vols. small fcap. Svo, Marble Paper Sides, Cloth Backs, with uncnt edges, price Eighteenpence each.

Each Volume contains Eight Illustrations reproduced from the Originals.

CARISTMAS BOOKS.

MARTIN CHUZZLEWIT, Two Vols.

DAVID COPPERFIELD, Two Vols.

OLIVER TWIST.

GREAT EXPECTATIONS.

NICHOLAS NICKLEBY, Two Vols.

SKETCHES BY "BOZ."

CHRISTMAS STORIES.

THE PICKWICK PAPERS, Two Vols.

BARNABY RUDGE, Two Vols.

BLEAK HOUSE, Two Vols.

AMERICAN NOTES AND PICTURES FROM ITALY.

EDWIN DROOD; AND OTHER STORIES.

THE OLD CURIOSITY SHOP, Two Vols.

A CHILD'S HISTORY OF ENGLAND.

DOMBEY AND SON, Two Vols.

A TALE OF TWO CITIES.

LITTLE DORRIT, Two Vols.

MUTUAL FRIEND, Two Vols.

HARD TIMES.

UNCOMMERCIAL TRAVELLER.

REPRINTED PIECES. 


\section{DICKENS'S (CHARLES) WORKS.-Continued.}

\section{MR. DICKENS'S READINGS.}

Fcap. 8vo, sewed.

CHRISTMAS CAROL IN PROSE. Is.

CRICKET ON THE HEARTH. Is.

CHIMES: A GOBLIN STORY. Is.

STORY OF LITTLE DOMBEY. Is.

POOR TRAVELLER, BOOTS AT THE HOLLY-TREE INN, and MRS. GAMP. Is.

A CHRISTMAS CAROL, with the Original Coloured Plates. Being a reprint of the Original Edition. With red border lines. Small 8vo, red cloth, gilt edges, 5 .

\section{CHARLES DICKENS'S CHRISTMAS BOOKS.}

REPRINTED FROM THE ORIGINAL PLATES.

Illustrated by JOHN LEECH, D. MACLISE, R.A., R. DoyLR,

C. Stanfield, R.A., \&c.

Fcap, cloth, 1s, each. Complete in a case, $5 s$.

A CHRISTMAS CAROL IN PROSE.

THE CHIMES : A Goblin Story.

THE CRICKET ON THE HEARTH: A Fairy Tale of THE BATTLE OF LIFE. A Love Story.

THE HAUNTED MAN AND THE GHOST'S STORY.

\section{SIXPENNY REPRINTS.}

READINGS FROM THE WORKS OF CHARLES DICKENS.

As selected and read by himself and now published for the first time, Illustrated. A CHRISTMAS CAROL, AND THE HAUNTED MAN. By Charles Dickens. Illustrated.

THE CHIMES: A Goblin STORy, AND THE CRICKET ON THE HEARTH. Illustrated.

THE BATTLE OF LIFE: A LOVE STORY, HUNTED DOWN, AND A HOLIDAY ROMANCE. Illustrated.

The last Three Volumes as Christmas Works, In One Volume, red cloth, 2s. 6d. 


\section{SCIENCE AND ART,}

\section{a Jourual for Teacbers atd Students.}

ISSUED BY Messrs. CHAPMAN \& HALL, LimtTeD, Agents for the Science and Art Department of the Committee of Council on Education.

\section{MONTHLY, PRICE THREEPENCE.}

The Journal contains contrihutions by distinguished men; short papers by prominent teachers; leading articles; correspondence; answers to questions set at the May Examinations of the Science and Art Department; and interesting news in connection with the scientific and axtistic world.

\section{PRIZE COMPETITION.}

With each issue of the Journal, papers or drawings are offered for Prize Competition, extending over the range of suhjects of the Science and Art Department and City and Guilds of London Institute.

There are thousands of Science and Art Schools and Classes in the United Kingdom, but the teachers connected wish these institutions, although engaged in the advancement of identicnl objects, are seldom known to each other except throngh personal friendship. One ohject of the new Journal is to enable those engaged in this common work to communicate upon subjects of importance, with a view to an interchange of ideas, and the establishment of unity of action in the various centres.

\section{TERMS OF SUBSCRIPTION.}

ONE YEAR'S SUBSCRIPTION ..

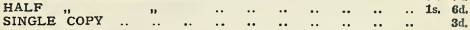

Cheques and Post Office Orders to be made payable to CHAPMAN \& HALL, Limited.

Answers to the Questions (Elementary and Advanced) set at the Examinations of the Seience and Art Department of May, 1887, are published as under, each subjeet being kept distinct, and issued in pamphlet form separately.

r. Animal Physiology ... ... ... By J. H. E. Brock, M.D., B.S.

(Lond.)

2. Building Construction $\quad \ldots \quad$... $\quad$ H. Adams, M.I.C.E.

3. Theoretical Mechanics $\ldots$... J. C. Fell, M. I.M.E.

4. Inorganic Chemistry (Theoretical) Rev. F. W. Harnett, M.A,

5. Ditto-Alternative Course … J. Howard, F.C.S.

6. Magnetism and Electricity … W. Hibbert, F.I.C., F.C.S.

7. Physiography ... $\quad \ldots \quad \ldots \quad \ldots \quad \ldots$ W. Rheam, B.Sc.

8. Practical Plane \& Solid Geometry H. Angel.

9. Art-Third Grade, Perspective A. Fisher.

io. Pure Mathematics ... $\quad \ldots \quad \ldots \quad$ R. R. Steel, F.C.S.

11. Machine Construction \& Drawing H. Adams, M.I.C.E.

12. Principles of Agriculture … Dr. Webb, B.Sc.

I3. Sound, Light, and Heat ... ... $\quad$ C. A. Stevens,

I4. Hygiene... $\quad \ldots \quad \ldots \quad \ldots . \quad \ldots \quad$ J. J. Pilley.

15. INorganic ChEMistry (Practical) … J. Howard, F.C.S.

The price of each Pamphlet will be 2d, net, postage included. Special terms will be given if quantities are ordered.

CHAPMAN \& HALL, Limited, II, Henrietta Fopreet, Covent Garden, W.C. 


\section{THE FORTNIGHTLY REVIEW. Edited by FRANK HARRIS.}

HE FORTNIGHTLY REVIEW is published on the ist of
every month, and a Volume is completed every Six Months.

The following are among the Contributors:-

GRANT ALLEN.

SIR RUTHERFORD ALCOCK. MATHEW ARNOLD.

AUTHOR OF "GREATER BRITAIN" PROFESSOR BAIN.

SIR SAMUEL BAKER.

PROFESSOR BEESLY.

PAUL BERT.

BARON GEORGETON BUNSEN.

DR. BRIDGES.

HON. GEORGE C. BRODRICK.

JAMES BRYCE, M.P.

THOMAS BURT, M.P.

SIR GEORGE CAMPBELL, M.P.

THE EARL OF CARNARVON.

EMILIO CASTELAR.

RT. HON. J. CHAMBERLAIN, M.P. PROFESSOR SIDNEY COLVIN. MONTAGUE COOKSON, Q.C.

L. H. COURTNEY, M.P.

G. H. DARWIN.

SIR GEORGE W. DASENT.

PROFESSOR A. V. DICEY.

PROFESSOR DOWDEN.

M. E. GRANT DUFF, M.P.

T. H. S. ESCOTT.

RIGHT HON. H. FAWCETT, M.P. ARCHDEACON FARRAR. EDWARD A. FREEMAN. J. A. FROUDE.

MRS. GARRRT-ANDERSON.

J. W. L. GLAISHER, F.R.S.

SIR J. E. GORST, Q.C., M.P. EDMUND GOSSE.

THOMAS HARE.

F. HARRISON.

LORD HOUGHTON.

PROFESSOR HUXLEY.

PROFESSOR R. C. JEBB.

PROFESSOR JEVONS.

ANDREW LANG.

EMILE DE LAVELEYE.
T. E. CLIFFE LESLIE. PROFESSOR LEONE LEVI.

W. S. LILLY.

MARQUIS OF LORNE.

SIR JOHN LUBBOCK, BART,, M.P. THE EARL LYTTON.

SIR H. S. MAINE.

DR. MAUDSLEY.

PROFESSOR MAX MÜLLER.

GEORGE MEREDITH.

G. OSBORNE MORGAN, Q.C., M.P. PROFESSOR HENRY MORLEY. RT. HON. JOHN MORLEY, M.P. WILLIAM MORRIS.

PROFESSOR H. N. MOSELEY.

F. W. H. MYERS.

F. W. NEWMAN.

PROFESSOR JOHN NICHOL.

W. G. PALGRAVE.

WALTER H. PATER.

RT. HON. LYON PIAYFAIR, M.P.

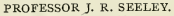

LORD SHERBROOKE.

PROFESSOR SIDGWICK.

HEREERT SPENCER.

HON. E. L. STANLEY.

SIR J. FITZJAMES STEPHEN, Q.C. LESLIE STEPHEN.

J. HUTCHISON STIRLING.

A. C. SWINEURNE.

DR. VON SYBEL.

J. A. SYMONDS.

THE REV. EDWARD F. TALBOT (WARDEN OF KEBLF CoLlegE). SIR RICHARD TEMPLE, BART. W. T. THORNTON.

HON. LIONEL A. TOLLEMACHE. H. D. TRAILL.

PROFESSOR TYNDALL.

A. J. WIISON.

GRN. VISCOUNT WOLSELEY. THE EDITOR

\&c. \&c. \&c.

Thr FortnightLy Review is published at as. $6 d$.

CHAPMAN, \& HALL, LIMITED, II, HENRIETTA STREET, COVENT GARDEN, W.C.

CHAREES DICKKNS AND IVANS, ]

[CRYSTAL PALACE PRESS. 



\section{UNIVERSITY COLLEGE, SOUTHAMPTON THE LIBRARY}

This book is to be returned to the Library on or before the last date stamped below 

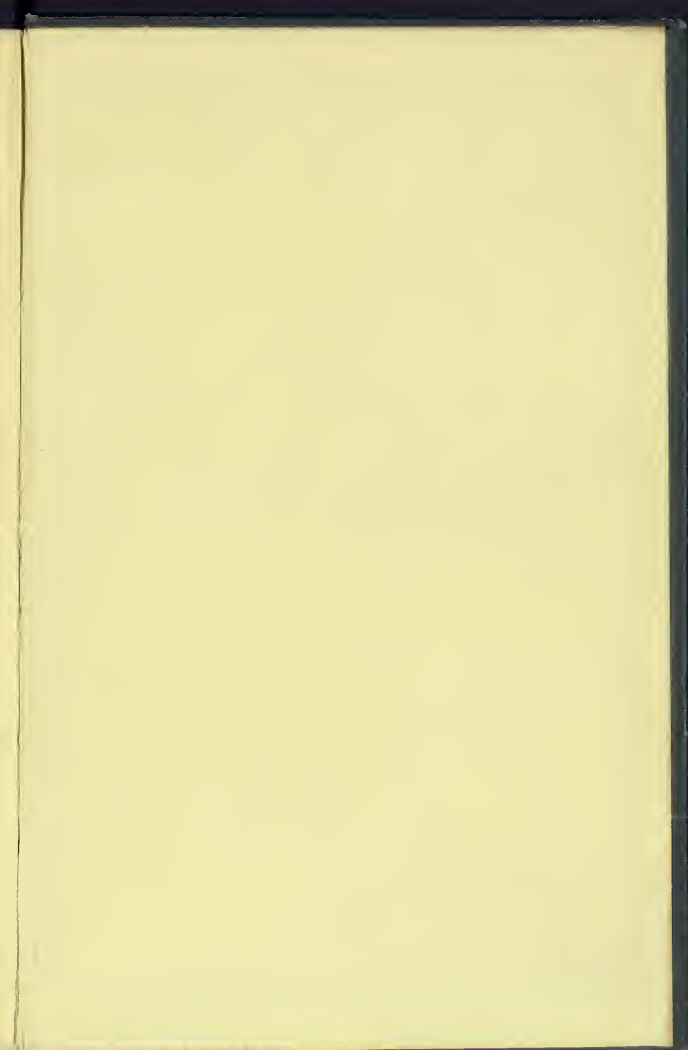


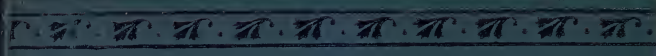




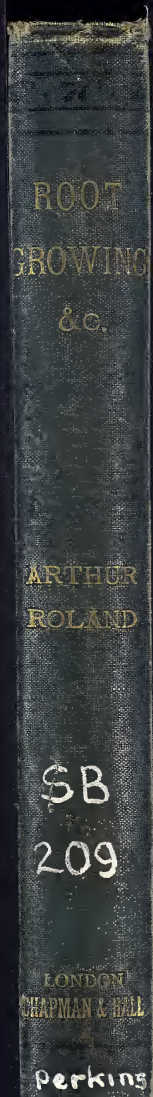

